\title{
COMPETING DISCOURSES SURROUNDING \\ PRIMARY CAREGIVERS OF \\ HOSPICE PATIENTS
}

by

PAUL KOZAR

Presented to the Faculty of the Graduate School of

The University of Texas at Arlington in Partial Fulfillment

of the Requirements

for the Degree of

MASTERS OF ARTS IN COMMUNICATION

THE UNIVERSITY OF TEXAS AT ARLINGTON

December 2012 
Copyright @ by Paul Kozar

All Rights Reserved 


\section{ACKNOWLEDGEMENTS}

I would like to acknowledge the courageous women and men who willingly shared stories of caring for their loved ones at the end of life. Many tears were shed during our conversations, and their words spoken from the depth of the soul continue to resonate within me.

I am deeply appreciative for hospice volunteers Yasemin Polat and Debbie Ernst who coded the interviews, a task that was both mentally and emotionally taxing. I am deeply indebted to Dr. Karishma Chatterjee for her insightful guidance which she willingly shared with me during the research, especially in view of the fact that it took place at the time of the birth of her daughter. The irony of life and death has not escaped me. Further appreciation is extended to Dr. Charla Markham Shaw and Dr. Brian Horton for their guidance and leadership.

Finally, I have no words other than thank you to my wife, Pam, who especially encouraged and supported me during those times when I was at my "wits end."

October 24, 2012 


\section{ABSTRACT \\ COMPETING DISCOURSES SURROUNDING PRIMARY CAREGIVERS OF HOSPICE PATIENTS}

Paul Kozar M.A.

The University of Texas at Arlington, 2012

\section{Supervising Professor: Karishma Chatterjee}

The aging of the baby boomer generation has resulted in dynamic growth in end-of-life care. In the year $2030,22 \%$ of Americans will be over the age of 65 . Given this projection and the lack of communication research based practices for end-of life care, this study is a contribution that helps facilitate the layperson and health care professional's awareness of endof-life communication. The researcher adopted relational dialectical theory to examine the discourse of twenty primary caregivers of hospice patients. The research questions guiding the study were what competing discourses do primary caregivers experience during end-of-life care and how do caregivers communicatively negotiate the competing discourses they experience? The analysis of the in-depth interviews revealed five major competing discourses. End-of-life communication is messy and themes are intertwined. Generally, during the pre-hospice period the competing discourse of care versus cure was found. During hospice care competing discourses of prolong life versus end life, open versus hidden, and theodicy were found. During the bereavement period the move on versus don't move on discourse was found. 


\section{TABLE OF CONTENTS}

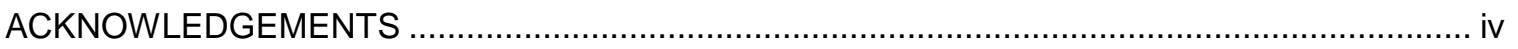

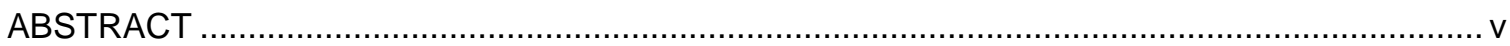

Chapter Page

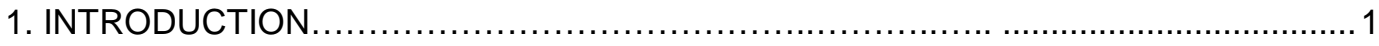

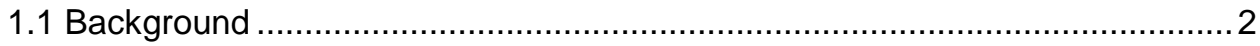

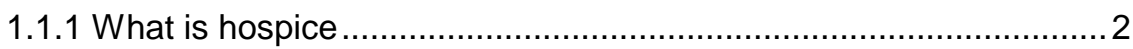

1.1.2 A Hospice History: There and Back Again .................................... 3

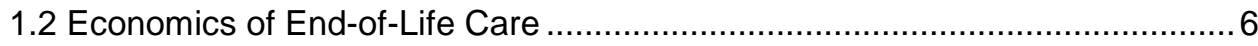

1.2.1 Medicare Hospice Benefit (MHB) ............................................... 7

1.2.2 Four Criteria for Hospice Care ................................................. 8

1.2.3 Increasing Cost of End-of-Life ................................................ 8

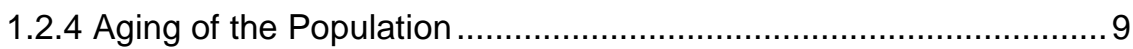

1.2.5 Cultural Expectations of Boomers............................................ 10

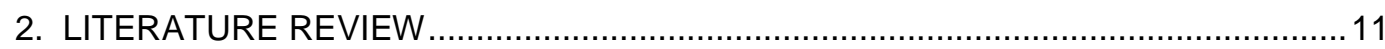

2.1 Communication Challenges at the End-of-Life .........................................11

2.2 Communication Challenges for Hospice .................................................. 15

2.2.1 The Dying Trajectory ........................................................... 17

2.2.2 Anticipatory Grief..................................................................... 19

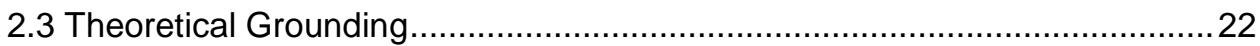

2.3.1 Social Construction ............................................................26

2.3.1 Mikhail Bakhtin and Relational Dialectical Theory .......................28

2.3.2.1 The Utterance Chain ..................................................28 


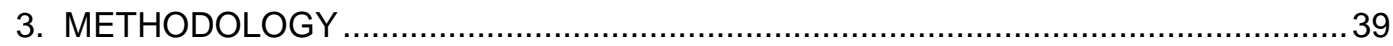

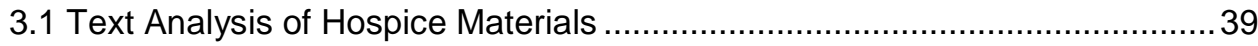

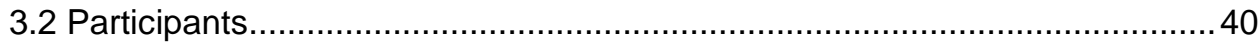

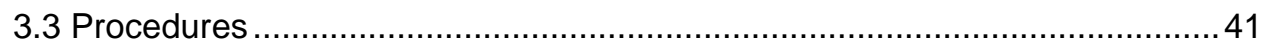

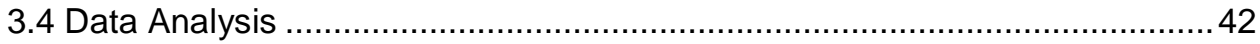

3.4.1 Contrapuntal Analysis ........................................................ 44

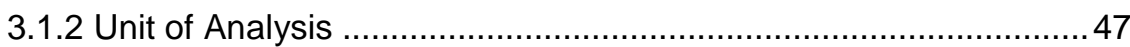

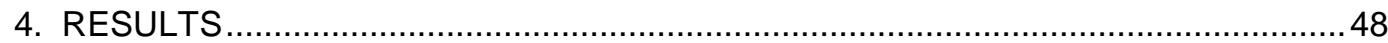

4.1 What Competing EOL Discourses are

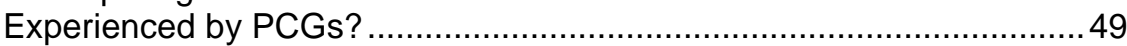

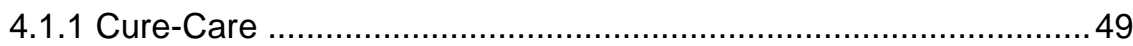

4.1.1.1.Advocacy of the Medical Community for a Cure............50

4.1.1.2 Giving up on Curative Treatments ..............................53

4.1.1.3 The Promise Pact.......................................................... 55

4.1.1.4 Hospice Materials Present the Care-Cure Conflict ........55

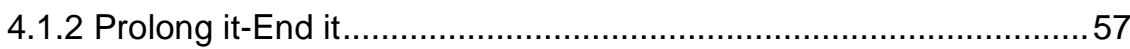

4.1.2.1 Does Hospice Mean Prolong it or End it ......................60

4.1.2.2 The Advocacy of the Hospice Materials for Prolong it ...61

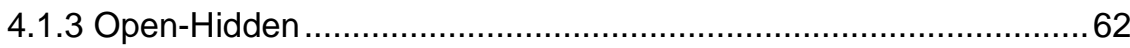

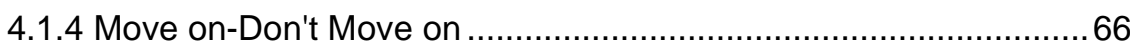

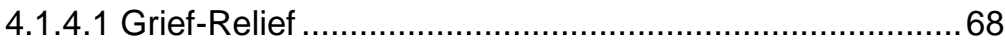

4.1.4.2 Hospice Bereavement Materials Mediation of Move on-Don't Move on ..................................69

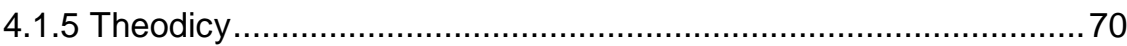


4.1.5.1 The Why Voice ....................................................... 72

4.1.5.2 The God Voice ...................................................... 74

4.2 How do PCGs Communicatively Manage

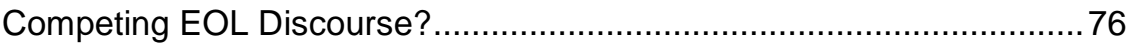

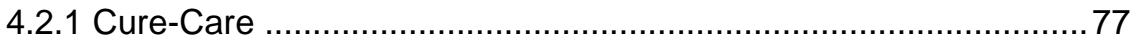

4.2.1.1 Passive Medical Voice ............................................... 77

4.2.2.2 The Family's Voice ...................................................... 79

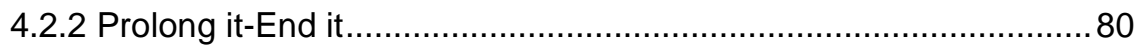

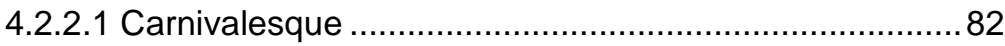

4.2.2.2 Death Prayer to End-it ............................................... 84

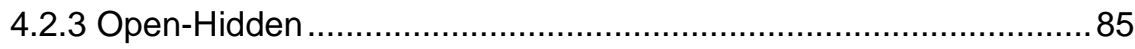

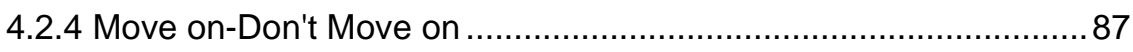

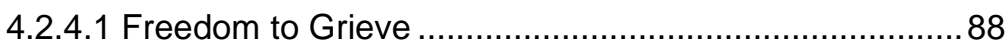

4.2.4.2 Resistance to the Move on Discourse .......................... 89

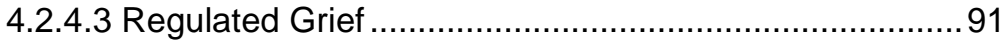

4.2.4.4 Rituals as Expressions of Grief.................................. 93

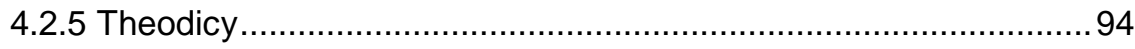

4.2.5.1 Justification of Suffering as God's Plan .......................95

4.2.5.2 Suffering Beyond Human Understanding ....................96

4.2.5.3 Patient is Now in a Better Place .................................. 97

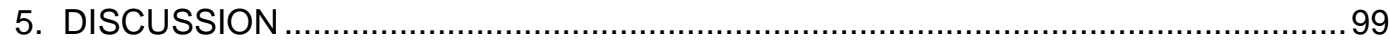

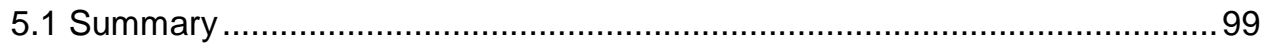

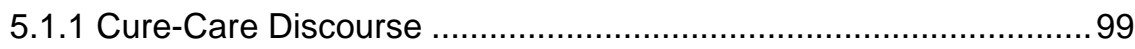

5.1.2 Prolong it-End it Discourse................................................. 101

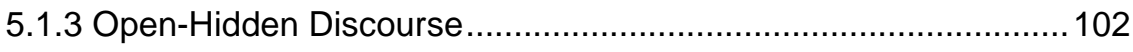

5.1.4 Move on-Don't Move on Discourse ........................................... 105 
5.1.5 Theodicy Discourse.......................................................... 106

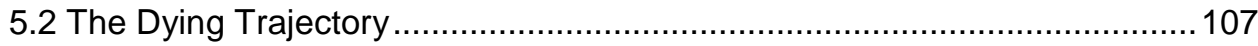

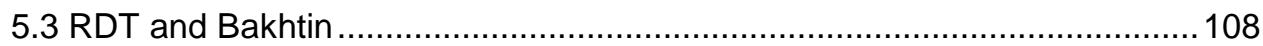

5.4 Interdisciplinary Team Summary ......................................................... 110

5.5 The Social-Economic Impact of EOL Communication ..............................113

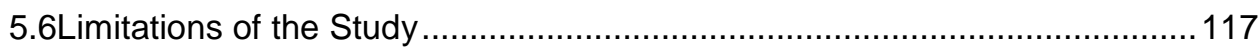

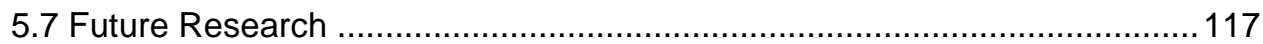

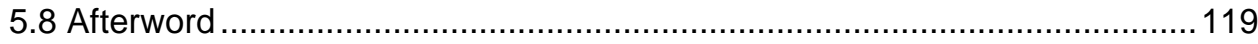

APPENDIX

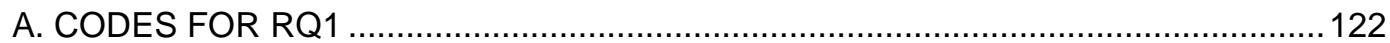

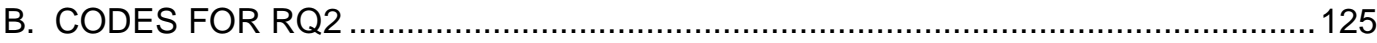

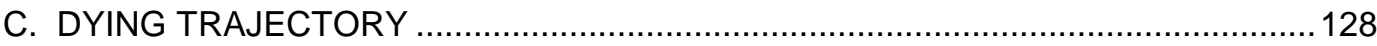

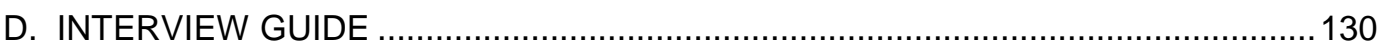

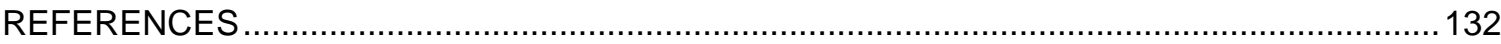

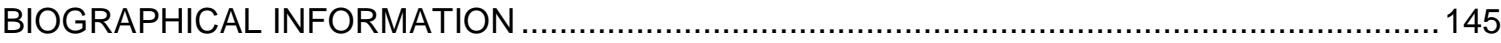




\section{CHAPTER 1}

\section{INTRODUCTION}

Talking to someone about loss is hard work. Most of us have found ourselves at one time or another at a funeral or a similar life situation where we feel the need to say something to a person who just lost a loved one. If we are honest, we will admit we often feel very uncomfortable. We default to "I offer my condolences," "I am sorry for your loss," or "I am praying for you." We all experience apprehension when communicating with a person who we know is struggling with a loss (James \& Friedman, 1998). That moment of tension we feel, of ambivalence, of being pulled in two directions, feeling totally inadequate with our communication is more than a reflection of our inadequacies; it reflects a societal struggle with death. Most individuals and families members are not prepared to handle the difficulties of endof-life (EOL) care, especially if this care is carried out in their home. In recent years there has been an upturn in research attention to the ways that families manage the challenges during the final months of life (Funk, Stajduhar, Toye, Aoun, Grand, \& Todd, 2010; Stajduhar, Funk, Toye, Grande, Aoun, \& Todd, 2010; Jennings, Kaebnick, \& Murray, 2005).

The impetus for this study is born out of my own experiences of working in a hospice, and talking to the dying person and the family members. I am not drawn to the issue of death. Like everyone else I struggle. But I feel I can bring some level of experience to this much needed conversation. I often wonder about the effectiveness of my communication with the nonprofessional primary caregiver (PCG). What have we, the professionals, communicated to the PCGs? What are we missing? How can EOL health care professionals be more effective in communication?

This study investigates discourse during the time period just prior to hospice, during hospice, and during bereavement. The use of the term discourse refers to a social construction 
about how the world works. This particular sense of discourse is from the works of Michel Foucault $(1970 ; 1972)$. For example, Foucault studied the idea of insanity and found that the concept changed over time. People in power drew arbitrary lines between what was considered normal and what was considered abnormal. Over time the culture no longer questioned the line between normal and abnormal. The arbitrary line between normal and abnormal became the natural way to talk about insanity. Another example is found in Philippe Ariès' book, The Hour of Our Death (1981). Ariès traces historically the discourse of death in Western society for the past thousand years. For the majority of that time, Ariès says, death was close and familiar. He writes, "The ancient attitude in which death is close and familiar yet diminished and desensitized is too different from our own view, in which it is so terrifying that we no longer dare say its name" (p. 28). He called the way people spoke and behaved around death as the tamed death.

The modern death discourse is a recent social construction. We do not question the modern construction of death; we assume it is how the world has always worked. In other words, discourse is a particular knowledge about a social situation which forms how the social situation is understood and how things are performed in that social situation. Although our culture has a general way of talking and behaving around death, it is still a very complex and conflictive discursive formation.

The goals of this study are to observe how the dying process is communicatively embraced within the hospice environment and to identify the communication challenges faced by the families and hospice staff.

\section{$\underline{1.1 \text { Background }}$}

\subsubsection{What is Hospice}

Hospice provides support and care for persons in the last phases of an incurable disease so that they may live as comfortable as possible. The National Hospice and Palliative Care Organization (2011) defines hospice care as treatment that enhances comfort and 
improves the quality of an individual's life during the last phase of life. Hospice is not about curing people, but rather helping people to be comfortable in their dying days.

\subsubsection{A Hospice History: There and Back Again}

The ancient origins of the idea of hospice still resonate in the hospice movement today. The concept of hospice is at least over three thousand years old. The first hospices sprang up in the vicinity of holy places such as Greek temples and Jewish synagogues. Hospice has always had an ethical element attached to its meaning. In Ancient Near East primitive society, traveling strangers or foreigners were under the protection of religion and the law. For example, in Homer's Odyssey a stranger was considered as being sent from the gods themselves. Hospitality was the right of the traveling stranger and care for the stranger was considered a sacred obligation of the host (Phillipson, 1911). Within Greek philosophy, being a stranger was an anthropological category. The strength of an ethical connection is illustrated with the Greek noun for stranger, xenos, which is the basis of the verb xenodocheo, meaning shows hospitality (Liddell \& Scott 1996).

The English word hospice has its roots in the Latin word hospes. Hospes means both host and guest and so reflects more of a process than a place. Hospes is also the basis of hostel, hospital, hotel, and hospitality. There are a number of examples of primitive hospices recorded in history. It is known that as far back as 1134 B.C.E. separate hospice structures existed for plague victims (Siebold, 1992). In 325 C.E. the council of Nicea, a gathering of bishops of the Christian church, decreed that each bishop should establish a hospice in each city that had a church building. The Roman emperor Constantine proclaimed in 335 C.E. that infirmaries (nosocomeia) should be erected in Romans cities. One of the most well-known hospices historically was the Port of Roman which was begun in 475 C.E. This hospice functioned as both a place for travelers and for the sick and dying (Phipps, 1988). Eventually the Romans referred to these infirmaries as hospitium. In 800 C.E. Charlemagne encouraged monasteries and cathedrals to attach hospices to their institutions. The institution of hospice 
flourished during the Crusades. With the coming of the Protestant Reformation and the general enlightenment of Europe, a shift away from hospice toward hospital began. Medical authority shifted from the sacred to the secular.

The hospital is the institution that grew out of the hospitiums. With the rise of modern medicine the emphasis in hospitiums became curative while care for the dying and the idea of hospices faded. The shift of hospitiums as hospitals/hospices to solely hospitals is attributed to the increased ability to treat sickness. The unintended result was that beginning in the late eighteenth century, a tendency developed in the medical community to avoid giving patients the prognosis of imminent death. Tolstoy's (1886) short story The Death of Ivan Illych is a good illustration of that tendency. Physicians and nurses were not educated to care for the dying and were uneasy with the notion of their patients dying. This often led to circumstances where the medical staff and sometimes even the patient's family knew the truth about the patient's condition but hid it from the dying patient (Connor, 2009). The rationale for keeping the prognosis of death hidden from the patient was the belief that patients relied on the hope that the silence allowed (Armstrong 1987). In America this trend started to reverse in the 1970s. Today, many hospitals are of religious origin and all are for the purpose of curing. Ironically, the high cost of health care has resulted in the trend of hospitals to get back to care and a willingness to openly embrace that people do die in hospitals. Many hospitals today have a hospice presence in their institutions.

Dame Cicely Saunders is the name normally associated with the beginning of the modern hospice movement. Saunders originally trained as a nurse, but she also obtained degrees in philosophy, politics, and economics from Oxford. She completed her medical studies in 1957 and started to work with patients who were dying at St. Joseph's Hospital in Hackney, England. On the basis of her work at St. Joseph's she started to write a number of articles about pain and death through which she developed a personal network of colleagues and friends. By 
1967 she raised enough money to persuade the English National Health Service to give her support to design and build St. Christopher's Hospice in the outskirts of London.

Saunders' work at St. Christopher's gained the attention of a number of physicians and nurses in the United States. During one of her speaking engagements in the United States she met Florence Wald, then the dean of the graduate school of nursing at Yale. They developed a friendship and Saunders was invited to Yale to give a workshop on hospice. The first United States hospice, New Haven Hospice, was opened by Wald in 1974. She and other hospice advocates called for terminally ill cancer patients to be released from the social isolation of medical institutions and supported them as they returned home to the care of their families. This was all part of the rise of a new discourse in western culture, particularly in the United States. Today, dying patients' basic human rights are often considered to be violated if they lack the knowledge to make their own end-of-life decisions. The hospice movement was at the forefront of this reform movement and cut across many societal boundaries by challenging prevailing assumptions about the appropriate care for the dying (Forman, Kitzes, Anderson, \& Sheehan, 2003). Again, as in ancient societies, hospice had a religious and ethical mandate.

In the first half of the 20th century the medical community believed it was their responsibility to keep death away from American society. The classic study by Glaser and Strauss (1965b), which was conducted within American hospitals, found the general unwillingness of families and professionals to talk about the dying process as well as the avoidance of telling the dying persons that they were dying. Although this sort of thinking has been found to be still present within some medical practices (Gillotti, Thompson \& McNeilis, 2002), much changed with the publishing of On Death and Dying by Dr. Elisabeth Kubler-Ross in 1969. The popularity of the book was such that in 1972 it sparked a United States Senate hearing on death and dignity in America (Ragan, Wittenberg-Lyles, Goldsmith, \& SanchezReilly, 2008). By 1982 policy makers recognized the need and value of hospice and introduced 
the Medicare Hospice Benefit. At the forefront of the movement within American society to be open to talk about death during those EOL moments was the hospice movement.

The modern hospice movement advocates not only care for the dying patient over cure, but also educates families and patients about the need to talk about the dying process. Silence regarding a patient's dying process creates, in the patient and family, a sense of loneliness and agony. Teno, Clarridge, Casey, Welch, Wetle, Shield, and Mor (2004) found that even today, outside of the hospice environment, $50 \%$ of dying patients do not receive enough emotional support and $21 \%$ complained that the dying patient was not always treated with respect. It has been comprehensively documented that hospice is more successful than other health care institutions in the relief of pain (Miller, Mor, Wu, Gozalo, \& Lapane, 2002; NHPCO, 2011), extended survival (Connor, Pyenson, Fitch, Spence, \& Iwasaki, 2007), the reduction of the risk of death for PCGs shortly after the death of the hospice patient and an overall improved bereavement (Christakis \& Iwashyna, 2003).

In summary, western culture seems to have gradually lost its way in its ability to communicatively embrace the dying patient. Why this has happened is beyond the scope of this study. But certainly, with the re-introduction of the hospice we are again learning to talk to each other about dying. Before we look at the question of communication, we need to examine the critical issue of economics which affects the whole of American society.

\subsection{Economics of End-of-Life Care}

How people die is a socio-economic issue. Medicare costs are about to exponentially increase due to the aging of the baby-boomer generation. In the year $2030,22 \%$ of Americans will be over the age of 65 . With this increased proportion of older Americans will come a decrease in the proportion of younger people. Potentially, the inverse growth rates will be a stress on the pool of caregivers and on the tax base to support Medicare (Field, 2009).

The primary issue that compounds the economic problem for EOL care is that, today, the majority of people die from chronic conditions. The leading causes of death in America are 
heart disease, cancer, and stroke. The dying trajectory of these typical chronic illnesses is slow and crisis filled. Often, the trajectory of the patient's health status is like a roller-coaster ride downward. Each health crisis along the way results not only in increased stress for patients, families, and healthcare providers, but also in increased Medicare costs.

Thirty percent of Medicare's annual budget goes for $5 \%$ of beneficiaries who die each year. About one-third of the expenditures in the last year of life are spent in the last month. Most of these costs result from life-sustaining care, with acute care in the final 30 days of life accounting for $78 \%$ of costs incurred in the final year of life (Zhang,Wright, Haiden, Huskamp, Nilsson, and Maciejewski, 2009). On the average, Medicare usage in the last year of life is greater than all the previous years combined (Nakhoda, 2010).

Where we die is also changing. In 1949 one half of all deaths occurred in a hospital or nursing home. By 1958 the institutional place of death raised to $61 \%$ and by 1980 it reached 74\%. In 1982 hospice care was extended to Medicare coverage and the trend of dying in institutions was turned downward, returning to below $50 \%$ in 1997 . The percentage of deaths occurring in the home increased steadily from 16\% in 1989 to 24\% in 2001 (Field, 2009).

All of these issues affect communication at the EOL. Conversations which surround traumatic deaths are different than those which take place around long term chronic illness. The place of communication is shifting from the hospital to the nursing home and, due to the increasing influence of hospice, into the living room.

\subsubsection{Medicare Hospice Benefit (MHB)}

On May 24, 1982, Senator John Heinz, a ranking Republican Congressman from Pennsylvania, conducted a hearing about proposed legislation that would provide reimbursement for the Hospice Alternative under the Medicare program (Buck, 2009). It was introduced as a cost-saving measure under the Tax Equity and Fiscal Responsibility Act. In 1983 Congress established a temporary hospice benefit for Medicare beneficiaries, and in 1986 it was made permanent. By 2007 there were over 4000 hospice programs in the United States. 
Connor (2007) sites three reasons for this growth in hospice, (1) Medicare Hospice Benefit, (2) acceptance of hospice by the United States health care system, (3) for-profit hospices. Since the enactment of the MHB, hospice has grown considerably and is now the fastest growing benefit in the Medicare program. Even with this, it still represents less than $3 \%$ of Medicare expenditures. In 2005 more than 1.2 million people received hospice care in the United States (Connor, 2007).

\subsubsection{Four Criteria for Hospice Care}

A person can get Medicare hospice benefits when all of the following conditions are met: (1) the patient is approved by Medicare; (2) the doctor and the hospice medical director certify that the patient is terminally ill and has 6 months or less to live if the illness runs its normal course; (3) the patient signs a statement choosing hospice care instead of other Medicare-covered benefits to treat the terminal illness; (4) the patient chooses care from a Medicare-approved hospice program (Medicare Hospice Benefits 2010). Patients can receive hospice care as long as their illness is certified by a physician as terminal. Following the patients' deaths, all hospices are required by Medicare to implement a 13-month bereavement program for the primarily caregivers.

\subsubsection{Increasing Cost of End-of Life care.}

In 2000 only $23 \%$ of Medicare beneficiaries took advantage of the hospice benefit (Nakhoda, 2010). Two reasons for this low number may be the Medicare requirement that physicians make a prognosis of a six-month life expectancy, and the requirement that the patient must give up curative treatment. Studies show that patients who use hospice have $36 \%$ lower expenses compared to those who do not. The higher costs for non-hospice patients are usually due to the use of more intensive "life-prolonging" care which does not improve the quality of death nor prolong life (Nakhoda, 2010). Poor EOL communication during this period is expensive. 
The MHB has been shown to save Medicare a significant amount of money by preventing a medical crisis that would end up in a costly hospital or nursing home. Medicare spends a lot of money on curative care for patients in their last year of life, but the hospice choice focuses on comfort at lower cost. In the current climate of rising healthcare costs and budget constraints, hospice will become a more cost-effective EOL care plan for the aging population.

\subsubsection{Aging of the Population.}

In the year 2030 there will be a large change in American demographics. Twenty two percent of Americans will be over the age of 65. By 2040 the number of Americans over the age of 85 will be nearly four times greater than it is today (Jennings, Ryndes, D'Onofrio, \& Baily, 2003). This means that in the future there will be great financial stress on Medicare funding. Hospice is cost effective in comparison to a nursing home or hospital care, and it is logical to assume that the number of hospice patients will increase in the coming years. This will result in a greater number of PCGs.

McDaniel and Clark (2009) refer to baby boomers as adult orphans. There are several salient features of this generation that would cause them to have a greater sense of loss than previous generations and thus a greater need for bereavement care. First, the high divorce rate within the baby boomer generation tends to have isolated the boomers more than previous generations. Second, increased mobility has resulted in the parents being the glue that forms the center for the far-flung family. Third, multiple moves have caused a lack of bonding with local communities. Thus, at the time of the death of a parent, support of community or family is often absent (McDaniel \& Clark, 2009). Health care workers, and particularly hospice workers, are often the first and only source of guidance for the boomers as they cope with EOL communication. As such, the bereavement programs can be an important source of personal contact and information on how to handle grief. 


\subsubsection{Cultural Expectations of Boomers.}

National Hospice Foundation research (2011) has shown that $80 \%$ of Americans said their wish is to die at home. Of the 2.4 million Americans who die each year, fewer than $25 \%$ actually die at home. Of the 700,000 patients who receive hospice care, over $75 \%$ die at home. Also, research has found that people are willing to have an outside organization come into their homes and assist with the care of family members in the last stage of life. Sixty six percent would welcome help from an outside organization like hospice and $24 \%$ would prefer to take care of the family member themselves. In a nation-wide survey, Teno et al. (2004) found that family members of hospice patients who received care at home were more likely to report a favorable experience than family members of those who died in an institution such as a hospital or nursing home.

In summary, the economics of increasing cost of health care is putting pressure on the political system to cut costs. Hospice seems to be a viable option for cutting costs of EOL care. In addition, the aging of baby-boomers means a four-fold increase in the palliative care population. Finally, there is a cultural shift today in which most people desire to die in their homes rather than in hospitals or nursing homes. These three contextual issues point to a dynamic growth in EOL care.

Given these dramatic projections, communication researchers need to explore ways in which their particular research field might facilitate caregivers' and health care providers' awareness of communication issues faced by families at the EOL. EOL is a stressful time for all parties involved. It is during these times that clear communication is critical both for families to communicate their needs to the medical community, and for the medical community to convey information to the families about the dying process. 
CHAPTER 2

LITERATURE REVIEW

\subsection{Communication Challenges at the End-of-Life}

Glaser and Strauss (1965) in their classic book Awareness in Dying found that Americans generally prefer to talk about particular deaths rather than death in the abstract and they are also unwilling to talk openly about the dying process. Poor communication during a terminal illness can cause more suffering than any other challenge with the exception of uncontrolled pain (Mauk, 2003).

The fragmentation of the American family and the frequency of institutionalization of elderly persons have had the effect that many people reach adulthood without ever being exposed to the practical issues surrounding the EOL. Death is often considered a taboo subject. Fear of death affects how people communicate about death. Some people believe that talking about death will make it happen, even if it is not remotely possible. Many people experience apprehension when communicating with a dying person (Ragan, et al., 2008). Thus communication at the EOL among family, patient, health care professionals, the social network of the family, and ultimately, the society at large is fertile ground for misunderstandings, conflict, paradox, and confusion.

Most of the scholarship which has focused on the challenges of communication at the EOL has concentrated on a range of essential decisions required as death approaches. There are two types of studies. First are those that focused on clinical decisions such as to withdraw life support or breaking bad news. These are physician centered studies. (Gillottia, Thompson, \& McNeilis, 2002; Trice and Prigerson, 2009). Second are those studies that focused on decisions made by patients and their social network. These are patient and PCG centered studies (Sparks, Villagran, Parker-Raley \& Cunnimgham, 2007; Werth, \& Blevs, 2008; Bachner \& Carmel 2009). This study is focused on the latter, the EOL communication in the hospice environment. Most of these studies have focused on such issues as breaking bad news, 
advanced directives or "do not resuscitate" (DNR) orders, prognosis, and the final conversation of the dying with their families (Considine \& Miller, 2010).

A number of studies have given attention to how health care professionals "break bad news" (BBN) to the patient and family. Gillotti, Thompson and McNeilis (2002) summarize the research that has been done with $\mathrm{BBN}$ and concluded that health care professionals experience great discomfort communicating a terminal prognosis. In addition, the more information that was communicated during BBN by the health care professional the more it was perceived as negative by the patient and family. In other words, BBN was not the time to go into great detail with medical information, but normally, information was welcomed in other situations. Sparks et al. (2007) found that health care providers used different strategies in handling BBN such as avoidance, being direct and cold, providing comfort with emotion, and empowerment by giving the patient choices. In addition, personal patient factors determine how the healthcare professionals BBN. For example, oncologists alter their communication based on patients' coping style and assertiveness (Thorne, Kuo, et al., 2005). Sparks et al. (2007) found that various strategies were employed and the strategies reflected the individual health care providers. The study concluded that whatever strategy was employed, it should be patientcentered. Larson and Tobin, (2000) found that many of the struggles in EOL communication could be tied to the tendency of people being uncomfortable when communicating a terminal prognosis. DNR discussions were sometimes communicatively part of the BBN conversations and it was at this point that hospice was often mentioned as an alternative.

Schulman-Green, McCorkle, Cherlin, Johnson-Hurzeler, and Bradley (2005) studied the struggle of the hospital staff in regards to communicating a terminal prognosis. They surveyed six hospital staffs using a self-administered anonymous survey on obstacles to communication of prognosis and referral to hospice. They found five major obstacles to the communication of prognosis and referral to hospice. First there was the unwillingness of a patient or the patient's family to accept a prognosis and/or hospice care. This included any number of the following 
reasons: the denial of terminal status, discomfort with hospice, the desire to maintain patient's hope, and the desire to continue aggressive treatment. The second obstacle to the communication of prognosis or a referral to hospice was the sudden or imminent death of the patient or the mental incapacitation of the patient. The third obstacle was the physician's hesitancy to give a prognosis due to being uncomfortable with discussing EOL topics or the physician's desire to continue aggressive treatment. The fourth obstacle was the nurses' discomfort with EOL communication. The fifth obstacle was the nurses' desire to maintain hope among patients and patients' families or a desire to avoid upsetting patients or patients' families.

The majority of EOL studies involve communication issues of the clinical staff. Some studies focus on the role of family communication in EOL communication. Wilkins, Quill, and King, (2009) state that "there are few empirical studies of family functioning in palliative care" ( $p$. 517). King and Quill (2006) and Nadeau (2004) believe the reason for this is the emphasis in the West on the individualistic approach which is focused on patient autonomy with a relative neglect of the social system or family that shapes EOL communication.

Family system theory has been used for understanding the family's adaption to the dying process and death. Walsh and McGoldrick (1991) found that a family reacts to dying as a system with the family members participating in reinforcing interactions. How a family adapts to dying and death depends on a number of variables. The family's adaptation to the dying process can be complicated if there are secondary losses involved. Murray's (2001) review of grief literature found studies that attributed concurrent losses such as personal, interpersonal, and material losses caused family complications when adapting to the dying possess. In other words, losses such as divorce, loss of a job, or health issues found in other members of the family accumulate and compound acceptance of the dying process of the patient and complicate grief. Other variables, such as the centrality of the role of the patient in the family and conflictive family issues that might surround the patient and the family, will also affect how well a family adapts to the dying process or death. 
King and Quill (2006), in their study of the role of family in EOL decisions, used the family system approach to understand how the family adapted to EOL issues. They found that collaboration among patient, family, and professionals was of primary value. All participants in the EOL situation needed to be acknowledged as having their own area of expertise. Mick, Medvene, and Strunk (2003) concluded, from their study on surrogate decision making at the EOL that family complications arise from the dying process and are often mitigated by the family's increasing degree of openness to death acceptance. But research findings concerning the importance of open communication are mixed (Murray, Toth \& Clinkinbeard 2004). In a similar manner, the presence of social support of the family and for the family appears to simultaneously complicate and facilitate acceptance of the dying process and grief. Nadeau (2004) used three concepts, roles, rules, and boundaries from family systems theory, as a template for understanding how the family accepts death and adapts to grief. She found that families rearrange themselves or make meaning out of the new situation. Zhang and Siminoff (2003) found within families a phenomenon of silence caused by psychological distress, mutual protection, or positive thinking. Bosticco and Thompson (2005) summarized the research on the role of communication in the grieving and bereavement process and found that grieving and bereavement do not take place within a vacuum. The family makes sense of the death by retelling the story of the death.

In summary, current research indicates that the medical community is aware of the need to communicate to the family about the condition of the patient. The communication of a terminal prognosis by the health care provider to the patient and family was found to be challenging. The awareness of the need to communicate a terminal prognosis often was at odds with the health care provider's behavior. If the family is informed of the terminal prognosis the next step is to prescribe a plan of care. It is at this point that hospice often enters into the story. 


\subsection{Communication Challenges for Hospice}

Today, most deaths are preceded by chronic conditions. The population is living in a dying state longer. Americans view technology as a means to put off the inevitability of death. Delaying death by medical means contributes to the inability to discuss death explicitly because there is always the choice of a possible life extending treatment option. Babrow and Mattson (2003) believe that these changes have created a paradox in health care due to the presence of a communication tug of war between the medical focus and the humanistic focus. Ragan et al. (2008) state:

The preeminence of medical science and advanced technology, which have led to the eradication of many diseases once considered death sentences, permit us the belief that we have conquered death, that it is no longer the inevitable, natural conclusion to life. (p. 5)

Feelings such as guilt, anger, and fear can come to the surface to inhibit open communication within a hospice environment. Denial of the terminal diagnosis is often evidenced by the construction of communication barriers such as telling jokes, changing the subject, or other avoidance strategies. Mauk says denial masked as hope for a cure is often used to circumvent honest EOL communication (2003).

A study with a Connecticut hospice found that not quite half of the bereaved caregivers reported being told of the patient's life expectancy at the time of hospice admission (Cherlin et al., 2005). Their study found that ineffective communication about EOL issues likely resulted from both the physicians' lack of communicating clearly the terminal prognosis and the PCGs difficulty in accepting the news. Trice and Prigerson (2009) found, in their review of the literature on EOL communication, that patients with cancer were more likely than not to want their physicians to tell them their life expectancy, suggesting that physicians may selectively disclose the prognosis to those patients whom they think want, and can "handle," this information. They also found that cognitive acceptance and emotional acceptance of a terminal cancer diagnosis 
are two distinctly different entities. In other words, the patient and PCG could cognitively accept the bad news but reject it emotionally.

There are those who can reconcile themselves to death and those who can't. Metaphorically speaking, some patients face death by communicatively putting themselves in forward gear, others put themselves in reverse gear, but most are stuck in neutral. Prigerson (1992) refers to the lack of communicating about EOL decisions as an inability of the those involved with the decision making process to socialize from a sick role to a dying role. This means that some PCGs and patients remain in the sick role, some are able to transition to the dying role, but most vacillate between both for a time. The sick role is a term used in medical sociology which refers to the obligations that surround an illness and shapes the behavior of doctors and patients (Parsons, 1951). The sick role of a patient allows the individual to have a temporary exemption from pre-sickness social obligations and actually provides the mechanism for the patient to return to health and normal role responsibilities. The assumption is that the patient will get well. The sick role is a role we all have participated in. The idea has a likeness to Goffman's (1959) concept of self-presentation as part of a personal strategy of impression management. It is similar to the sick person taking off from work in order to recover, or family members pulling the weight of the family duties of the sick person until the individual recovers. In the case of chronic illness, which was rare at the time of Parsons' study, the anticipation of recovery is not possible. There is no return to normal. The general thesis of Prigerson's study was that EOL patients receive curative treatments largely because the family and the doctors have been socialized to think sick role rather than dying role. In other words they remain in the sick mode. Her study found that patients who make the transition from the sick role to the dying role would more likely use hospice, those who do not, would more likely use hospitals. Her study also found that the dying patient was often passive in the decision making process. Gawande (2010) calls the transition or lack of transition from sick role to dying role the great divide within palliative care. 
Closely related to the sick role-dying role is the study by Glasser and Strauss (1965) regarding the lack of communication between doctor and patient about the time of death. Their study found that doctors are socialized into thinking that their role was to protect the patient from further injury by not communicating the diagnosis of death to the patient. Today doctors are hesitant to communicate a prognosis of death. The reason for this is that death is medically rarely certain because medical technology can prolong life. However, if a family and patient have been socialized into a dying role then a six month prognosis by the doctor makes the hospice option a viable choice for them.

An additional communication challenge within the hospice environment today is that hospices are now promoting their businesses as medical alternatives that can extend longer than six months through a recertification process. Theoretically, the patient with a six month prognosis can be in hospice for years

Larson and Tobin (2000), in their study of EOL communication, found the barriers to communication to be both intentional and unintentional. Communication barriers were erected by patients, family, healthcare providers, and even the structure of the health care system. Professional palliative caregivers were not exempt from struggling with communicating to the patient and family about death. Randall and Downie (2010) found in their research that prior to admittance into hospice care the patient and family had to navigate past two critical issues, the decision to Do Not Resuscitate (DNR) the patient in the case of heart or lung failure and the place of death; a facility or the home. Both issues usually caused some sort of controversy within the family. In respect to patient/hospice communication, many EOL conversations are complicated by the dying trajectory and anticipatory grief.

\subsubsection{The Dying Trajectory}

The pattern of illness and fatality at the turn of the 20th century is in striking contrast to the patterns illness and fatality at the turn of the 21 st century. A hundred years ago, if one did not die of influenza, smallpox, tuberculosis, or typhoid fever, one got well (Imhof, 1985). 
Sickness was a relatively temporary phenomenon. As we progressed through the 20th century, the medical community became increasingly more effective with curing infectious diseases and developing effective therapies. Today, death principally results from chronic organ failure or degenerative diseases of aging. Callahan (1993) sums it up with three points. Today we have longer lives and worse health, we have longer illnesses and slower deaths, and, finally, we have longer aging and increased dementia. Because of these changes, controversy often occurs within families, which closely follow the dying trajectory of the patients. A dying trajectory refers to how long it takes to die and the number of crisis episodes before death. The vast majority of patients in hospice are suffering from chronic illnesses and thus the road downward is long and bumpy. Glaser and Strauss (1968), in their seminal work Time for Dying, studied the influence of patients' dying trajectories on their caregivers. They found that each time a non-fatal crisis event occurred there was an increase in economic demands on the family and on the health care facility. The dying trajectory is like a rollercoaster (see appendix C). A chronic dying trajectory is a series of possible death crises alternating with recoveries. Each time the patient's health took a turn for the worse, a potential for the family to reevaluate the DNR and the transfer of the patient to the hospital occurred. In addition, downward turns caused the family to go into crisis mode and affected the communication within the family. Upswings in health provided a sense of false normalcy that circumvented crisis communication.

Glaser and Strauss (1965) also found mutual pretense as a communication barrier. Mutual pretense is when there is a silence about the seriousness of the illness between family members and/or healthcare staff and they behave and communicate as though the patient is not dying. The family pretends all is well but actually knows differently. Reality comes when it becomes apparent physically that the patient is not going to recover. Often there is an oscillation between open awareness and mutual pretense.

Wittenberg-Lyles, Goldsmith, and Ragan (2011) approach EOL communication from narrative theory. They describe the dying trajectory as linear and composed of three different 
scenarios based upon the patient's death awareness. First is closed awareness, varying degrees of being closed to the fact that the patient is dying. This is followed by the drama of mutual pretense. Finally, open awareness, which often includes the acceptance of hospice. They use the term illness trajectory which is tied conceptually to Kubler-Ross's (1969) book On Death and Dying in which five stages of dying are progressive. Wittenberg-Lyles et al. (2011) based their EOL communication strategy on the degree of the death awareness of the patient and family. Their goal was to highlight EOL communication issues so as to inform nurses how to communicate at the EOL. The Yale Bereavement Study (Maciejewski, Zhang, Block, \& Prigerson, 2007) seriously questioned the existence of progressive stages of dying. Their study questioned the use of the metaphor of a journey to understand EOL communication

The dying trajectory of chronic illness causes communication challenges for the hospice staff. When a family chooses to ignore the DNR or decides to change the place of death to a hospital, it is counter to a previously agreed upon course of treatment. The communication challenge for the hospice staff is found in the difficulty of the staff's continuing support of the family in the face of choices made by the family that are contrary to hospice values. The dying trajectory of the hospice patient puts a unique twist on competing discourse in EOL communication because the presence of a series of health crises changes the discursive struggles. In addition to the dying trajectory, anticipatory grief also plays a significant role in the PCGs' expressions of grief.

\subsubsection{Anticipatory Grief}

The term anticipatory grief was first coined by Lindemann (1944) in a series of interview studies conducted with the bereaved of WWII. Lindemann wrote:

We were at first surprised to find genuine grief reactions in patients who had not experienced bereavement but who had experienced separation, for instance with the departure of a member of the family into the armed forces. Separation in this case is not due to death but is under the threat of death. A 
common picture hitherto not appreciated is a syndrome which we have designated anticipatory grief. (pp. 199-200)

Lindemann concluded that the family and friends who are forewarned or prepared for the death are better able to prepare psychologically. Recent data have confirmed Lindemann's findings that bereaved caregivers who recognized themselves as unprepared for the death are less content and suffer from worse mental health than those who were prepared (Herbert, Holly, Prigerson, Schulz, \& Arnold, 2006). Valdimarsdottir, Helgason, Furst, Adolfsson and Steineck (2004) conducted a survey of 506 Swedish women who lost their partners to prostate cancer. Generally they found that an abbreviated time of death awareness resulted in additional psychological trauma. Widows who were not informed of their husbands' impending deaths during the last month before death were at increased risk of anxiety. The study concluded that additional trauma for surviving spouses may be avoided by the clear presentation of information about the terminal prognosis.

Main (2002) found that emotional support for the PCG by health professionals during the final stage of illness is a key component to the easing of mourning during the bereavement period. Talking about death before death occurs eases bereavement. This suggests that one of the important roles of hospice is to recognize that the grieving process starts before death and the hospice staff should be aware that it should not shy away from the subject. However, health care providers bring their own personal experiences and fears into the relationship with the PCG in the hospice environment.

Main (2002) conducted focus groups with PCGs and medical staff members on the issues that surround the death of a patient. Main found that the palliative staff expressed feelings of "being uncomfortable" with how to talk about death to the family. Often the staff avoided the word death and used euphemisms such as "gone to heaven." Also, the desire to avoid the role of who communicated to the relatives that the patient was going to die often resulted in "passing the buck" to the doctor. The palliative staff generally considered relatives of 
the dying patient to be creating their own problems by their lack of insight in regards to the dying process. A staff trained in EOL communication skills was more likely to be communicatively proactive with the family whereas untrained staff was more likely to focus on performing tasks rather than communicating. This is critical because information about diagnosis prior to death starts the anticipatory grief process and helps people during bereavement to come to terms with loss. How a family functions during the course of a terminal illness can influence the caregiver's health and well-being long after the death (Schulz \& Beach, 1999). Shajduhar, Mardin, and Cairns (2010) found that the caregiving experience is an important predictor of bereavement outcomes. In other words, the hospice experience of the caregiver during the illness has a powerful impact on the bereavement of the caregiver. One of the purposes of this study is to explore communication obstacles that persist into the bereavement period.

Funk et al. (2010), in their literature review of recently published qualitative research for home-based family care giving, found that a number of studies conceptualize family care giving at the EOL as fundamentally uncertain or ambiguous in part because of the unpredictability of the course of the patient's illness and death. Harding and Higginson (2001) studied the identity crisis faced by PCGs of patients at the EOL. They found that the PCGs often vacillated between their role as spouse of the patient and their role as caregiver. Communicatively, this results in conversations in which the palliative care staff has to determine whether they are talking to the caregiver or the spouse, which can vary several times in the course of a single conversation. The apprehension, ambivalence, and feelings of inadequacy when communicating with families experiencing dying or death of a loved one is a core challenge for health care professionals, family members, and friends who desire to help those who grieve.

Communication challenges at the EOL often arise due to the ambivalence that individuals and families have towards death. This affects both the dying and those caring for the dying. EOL communication is further complicated by uncertainty that results from the dying 
trajectory. Any communication theory that is used to ground one's understanding of EOL communication needs to take into account the messiness of EOL communication.

\section{$\underline{2.3 \text { Theoretical Grounding }}$}

There are several communication theories that have been used to help illuminate and inform communication within palliative care situations at the EOL. Ragan et al. (2008) found that the most common theoretical approaches to understand EOL communication are (1) narrative theory (2) uncertainty management theory (3) dialectical theory, and (4) social construction of health and illness. There are also several psychology-based theories that have been used to help the bereaved work through their grief, such as the grief work theories, attachment theory, continuing bond theory, family systems theory, and dual process model (Neimeyer, 2001).

Narrative theory has been used to explain how hospice volunteers (Wittenberg-Lyles, 2006) and hospice staff (Considine \& Miller, 2010) within a palliative context use narrative to help with communication. The communication of a personal story that connects with palliative patients and families is a powerful way of expressing empathy and gaining trust without feeling one has to be an expert. To a lesser degree in the literature, we find the uncertainty management theory (Brashers, Neidig, \& Goldsmith, 2004). In hospice situations uncertainty management is not used to reduce uncertainty, but to learn to accept it. Hospice team members have to learn to not communicate predictions about future health to patients and caregivers but, rather, should be trained to become comfortable with communicating ambiguous, complex, and unpredictable situations. These two theories, narrative and uncertainty management, describe EOL discourse conflict within the hospice and bereavement contexts.

Family communication studies provide general insight into how families function during times of crisis. Vangelisti (1994) and Vangelisti and Caughlin (1997) mention that families keep boundaries or secrets. Sometimes these boundaries are within the family as a whole or between couples. In a hospice situation, the PCG and the patient are usually from within the same family. They have a unique relationship which has a proclivity toward not sharing with the 
rest of the family the suffering of the patient or the nearness of approaching death. At other times the family keeps information about the coming death from the patient so as not to stress the patient. Karpel (1980) argued that the primary function of withholding information is protective. Within the context of end-of-life situations it serves to protect various members of the family from the dying process of the patient. The withholding of information serves to protect the family from stressors (Vangelisti, 1994). There is a general lack of family communication studies regarding end-of-life communication as evidenced by its absence in family communication literature (Vangelisti 2004; Funk et al. 2010). On the other hand, there are a number of studies within palliative care research that focus on family communication. For example, Zhang and Siminoff (2003) found both in their study and in the literature that withholding of information by the PCG and patient from the family is widespread within palliative care.

For the purpose of this thesis, however, I will be using Leslie Baxter's (1996; 2011) relational dialectical theory (RDT). The rationale for this choice is that communication within a palliative care context is saturated with competing discourses or discursive struggles; the source of which is embedded and circulates in society at large (Baxter \& Braithwaite, 2010; Mishler, 1981; Werth \& Blevs, 2008). Competing discourses are inherent in social life and so their presence within a relationship should not be taken as a sign of relational problems. Baxter's highlights the location of discursive struggles is the broader culture and not just interpersonal and intrapersonal. An example of such competing discourse in society is the tension between length of life versus quality of life. In all probability, sometime before the death of the patient, the patient and PCG had a choice between these two voices. The source of the conflict could be intrapersonal, between family members, the larger social network of the PCG, the health care community, or cultural expectations. We know that people in our society struggle with the dilemma of whether to fight with the hope of a reprieve or to bow out gracefully with the acknowledgement that meaningful life is essentially over. Major socio-cultural movements have formed around one side of this dilemma or the other (Kleespies, Miller \& Preston, 2009). 
In principle, hospice makes its services available to those who have refused lifesustaining treatment. In practice, there is no small amount of ambivalence and struggle for families, patients, and PCGs. Families hear the voice of society saying "fight on to the end." This voice usually comes from either the medical field in general whose primary goal is cure or, more particularly these days, cancer treatment centers whose primary goal is business. The other voice says in the face of a terminal diagnosis, "you are terminal, die in comfort." This voice often comes from the palliative field whose primary goal is care. These voices can be heard within or outside of the family.

RDT is meant to be utilized as a heuristic device which sensitizes the investigator to communication processes. RDT has been used for communication research in the context of palliative care.

Toller (2008) and Toller and Braithwaite (2009) used dialectical theory to examine how bereaved parents used communication to negotiate and manage changes in their identity after the death of their child. The contradictions that Toller (2008) found were "a parent without a child to parent" and "I am an outsider-I am an insider." The second contradiction refers to being outsiders when present with their general social network and insiders when with other bereaved parents. Toller and Braithwaite (2009) also found dialogical tension of parents grieving differently. Healthy couples were able to manage a grieving together-grieving apart contradiction and challenged the notion that parents must be unified in how they dealt with their child's death.

One can see how these dynamics could work within a hospice situation. For example, whether or not the PCG communicates about the recent death of the loved one depends upon how he or she manages the tension of the move on-don't move on discourse. At what point does the bereaved move on?

RDT is based on the dialogism of Mikhail Bakhtin (1973; 1981; 1986). Baxter's RDT has progressed over the years from a theory that analyzed tensions inherent in romantic 
relationships, which she refers to as the RDT 1.0, to her more recent RDT 2.0 which borrows heavily from Bakhtin (Baxter 2004, 2001). "Relational dialectics, framed in dialogism, also stands in sharp contrast to my earlier dialectical work, which I would characterize as more Hegelian in nature" (Baxter, 2004, p.11). It would be more accurate to label Baxter's current approach as a Relational Dialogic Theory. Besides this theoretical shift, a number of terms have changed. Two in particular are important because they are correspondingly associated with the two research questions of this study. The term competing discourse is used interchangeably with discursive struggle, but in the earlier writings Baxter used the expression contradiction. The expression was changed in order to underscore that contradiction was a discursive struggle and not a conflict between individuals or a psychological tension within an individual (Baxter, 2011). The emphasis is that discourses are competing and not a type of internal psychological, ethical, or philosophical struggle of the person. This does not preclude the presence of an internal struggle, but it is not the place of emphasis for RDT. Discourse is being used to refer to any specific point of view, worldview, value, or ideology. The object of analysis is the competing discourse, not the individual. Competing discourse is the dynamic interplay of unified opposites. The second term that has changed is praxis. Praxis focuses on the practical choices individuals make in the midst of a discursive struggle. The basic concept has not changed but the focus has turned to the interplay or interpenetration of competing discourses and how the individual communicatively negotiates the interplay.

These are critical theoretical developments. RDT2 has become more conducive for the study of communication in the palliative care context than RDT1. There are two critical distinctions that this study makes as it approaches RDT and competing discourses. Both are based on Bakhtin's original purpose which Baxter has embraced. Bakhtin, in my opinion, did not develop his dialogical theory to help the reader understand the nature of contradiction in the literary context, but rather, Bakhtin's purpose was to sensitize us to their presence in the text. 
Bakhtin simply helps us observe it. Second, the theory is descriptive, not prescriptive. The theory does not propose or imply a particular course of action.

Baxter and Braithwaite (2010) state that meaning making is the process that emerges from these sorts of competing discourses. The assumption is that meaning making is socially constructed.

\subsubsection{Social Construction}

Social construction and health communication have shared common ground since the 1980s. Historically, social constructionism was defined by Berger and Luckmann (1966) as

reality being dialectic between personal understanding and the social reality of commonly accepted knowledge. Berger and Luckmann further argued that people together create and sustain all social phenomena through social practices. In other words, competing discourses are primarily social, not a psychological struggle. Craig (1999) proposes that the social construction perspective is a metamodel for communication studies.

To refer to something as socially constructed is to emphasize this "something" is dependent on contingent aspects of our social selves. Had we been a different kind of society, with different values and needs, we might have constructed a different kind of "something." For example, the death of a hospice patient is not a social construction. The EOL communication that surrounds death is a social construction because it was shaped in the context of the social. The latter is an epistemic claim that explains why EOL communication has certain competing discourses. Competing discourses are socially constructed or maybe better, socially maintained.

Most social constructionists acknowledge that the experience of illness or suffering exists as biological reality but they also point out that illness and suffering are given meaning and therefore comprehended and taught by experience through a social process (Carpentier \& Brussel, 2012; Sharf, \& Vanderford, 2003). The explanation for why we have a particular belief or why a particular discourse competes with another has to do with the role that belief plays in 
our social life. For example, Prigerson's (1992) study of the sick role and the dying role, which was discussed previously, could be called a social construction of the dying process. The role formation is socially based. Within the literature, sometimes death as a process is combined with death as an event. Carpentier and Brussel (2012), in their theoretical study of discourse, social construction, and death, do not consistently distinguish between the process and the event. This can be confusing. For the purpose of this study, the process is a social construction and it is called the dying process.

Mishler (1981) and Nadeau (2001) are two examples of how social construction has been utilized in EOL research and how its use is associated with RDT. Mishler's study focused on two competing voices, the Voice of Medicine and the Voice of the Lifeworld. Within the hospice context, these two voices are embodied by the four primary members of the hospice team. The medical voice normally is the nurse and doctor. The life voice is normally the social worker and chaplain. Mishler called his theory the social construction of illness. Social construction of illness theory reflects a tension between the objective scientific and subjective humanistic voices (Mishler, 1981). In Mishler's study, the two ways of communicating about death are expressed through habitual speech patterns. For example, in a physician/patient interview the medical voice of the physician usually dominates. Any sort of interrupting question from the patient, the life voice, which is not a medical type question is suppressed or ignored. "The physician either breaks into the patient's statement before she has completed it, thus terminating her statement with his own comment, an 'Okay' or ' $\mathrm{hm}$, hm' or he takes his next turn without pause as soon as the patient finishes" (Mishler, 1984, p. 72). From the perspective of hospice, the two voices strive to complement each other, rather than compete. It is absolutely critical for the hospice team to strike a balance between the medical and life voices. A doctor or nurse who only communicates medical information in a patronizing style of conversation has no place in hospice. Babrow and Mattson (2004) considered the two voices as symbolizing the "age-old question that embodies our deep ambivalence about death: whether it should be 
fought or accepted" (p. 42). I am not sure if it is an age-old question, but it is a social construction that has been around for some time. Pearce (2009) wonders if the embodiment of our deep ambivalence about death is something discovered or constructed

\subsubsection{Makhail Bakhtin and Relational Dialectical Theory}

There are two critical concepts in RDT2: the utterance chain and centripetal-centrifugal struggle (Baxter, 2011). Baxter leans heavily on Bakhtin for the use of these two concepts in her RDT2.

\subsubsection{The Utterance Chain}

Bakhtin (1986) wrote "Each individual utterance is a link in the chain of speech communication" (p. 93). An utterance is not an isolated occurrence, but a link in a chain of utterances that includes already voiced discourses and anticipated discourses (Baxter, 2011; Baxter \& Braithwaite, 2010). In other words, all utterances are part of a chain of communication in which the speaker is not the first to speak. Bakhtin (1986) writes "The speaker is not the biblical Adam, dealing only with virgin and still unnamed objects, giving them names for the first time" (p. 93). The utterance is never ex-nihilo; an utterance is always an answer to another utterance. Therefore utterances are drenched in social factors. The utterance is but a link in a larger chain of communication where prior utterances and anticipated future utterances are taken into account. An additional important aspect to Bakhtin's utterance chain is that speakers may be part of a social situation in which certain discourses are part of the community and an utterance might be unsaid because it is taken for granted. This takes us back to the idea of contingency and social construction.

Baxter (2011) divided the utterance into four categories. The first type of utterance link is the distal already-spoken, which is a discourse circulating in the culture at large. It is cultural communication. An example of a distal already-spoken discourse is the American ideology of individualism. 
The second type of utterance link is the proximal already-spoken, in which the past meaning of a relationship informs and sometimes competes with the present meaning of the relationship. In EOL communication in hospice situations all parties are contending with a discursive struggle of remaking the nature of their relationship. Baxter (2011) would consider a relationship that transitions into the EOL as a turning point. Turning points "are occasions in which contradictions can be identified in bold relief" (p. 94). For example, the past discursive site of a marriage relationship bumps up against the current relationship of caregiver and patient.

The third type of utterance link is the proximal not-yet-spoken, which is the anticipation of the response that will be received from the relational other. The final type of utterance link is the distal not-yet-spoken, which is the anticipation of how a generalized other or third party will respond. The focus of this study is on the first two types of utterance links.

\subsubsection{Centripetal-Centrifugal Struggle}

The second concept critical to RDT2 is the centripetal-centrifugal struggle (Baxter, 2011). Bakhtin (1984), as a literary scholar, argued that Fyodor Dostoevsky's novels (including Crime and Punishment, The Brothers Karamazov, and The Idiot) embodied two voices. Bakhtin viewed Dostoevsky's novels as moving beyond a single monolithic voice, beyond resolution of clashing viewpoints. According to Bakhtin, within Dostoevsky's novels there is no progression towards a resolution, no synthesis of contrary voices. Bakhtin (1973) writes in his seminal work The Problems of Dostoevsky's Poetics:

"Life is good." "'Life is not good." We have before us two judgments which have a specific logical form and a specific concrete semantic content (philosophical judgments on the value of life). There exists between these two judgments a specific logical relationship: the one is the negation of the other. But there is and can be no dialogical relationship between them, they do not dispute with one another (although they can supply matter and the logical basis for 
disputation). Both of these judgments must be embodied in order for a dialogical relationship between them or toward them to arise. Thus, as thesis and antithesis, these two judgments can be united in a single subject, an utterance which expresses that subject's unified position on a given question. In that case no dialogical relationships arise. But if the two judgments are divided between two different utterances of two different subjects, then dialogical relationships arise between them (pp. 151-152).

This is the value of Bakhtin for a study of communication within the palliative care field. It is not about cognitive dilemma within the self, but rather competing discourse between parties. Communicational paradox is common in palliative care situations due to the heightened crisis of the approaching death in the family. In Holquist's (1990) seminal work on Bakhtin, he coined the term "dialogism" to describe the on-going tug of competing discourse. He refers to dialogism as "the unique and unified event of being" (p. 24). Baxter (1998, 2004, \& 2011) refers to dialogism as the interaction between voices in which there is a dynamic interplay between unified opposites. Em (2009) states that "most Westerners are bothered" by this concept of Bakhtin because it seems to state a paradox (p. 156). When Westerners hear two truths that lay claim to one concept they try to logically reorder it as a contradistinction. But Bakhtin was trained early in his life in the Russian Orthodox tradition that embraced paradox (Brueggemann, 1997). Bakhtin and, especially, Dostoevysky, through the development of his literary characters, embraced competing discourse not as an either/or but as both/and. Bakhtin argued that social life is not a monologue in which only one voice, perspective, theme, or point of view is heard. Life is a dialogue in which multiple opposing themes are given voice.

To eliminate confusion around competing discourse it is helpful to first illustrate the difference between binary opposites, dialogism, and Hegelian dialectics, using two planets. First, binary opposites are like two planets that have no relationship with each other. They are far enough apart that they do not interact. Second, in Bakhtinian dialogism, one planet is red, 
and everything this planet represents stands in contradiction to the other planet, blue. The planets share gravitational fields; however, neither planet will ever share a part of the other. This is a unity of opposites. Third, Hegelian dialectics would argue that all things work towards a resolution, the goal being that the blue and red planets will at some time in the future become a purple planet, so to speak. Bakhtin (1984) referred to Hegelian dialectics as "theoretism" and he regarded it as historically dominant in modern Western thought. This third option was Baxter's (1988) original idea of dialectical relationships. Bakhtin was critical of Hegelian dialectics because of its mechanistic progression toward synthesis. According to Bakhtin, there is not always a resolution of the tension between contradictions. They simply coexist (Baxter, 2004). Bakhtin's dialogism conceptualizes two planets that are within the gravitational field of each other and, thus they do affect each other and in this sense they are unified. The gravitational forces of each are constantly in flux, sometimes one dominating, sometimes the other. Baxter says this triggers change within the relationship. Bakhtin (1984) calls the dominant voice a centripetal voice, the one that symbolizes normative social conventions. The other voice is called centrifugal, and it is the socially marginalized voice. The dynamic that is happening between the two voices is dialogic. They are not binary opposites because they interpenetrate each other through the force of their gravitational fields. This dynamic is a power struggle and the two voices could swing back and forth taking turns being the dominant voice. Morson and Emerson (1990) additionally point out that Bakhtin considered the competing voices themselves to be messy. Each planet was not a pure voice. The centrifugal and centripetal voices themselves were "unfinalized" and defied any sort of systematization. In other words, each discourse had a propensity to defy a precise definition.

If this process of interplay between voices is diachronic, it is characterized by a shift over time in which competing discourses might switch their centripetal and centrifugal positions. Baxter and Montgomery (1996) used the terms spiraling inversion and segmentation to refer to two diachronic practices. Spiraling inversion includes a back and forth pattern of discourse 
dominance over time (Baxter, 2011). Segmentation, on the other hand, includes a back in forth pattern as well, but according to context or activity rather than time. Both are prominent features of EOL communication. The dying trajectory of chronic illness drives competing discourses to flip multiple times in their positions as dominant voice.

In summary, Bakhtin's approach to understanding interpersonal communication is a sociocultural process. This is in contrast to understanding communication as isolated and driven by internal relational dynamics between dyads. According to Bakhtin, communication is not contained between two people, but rather is linked to utterances spoken in the culture at large. "The topic of the speaker's speech, regardless of what this topic may be, does not become the object of speech for the first time in any given utterance; a given speaker is not the first to speak it” (Bakhtin, 1986, p. 93). When one encounters, for example, a conversation about the quality of life versus the quantity of life at the EOL, one has entered into a very complex organized chain of utterances which is embedded in the world view of the culture. This is discourse, and if this discourse finds itself in competition with other discourses, then they are competing. Competing discourses are linked to utterances spoken in the culture at large. The utterance is socially constructed from previous conversations. The utterance is not an isolated communicative act with a one-to-one correspondence but a chain which has connections to the preceding and subsequent links in the chain of speech communication. In relationship to the utterance Bakhtin wrote (1986):

Everything that is said, expressed, is located outside the "soul" of the speaker and does not belong to him. The author (speaker) has his own inalienable right to the word, but the listener also has his rights and those whose voices are heard in the word before the author comes upon it also have their rights (after all, there are no words that belong to no one). The word is a drama in which three characters participate (it is not a duet, but a trio). It is performed outside the author, and it cannot be introjected into the author. (pp. 121-122) 
What one says is influenced by what has been said and also by possible future responsive reactions. Our utterances are filled with others' words, and depending on the speech genre, a particular utterance has varying degrees of otherness and varying degrees of our "own-ness." Bakhtin's (1986) contribution of the idea of utterance and the various possible types of speech genres that result from the social context is critical for understanding EOL communication. EOL communication is a speech genre of its own. It contains its own set of unique utterances.

RDT rejects the linear stage models in which relationships develop or progress. Instead, social life is viewed as a dialogue consisting of the interplay of the centripetal and centrifugal forces. The competing discourses are not worked out or overcome through a lasting synthesis as the relationship progresses. In the case of EOL communication, they often just cease to be.

In terms of EOL communication, the centripetal and centrifugal forces can be fleshed out with the military discourse used in references to illness. In American society the dominant voice in framing illness is the voice of a medical cure and fighting on. People "battle" cancer. People "lose" their "fight" with cancer. People "win" their "battle" with cancer and become "survivors." The marginalized voice would reflect the non-conventional behavior of refusing potential treatment options and focusing on a care treatment (Ragan et al., 2008; Babrow \& Mattson, 2004). Glasser and Strauss (1965) found that the patient's passivity or non-combative attitude tends to be judged by the American culture as an unacceptable style of dying. One would assume that a hospice would voice a passive approach, and a cancer care center would voice a more combative approach.

\subsubsection{Relational Dialectical Theory in End-of-Life Research}

Many research studies on EOL communication are not focused on dialogism, but it is implicit. The research literature on EOL communication is implicitly replete with dialogical tensions but does not mention dialogism on a theoretical level. For example, Weinstein (2009) 
observed, through the narratives of bereaved caregivers, a number of contradictions the caregivers experienced during and after the patients' deaths. He found tension between the once "healthy person" who is now an "ill person," as well as between "fighting the illness" and "a good death." Gentry, Kennedy, Paul, and Hill (1994) summarized those in bereavement as having a very limited existence due to the death of a spouse resulting in traumatic confusion. They found, for example, that the bereaved experienced the contradiction of the deceased person's possessions being both helpful and painful. Planalp and Trost (2008) found that the main issue hospice volunteers reported in regard to the PCGs was denial and ambivalence about the approaching death of the spouse. PCGs often avoided communication of "care for the patient" versus "cure of the patient" issues.

Nadeau (2001) approached her study on EOL communication with a mixture of social constructionism and family systems theory. She focused on the social constructionist approach to how meaning is jointly created within a family during EOL. Although her study did not identify EOL communication as competing, most of the examples she provided to illustrate the family construction of meaning during EOL were examples of competing discourses. Nadeau includes an interview of a widow of six years who still struggled with a family decision to remove her husband from a ventilator. The removal resulted in the death of her husband. The widow was divided on the decision. On the one hand she thought her son, a physician, convinced the family that her husband was brain dead. She, on the other hand, had doubts because she had read stories of people coming out of comas.

The family dialogue that might have helped her make sense of his death was inhibited by her fear that, if she expressed her doubts, she would be calling into question her son's professional judgment. She could not share these doubts with her other children. The matter of how her husband had died became a taboo subject in the family discussions. Sharing was restricted, and the entire process of family meaning making was inhibited (p. 98). 
The competing discourses were from, respectively, outside and within the family. Nadeau concluded that the issues that plagued the family before the loss are likely to be accentuated by the loss.

Chang and Sambamoorthi (2009) found that decision-making in palliative care situations had several competing discourse features. De Haes and Koedoot (2003) found that $40 \%$ of breast cancer patients undergoing chemotherapy would be willing to accept chemotherapy even if it had no clinical benefit at all, with zero gain in survival changes. Mixed feelings about the coming death of a loved one often resulted in last minute changes in treatment options. De Haes and Koedoot (2003) referred to the last-minute competing discourse within a family as a world of paradoxes. Conflicts in families occur when the patient does not have the capacity to make decisions or when there is a request for hastened death (Raye, 2009; Voicer, 2009). These discourses do not disappear after the death of the patient.

The literature also has a number of explicit studies that use Baxter's relational dialectical theory to understand contradiction in relationship to EOL and bereavement. Originally Baxter (1994) proposed six types of contradictions in relationships and divided them into two groups, internal and external dialectics. Internal referred to those contradictions that a couple would face between themselves. The dialectic was located within the relational dyad. The external dialectics were located at the interface of the dyad and society. The three internal contradictions between the dyad were connection-autonomy, predictability-novelty, and openness-closedness. The three external contradictions between the dyad and the society as a whole were inclusion-seclusion, conventionality-uniqueness, and revelation-concealment. The boundary between external and internal competing discourses can be fuzzy. Competing discourse might or might not be recognized by the subjects of the study. Baxter and Braithwaite (2007) called these discourses front stage (aware) and back stage (not aware).

Recently a number of scholars have looked at dialectical tensions that occur in relationships where one member of the equation is missing or incapacitated. Baxter, 
Braithwaite, Golish, and Olson (2002) studied "married widows" of husbands with dementia. They studied the contradiction between the husbands' physical presence and cognitive absence and how the widows communicatively navigate the contradiction. The researchers interviewed the wives of both living and dead spouses. The wives used a variety of communication practices to manage their experience of the absence-presence of their husbands. The researchers found four salient practices: (1) the emphasis on nonverbal communication, (2) increasing interpretative work, (3) the use of medical staff as information mediators, and (4) limiting contact with the spouses. RDT refers to these changes in communication practices as praxis, which is the result of the contradiction of the presence-absence of the dementia patient (Baxter and Montgomery 1998). The study also found a knot of other sub-contradictions which fall under the presence-absence category such as openness-closedness. An example of opennessclosedness is a willingness to speak with the husband but choosing not to because it might upset him. Presence-absence is reflected in the conflict of the past memories of the "true" husband as compared with the current situation.

Considine and Miller (2010) used dialectical analysis to investigate spiritual communication among hospice workers and the patient. In their ethnographic study they found three main techniques used by the hospice team for managing competing discourse: (1) they choose to focus on one side of the dialectic, (2) they vacillate between the two poles of the dialectic depending on the situation or topic by either leading a discussion or following the patient's and family's discussion, (3) they transcended a direct leading and following role by asking questions to help the patient and family themselves process the competing discourse.

Toller (2005), in regards to parents after the death of a child, observed the presenceabsence tension, a continuing bond with the dead child. She also observed an opennessclosedness tension when the parents were communicating with their social network about their child's death. Toller found that the parents were selective in their communication in regards to openness-closedness. The discourse of openness reflects the freedom of expression and 
closedness the right to privacy. Both are steeped in American individualism. The study found that the parents used discernment to decide when to communicate or not communicate with others about the death of their child. This was how they managed communicatively.

An important distinction needs to be made here between this study and Toller's in regards to the openness-closedness discourse. Openness-closedness is the most common contradiction found in dialectic EOL studies. But this sort of contradiction is not a competing discourse expressed interpersonally or by culture. Hooghe, Neimeyer, and Rober (2011) summarize Toller use of the openness-closedness discourse in regards to parents who lost a child as an "internal conflict, or ambivalence over emotional, which is better characterized by the competing goals of wanting to show how one is feeling yet fearing the consequences of such self-expression" (p. 911-912). If this behavior was reframed as discourse within an individual's social, cultural, and health care networks, it would be the dialogic tension between the parents hearing the voice for them to move on or to not move on in regards to talking about the loss of their child. The competing discourse of move on-not move on is causal of the opennessclosedness behavior. In my study I use the term move on-not move on rather than opennessclosedness because I want to emphasize the discourse or expressions that are heard by the individuals rather than how they respond to what was heard.

In summary, the literature indicates that competing discourses are found within the palliative care environment. This is reflected in the first research question of voiced conflicts that PCGs face. The second research question is proposed in order to examine how competing discourses are managed or negotiated by the PCG. For example, does the PCG ignore or deny contradictions? Is there oscillation between or mixing of competing discourses? RQ 2 focuses on how competing discourses are both revealed and concealed by the PCG's communication with others. 


\subsubsection{Research Questions}

RQ1: What competing EOL discourses are experienced by primary caregivers?

RQ2: How do primary caregivers communicatively manage competing EOL discourse? 


\section{CHAPTER 3}

\section{METHODOLOGY}

The intrinsic nature of hospice care is such that people encountering such services are often forcibly faced with unanswerable questions related to life, death, purpose, and meaning. Due to the sensitive nature of the research, it was deemed important to know what questions to ask and how to ask the questions. Methodologically, the development of the questions and the process in which those questions were asked could affect the outcome of the research. First,

the development of what questions to ask was guided by a qualitative content analysis of hospice materials conducted prior to the development of the interview guide. A list of reoccurring themes was developed from the hospice materials. Second, the interview guide was semi-structured. I acknowledge that the interviews could become part of the participants grieving process and so there was latitude given for the participants to tell their story. The interview guide was organized chronologically, starting with pre-hospice and ending with bereavement. Zhang and Siminoff (2003) found that conducting interviews following a timeline eased the participant's recall of facts and was flexible when a participant refused to respond to a question about an EOL issue. The participants were encouraged to tell their stories. Research has found that when people refer to distressing life experiences they often use narrative (Caplan, Haslet, \& Burleson, 2005).

\subsection{Text Analysis of Hospice Materials}

A qualitative textual analysis was done on the materials that were given to the PCGs by the hospice team. The materials were divided according to the three phases of hospice care: promotional materials, materials used by the hospice team during hospice care, and materials mailed to the PCGs during the bereavement period following the death of the patient. The materials were analyzed by qualitative textual analysis and divided into two general categories, competing discourses and non-competing discourses. The textual analysis was part of a triangulation process of comparing the two forms of evidence: the text analysis of the hospice 
materials and the participants' interviews. Lindlof and Taylor (2011) state that such an approach bolsters confidence in the objective reality of research findings. The textual analysis revealed the competing discourses communicated by the hospice to the PCGs.

The materials were divided chronologically into three groups. The first group consisted of hospice promotional materials used to introduce the hospice philosophy and the hospice itself. These included a 12 page printed brochure, Enhancing Quality of Life, and a CD, The Additional Healthcare Option. In addition to these, the materials found on the Hospice Plus website were also considered, which included a FAQ link. The second group of materials analyzed was those used by the hospice during the patient's time of hospice care. This included two pamphlets. One was for patient orientation to hospice care and the another was an educational pamphlet for the PCGs. The third group analyzed included six form letters which were mailed out by the bereavement coordinator over a thirteen month period and which included various sorts of bereavement education.

\subsection{Participants}

The sample for the study was PCGs of patients enrolled in Hospice Plus, one of the largest hospices in the Dallas-Fort Worth area. The participant list was gathered with the help of the hospice management team consisting of the bereavement coordinator, volunteer coordinator, and chaplain coordinator. The management guided the process of obtaining names, with the help of the chaplains. Additionally, the patients' files were made available to me. I was able to pick the PCGs who met the criteria specified below. Further, once the list of PCGs was established, the chaplains who worked with the PCG during the hospice stay and bereavement called the PCG and introduced the research project. All PCGs agreed to interviews. Once the initial contact was made, I called the PCGs and introduced myself and the study.

Seventeen interviews were conducted with twenty PCGs. Two interviews consisted of husband-wife teams and one a sister team. The team care was equally shared by both 
members. The criteria for the participants was: (1) PCG was the spouse, sibling, child, or significant other of the patient and cared for the patient on a daily basis, (2) PCG took part in the 13-month hospice bereavement program, (3) hospice care took place in the home, and (4) hospice was involved for at least three months.

\subsection{Procedures}

The interview guide (see appendix D) was developed to answer the two research questions. Due to the sensitive nature of the subject the questions were nondirective (Lindlof \& Taylor, 2011). The questions consisted of further floating prompts if I felt the caregiver was open to further discussion (McCracken, 1988). The interview guide was very flexible. Some of the interview questions for this study were inspired through the readings of Glaser and Strauss' Time for Dying (1968) and Awareness of Dying (1965). The first sentence in Awareness of Dying is "American perspectives on death seem strangely paradoxical" (p. 3), which reflects thematically the nature of my study. Considine and Miller (2010) found in their study that hospice staff communication to the patients and family was a dialogic of shifting between leading and following the conversations, of leading and being led. It is assumed in hospice work that the PCGs always know more about their situations than the staff does. This sort of communicational dynamic was practiced throughout the interview process.

The interview guide was chronological, starting with questions about communication the PCGs found challenging during the time period just before entering hospice, including the doctors' prognosis of terminal illness. Following this, questions dealt with establishment of a DNR, hospice admittance, hospice stay, the last week, the last day, the time of death, the weeks following death, and present issues. All questions were asked with an eye toward answering the RQs.

The interviews were audio-taped. Of the seventeen interviews conducted, sixteen took place in the participants' homes and one at a local café. Pseudonyms were used for all participants. Names of patients were substituted by relationship terms, for example, "my sister." 
The names of doctors, nurses, and hospitals were also avoided. The interviews ranged from 40 minutes to $1 \frac{1}{2}$ hours in length.

The transcription of each interview took place within 48 hours of the interview. The interviews were transcribed verbatim. Words and phrases that were apparently spoken in a nonstandard way were spelled in the text as they were heard: "yall," "yaknow." Short pauses were indicated by three dots "...", and long pauses were indicated in parenthesis (pause, 15 seconds). Interruptions during the interviews were noted, such as phone calls, visits, crying, and, once, a tornado warning. The transcribed interviews generated a total of 170 pages of single-spaced data.

\section{$\underline{\text { 3.4 Data Analysis }}$}

Generally, the data analysis followed Hsieh and Shannon's (2005) approach to qualitative content analysis of EOL issues. The following basic format was used for the development of results: (1) immersion in the data, (2) identification of statements that captured the idea of competing discourses, (3) the development of code labels for main ideas that emerged from the analysis, (4) sorting the various codes into categories, (5) providing definitions for each category, and (6) reporting the findings through exemplars for each category.

In order to gather data to help answer the first RQ 1, What competing EOL discourses are communicated to the primary caregivers, a triangulation strategy was used. First, a qualitative content analysis was conducted of the materials that the hospice used to communicate with the PCG. This helped with the formulation of the interview questions and with the coding of the interviews. These materials were collected with the help of the management team of Hospice Plus. The materials available from the hospice were (1) introductory literature on hospice care, (2) the hospice admission packet which included the philosophy of the hospice, (3) training materials for all staff and volunteers, and (4) materials used for the bereavement program. 
All materials and interviews were coded by XX coders and the author. Two coders were used for the materials and three for the interviews. Those who coded the materials read the literature review of this paper to obtain a feel for the issues. Further, they received one hospice publication pre-coded as an example. The coders were also asked to provide their working definition of the codes they used.

The volunteers were recruited through the Hospice Plus volunteer and bereavement coordinators. Their training included 12 hours on care issues for patients and bereavement issues for PCGs, and they were experienced volunteers. One was a student nurse and the other an individual who went through hospice as a family member of a former patient. A training document on basic coding principles was developed for the coders. The coders first read the interviews entirely through, taking notes. Then they reread the interviews, developing codes from the notes. A code was defined as a repeated phrase or concept. Finally, they provided a definition for all their codes and developed their own codebooks. One pre-coded interview and an example of one code across several interviews was provided to the volunteer coders. For the purpose of objectivity and simplicity, the coders coded for general themes found in EOL communication, not specifically for competing discourse. Some general themes were conversations about the signs of approaching death, final words of the family to the patient, cost of treatment, and pain management. A final codebook was constructed from a synthesis of all the competing discourses found by the coders (see appendix A and B). The major difference in coders was that the principle coder developed the codebook with the theoretical understanding of competing discourse and the other coders developed their codebook on a thematic basis.

Contrapuntal analysis, as suggested by Baxter (2011), was used to narrow down the code book to competing discourses in EOL communication. Once the analysis was done, the definitions of codes from the coders were compared and pieced together to make general themes. The general themes were then gathered under common categories and analyzed. Some general themes such as the signs of death of the patient, pain management, financial 
issues, and hospice staff problems were filtered out because they were not part of a competing discourse. Other themes were grouped together to form competing discourses.

\subsubsection{Contrapuntal Analysis}

Contrapuntal analysis is a specific kind of discourse analysis. Foucault (1972) informs us that discourses are socially constructed knowledge of some aspect of reality. A discourse might be thought as a system of meaning, a point of view, a worldview, or an ideology. In the literature, discourse is also referred to as statements which structure the way a thing is thought and how we behave based on that thinking. Discourse analysis searches for these sorts of patterns in language use. Discourse analysis searches for assumptions one is making about society, reality, or even, the interviewer. For example, the stories I heard during the interviews were socially constructed. There is a pattern of language use, an EOL discourse. Generally, the language pattern used is foreign to normal everyday usage because the topic, EOL, is normally avoided or not appropriate.

Although contrapuntal analysis is a term coined by Baxter (2011), Bakhtin (1984) practiced contrapuntal analysis in his study of Dostoevsky's works. Bakhtin analyzed linguistically Dostoevsky's text with an emphasis on looking for polyphonic or multi-vocal prose. In the case of Dostoevsky's novels, the rudiments of counterpoint were embodied in characters in the novel. As in the case of any sort of discourse analysis, be it rhetorical, conversational, or some other variation, there has to be a question that guides the analyst. For contrapuntal analysis the question is "what are the competing discourses in the transcriptions and how is meaning constructed through their interplay?" Contrapuntal analysis is discourse analysis with a Bakhtinian twist.

This study followed the methodological approach, developed by Martin and White (2005) and Baxter (2011), of contrapuntal analysis for identifying competing discourse. This approach was chosen in order to identify competing discourse and the interplay between the competing discourse. Four steps were developed based on Martin, White, and Baxter's works. 
First, there was the recognition of codes that had dialogic potential. The dialogic codes were from those parts of the interviews that captured the idea of competing issues that were conflictive, problematic, and challenging for the PCG. Bakhtin (1973) called these sorts of expressions doubled voiced discourse. Through her research, Baxter (2011) found three common discourse markers that are important for the identification of "discourses positioned in counterpoint relation to one another: negating, countering, and entertaining" (p. 166). Baxter's idea of identifying competing discourse was used also as a basis of codes that had dialogic potential. Baxter leans heavily on Martin and White (2005) to define these three markers. Negating is a kind of disclaiming where the interviewee will voice both discursive positions, such as "I didn't agree, but ..." Countering replaces the alternative discursive position. An example of this is "Even though I appreciated the medical advice, in the end I really just needed to talk to someone about my husband's death." Martin and White (2005) suggest a number of conjunctions and connectives as markers including although, however, but, yet, nonetheless, and so forth. The final marker is entertaining, in which the competing code was a statement that mentioned an alternative. Such codes would include an expression such as "on the one hand" paired with "on the other hand."

The majority of codes and competing discourses were developed from themes that emerged from the analysis of interviews and hospice materials. Some codes and competing discourses were informed by the RDT literature such as openness-closedness, rituals (Toller 2005), and frontstage-backstage (Baxter \& Braithwaite 2006). The use of Baxter's RDT and Bakhtin's dialogic perspective seemed to be a natural fit for understanding competing discourse at the EOL. Dialogic tensions in EOL communication are often acute, and those places where the tensions exist are usually well-known both in the literature and professionally.

Second, various codes with dialogic potential were sorted into general categories of competing discourse. This step consisted mostly of reorganizing codes from the various coders into larger patterns. The process ended when no new coding categories emerged. The 
competing discourses were expected to partially overlap each other in their semantic domains. Baxter (2011) and Bakhtin (1984) reference this as intertextuality, an interpenetration of discourses. For example, in this study the competing discourse of prolong it versus end it overlaps with the cure versus care discourse in the sense that the ending of the cure discourse morphs into a prolong it discourse. It was also helpful in the process of building categories of competing discourse to be sensitive to the fact that the interviews were part of a larger conversation, an utterance chain, which did not start or end with the interview.

The third step consisted of defining and naming the competing discourses. Previously, an illustration of competing discourse was conceptualized as the dialogic tension between two planets that shared a common gravitational field. The naming and defining step included the naming of the alternative positions and defining the nature or interplay of the tension within the competing discourse. The defining of the competing discourse describes the power relationship. A competing discourse is rarely democratic, one part is usually marginalized.

Finally, competing discourses were divided into two groups, contractive and expansive. A contractive competing discourse is more monologic, in which the counterpoint discourse is very weak in comparison to a dominant discourse. For example, the discourse that the family or patient is in control and the hospice is there only to support their decisions dominated in the interviews. From the PCG's perspective the discourse is "the customer is always right." The weak counterpoint discourse is, "but that does not mean it is always best." The nature of these discourses is contractive; meaning that one side of the discursive struggle tends to be weak and often is dismissed. An expansive competing discourse mentions both alternatives. In these cases, the conflict and the source of the conflict are often recognized by the speaker. An example would be a PCG stating that her son told her to stop grieving over the death of her husband and she told her son that she is going to continue to grieve. The source of one discourse is the son's expression to his mother to move on. The other discourse, the source of 
which is unidentified, voices she will not move on but continue to grieve. Expansive discourses bring both sides of the discursive struggle into bold relief.

\subsection{The Unit of Analysis}

Conceptually, for the purpose of this paper, the objects of analysis are statements that have been spoken, not thoughts. What Bakhtin (1984) calls the utterance chain takes place between individuals. However, it should be acknowledged that these utterance chains have repercussions with one's internal dialogues with the self. Intrapersonal struggles cannot be ignored because on a practical level they are caused by and inseparable from interpersonal or cultural discourses. But these internal struggles that result from a competing discourse is not the unit of analysis for this study. For example, in regards to EOL communication, when the PCG expresses that it was difficult to decide to "pull the plug." this difficulty comes about because of a mixture of competing utterances that say "fight on," and "it's time to let him go." I am interested in identifying the competing discourse and how they were communicatively managed by the PCG and not so much the internal difficulty that results from a discursive struggle. 


\section{CHAPTER 4}

\section{RESULTS}

These interviews are the stories of individuals who, often at great personal cost, decided to care for their dying loved ones in their homes. In addition, these individuals agreed to participate in this study by sharing their stories. Often with the unfolding of their stories their grief was revisited.

The textual analysis of the hospice materials and the discourse analysis of the interviews led to the finding of five major competing discourses in EOL communication. These are cure-care, prolong it-end it, open-hidden communication, move on-don't move on, and theodicy. The themes reflect the major changes in the PCG stories. The dominant pre-hospice competing discourse was cure-care. The competing discourse found during the time period of hospice services was prolong it-end it,' open-hidden communication, and theodicy. Posthospice, or the bereavement period, primarily focused on the move on-don't move on discourse. For an overall summary of the results see appendix A and B.

Most of the PCGs mentioned reading some of the literature provided by the hospice. When asked if they could specifically remember any of the materials they read, all said they could not with the exception of one item. The hospice provides a booklet on the signs of approaching death called Journey's End (Excel Publishing, 2002). The booklet lists physical signs that indicate the body is shutting down and death is only a week or two away. The booklet was very much appreciated by PCGs. Sara said "It was the signs you are looking for that you are really at the end-of-life." Jen said "But the check list is the one thing, now in retrospect, that checklist was so on point that it is scary." This was the one piece of literature that factored into the EOL conversations. When I asked Faith about the value of the bereavement materials from the hospice she responded with a dead-pan face "It wasn't interesting. I am sorry, when you 
lose your husband, you know it sucks; they don't have to tell me that, I knew that." Although it seems that most of the PCGs were not engaged with the hospice materials, the materials still generally reflect with some accuracy the discursive struggles of PCGs and their families face at the EOL.

The results section is organized into two general sections. See tables 1 and 2 for an overview. Each section is headed by a $R Q$. The two sections are then divided by the five competing discourses. Each competing discourse is given a definition and is followed by a general discussion in respect to the competing discourse. Following the general discussion of each competing discourse the results are presented, usually in sub-categories. The results of the text analysis are combined with results of the interviews in order to capture the sense of moving through time.

\subsection{What Competing EOL Discourses are Experienced by PCGs?}

The cure-care and prolong it-end it discourses are interrelated by the voicing of the pursuit to prolong the patient's life. The cure discourse voices the prolonging of life by curative treatments. The prolong it discourse expresses the concession to the terminal prognosis but voices a pursuit to prolong the life of the patient through care treatment. The cure and the prolong it discourses don't compete. Rather, once the patient receives a terminal prognosis the pursuit of a cure morphs into prolonging the life of the patient.

\subsubsection{Cure-Care}

The competing discourse of cure treatment versus palliative treatment is frequently the first EOL communication challenge for the patient, PCG, and family. The cure discourse is the voice that advocates trying to beat the patient's illness by medical means. The care discourse is the voice that advocates trying to make the patient as comfortable as possible without seeking treatments for the illness. The acceptance of hospice discontinues the curative treatment approach and ends the cure discourse. PCG and family conversations generally shift from cure

to care. This is not a smooth transition. Often discursive struggles within the family arise when 
the hospice asks the family to sign a DNR or the six month terminal prognosis is made known. The six month prognosis is a legal requirement for hospice qualification. Any attempts to pursue a curative treatment would cause the hospice benefit to be revoked. Occasionally, the cure-care discourse lingered around the family up to the time of death. A couple of the participants did revoke hospice and pursued a curative path for a while only to be readmitted into hospice at a later point in time. Sometimes there was conflict between the PCG and the patient about the choice of pursuing the palliative treatment. Several PCGs spoke of making a pact with the patient, promising that the patient would not be 'hooked up to machines' or other heroic medical efforts at the time of death in order to prolong life. The cure treatment discourse often was voiced by the medical community. The PCGs related stories of doctors being confused when the PCG would not pursue cure treatment. The medical community verbally framed cure treatments for terminal patients as life prolonging treatments. This reflects the dialogic tension between quality and quantity of life. When one is terminal, which does one choose? Practically speaking, the conversations consisted of making a choice between an extra few months of life which includes suffering or a shorter life without pain.

The following results of the cure-care competing discourse are divided into four subsections; the medical voice, the DNR, the promise pact, and the text analysis of the hospice materials. In the interviews the first three sub-sections were the issues being discussed when the cure-care competing discourse was expressed.

\subsubsection{The Advocacy of the Medical Community for a Cure}

The discourse of care over cure is well accepted within the hospice movement; actually, in part, defining it. The cure discourse is often advocated by the medical community. A number of PCGs expressed frustration with the medical establishment's curative approach before the patient entered hospice. Sara told a story about her mother visiting family in another city. Sara's mother got sick and was admitted into a local hospital. The following is how Sara characterized her conversations with the hospital. 
They wanted to do radiation and, you know, do different treatment, you know, on her that was just not in our medical plan. But it was very difficult to explain what it meant to do medical care that was for comfort versus healing. Even though they knew that it wasn't going to be healed. So I think that was the most frustrating, you know. It comes to mind immediately.

In the end, the family on "x-day" decided to simply walk their mother out of the hospital without being discharged. Main (2002) postulates that the power of the medical profession has resulted in the continued curative approach for those who are in the terminal phase of life. The story of Sara's mother is the contrast between a care discourse and cure discourse. In this case, Sara and her family had already shifted from the cure discourse to the care discourse.

Communication between the medical community and patient is unclear or unrealistic at the EOL. The medical community is unable to communicate a standalone palliative treatment without some active curative treatment (Ragan et al. 2008). This most likely reflects the dominance today of the curative discourse over the care discourse. It is difficult for the medical community to say "we cannot cure you." Kim was the PCG for her 86 year old mother who had kidney and heart problems. Just before she put her mother into hospice, the heart doctor gave Kim an ambiguous cure treatment option. "We can do it. She needs this, but she is very frail. It could put her into a coma, or it can kill her." Kim's family was ambivalent and left the choice up to her. The doctor's office finally called hospice to have a nurse talk to Kim.

She did not tell me I was right or wrong. She told me that I need to do what my heart tells me to do and what common sense says. So, you know, it did not help me make my decision, but it helped make me more comfortable in making a decision. It was hard to know that if I do this operation and if by some miracle she gets another 5 years out of it, that would be great. But if my mom dies from the operation it is going to be because I decided that? I can't live with that. 
It is telling that the doctor's office called the hospice in order to present the options so a decision could be made. Due to the increase of chronic illness and the concomitant increase in issues related to the prolonging life in the face of terminal illness, there is a mixing of the curecare discourses. As evidenced in the stories above, the doctors were uncomfortable talking to the patient about a care treatment. Lace's husband had Parkinson's for 21 years. The doctor who helped them over the years never informed them that the Parkinson's had reached its final stage and her husband was terminal until Lace herself brought the subject up.

Lace: I didn't even realize what he was trying to tell me.

Interviewer: The doctor?

Lace: Yes because I was telling him, you know, they gave him of all the things he goes through and the stages he was in and he was in the last stage and I didn't realize it. I found out about it on the computer. And the doctor actually told me after I have given him all the symptoms and he looked at me and said "If you need to make another appointment just call." But I didn't realize that he was trying to tell me that, that was it.

The majority of the PCGs did not mention in any details about how the doctor broke the bad news. A number of patients were suffering from a chronic illness before the terminal prognosis, but for the PCGs the time frame was fuzzy.

In summary, the cure-care competing discourse was expressed when the PCG encountered the medical community. This time period was pre-hospice and the curative treatment was still an option in the minds of the PCGs. The prognosis at this point was often unclear. It was not until the doctor gave the six month terminal prognosis and hospice was introduced that the curative treatment gave way to the care approach. Many of the PCGs expressed the cure-care discourse at the time of the signing the DNR. 


\subsubsection{Giving up on Curative Treatments}

The signing of the DNR often served as a final decision of the family to pursue the care treatment over the cure treatment. Patients with a DNR will not be resuscitated if heart or respiratory failure occurs. Some patients had DNRs already in place as part of a living will. Usually the rationale was a choice of quality over quantity of life. Jen said, "Neither one of us just wanted to be there, you know, on a bunch of machines." Two sisters who were taking care of their mother said, "She would not have wanted...she didn't say to 'I want to die' she did not want to live like she was having to live." But for those patients without a DNR in place it was more of a dramatic milestone. Hospice policy is to have all patients with a DNR. Although not having a DNR is not a requirement for admission, it usually is strongly advised due to possible complications that might arise. One PCG spoke of a time she went to church leaving her daughters to care for their father. The patient went into convulsions and the daughters panicked and called 911 . When the emergency unit arrived, they saw the DNR posted on the wall and did not take the patient to the hospital. The DNR affords the family a sense of control in regards to their desire to seek only the care option. The very need for the existence of a document to prevent a curative pathway is a metaphor for the struggle that our culture has with the competing discourse of cure versus care. Faith expressed the meaning of the DNR in relationship to her husband who was dying of cystic fibrosis.

Every time I went to the doctor I was looking for some good news. And I think you could feel it getting worse. And so he was much more realistic about it. And...ah...it was...when he got...I think I finally...the DNR I accepted before that because I thought that "OK if it gets to that point." I wasn't accepting that it was hopeless at that point, but if it gets to that point, then that is the obvious thing to do. You just don't keep him alive drugged out of his mind. I mean that is just stupid. 
Sometimes the signing of the DNR was a matter of course, other times it had symbolic value of resolving, at least publicly, the competing discourse. A number of PCGs mentioned that the family had put off the signing of the DNR until the patient had a medical crisis. The idea of the patient being taken to hospital without the ability to deny treatment caused a panic. Kala related a story about her mother's sudden medical crisis and the panic to sign the DNR.

And I have always been the strong one, and I ended up falling apart, because I had to go out and find someone who would witness my signature in the neighborhood. I don't think we intended to put it off; we just did not do it. And it is something you really need to think about. I know that mother never would have wanted to be hooked up to a...you know, she would never have wanted that. But I think when you sign that, you know, you are thinking just do one thing, make them comfortable, and I don't know why we have not signed that, we should have signed that when she went into hospice but we didn't. And don't ask me why because I really don't know. But anyway, it was a traumatic morning when we realized she had that signed.

The last sentence signals that this incident somewhat shocked the family into facing something that was previously too uncomfortable to talk about. The signing of the DNR does not mean the quality versus quantity of life struggle is resolved. Sometimes it brought the struggle into bold relief. Often the PCG sought help from the hospice to find the justification for signing the DNR. Rose related the following conversation with the hospice nurse.

I'm thinking that the Do No Resuscitate...well of course I am thinking I want her to be resuscitated. But the nurse sat me down and told me. She said "I am not trying to change your"...you know, she was honest and open and she said "here this is what could happen in situations like your mother's where the bones are so weak that they could shatter a breast bone doing it (CPR) and make things even worse." And I didn't want her to hurt anymore. She hurt for 10 
years. For 10 long years she hurt. So that was the hardest, those last...when it comes down to it situations.

The cure-care competing discourse was expressed pre-hospice in conjunction with the medical community and also at the time of the signing of the DNR. The discussion of a promise pact between the patient and PCG was the third circumstance in which the cure-care competing discourse was expressed during the interviews.

\subsubsection{The Promise Pact}

The promise pact is an agreement between the patient and the PCG not to hospitalize. This usually reflects the awareness of the patient that the PCG might not follow the DNR and choose to seek a treatment option at a future medical crisis point. Over a third of the PCGs mentioned some form of promise pact. Near the end of Faith's husband's life this pact came into play. The "that" in the following quote is putting her husband in the hospital. "You could just see the terror and agony and so I was considering that at the point that he died, and I thank God that I never had to do that because I promised him that I wouldn't do that." Another common expression which was also part of a promise pact was the rejection by the patient of being "hooked up to a machine." It was one of the motivating factors for hospice care in the home.

The first three sub-sections, medical voice, DNR, and promise pact, were the circumstances in which the cure-care competing discourse was expressed. The final section is the expression of the cure-care competing discourse within the hospice materials.

\subsubsection{Hospice Materials Present the Care-Cure Conflict}

The text analysis of hospice materials revealed a density of competing discourses in the promotional and bereavement materials and almost none in material dealing with the hospice stay itself. The promotional materials explicitly stated competing reasons for using or not using hospice. The cure-care' tension presented in the promotional materials reflects the hospice philosophy of care for the patient without the continuing attempts to seek a cure. This discourse stands in opposition to the voice that the patient should fight to the end. Another way to frame 
this counterpoint is: do we seek a longer life or a better life? The hospice promotional brochure Enhancing Quality of Life mentions six myths/facts about hospice. The myth/fact contrasts are competing discourses. Several refer to the cure-care discourse. For example:

Myth: A referral to hospice means "nothing more can be done."

Fact: hospice care means there is much that can and should be done for the patient and their (sic) families. Relief from pain and other discomforts are at the center of good hospice care. There are numerous interventions that hospice can provide, including spiritual and emotional support (Hospice Plus, 2012a).

The materials are clear as to the competing discourses that people face when they enter hospice. The following FAQ from Hospice Plus website (2012b) clearly sets the discourse in bold relief, care versus aggressive effort to beat the disease. The first question on the FAQ page of the Hospice Plus website:

Q: When should a decision about entering a hospice program be made?

A: At any time during a life-limiting illness, it's appropriate to discuss all of a patient's care options, including hospice. By law the decision belongs to the patient. Understandably, most people are uncomfortable with the idea of stopping aggressive efforts to "beat" the disease. Hospice staff members are highly sensitive to these concerns and always available to discuss them with the patient and family (Hospice Plus, 2012b).

The first example contrasts the cure-care competing discourse as being between one voice that says hospice means dying, and the other voice that says, no, it is about living and defines living as having choice. The choice is electing to have quality time with family and friends. There are two conflicting cultural discourses or ideologies being expressed. The first is that death is a part of life and should be embraced with grace and dignity. There is the assumption that accepting death is not a negative value or even immoral. The acceptance of death means care and the celebration of what life is left. 
Additionally, the hospice mentions another value, the value of choice, to die on your own terms with your family and friends. For Americans this feels right, individualism is highly valued. The second example provides a clear voice for the other side of the conflict. Death is to be repudiated; it is an enemy of life to be fought or beaten. This competing discourse is very powerful and the hospice admits "most people are uncomfortable" with accepting death.

For the purposes of this study, death is not viewed as a process, but as an event. The dying process is viewed as a process of physical disintegration. For Medicare purposes the hospice team documents the physical and mental decline of the patient. If the patient stops declining, the patient is discharged from hospice. For all intents and purposes then, all PCGs interviewed were aware of the patients' progressive decline, but the rate of decline is never predictable. This results in the prolong it-end it competing discourse.

\subsubsection{Prolong it-End it}

When the patient has been given a terminal prognosis and the PCG accepts it, the cure discourse ends and the prolong it-end it discourse begins. It is the point when PCG and patient acknowledge that a curative treatment path will not result in a better outcome. Prolong it discourse does not mean cure, but rather is the expression by the PCG of a strategy to delay the patient's death.

The prolong it-end it discourse illustrates that EOL communication is messy. The patient usually goes through a number of medical crises during the time in hospice. Even though the family knows there is no cure, there is a cultural discourse that voices that family members should not simply give up on the terminal patient. Then, on the other hand, when the patient's health is on the downward trend, the discourse is put into question; there is uncertainty, especially if the patient is in pain.

The suffering and pain of the patient often results in the PCG and family starting to embrace the end it discourse. Chronic illness is like a rollercoaster in which the patient and family rides. When the rollercoaster was on the upswing the prolong it discourse dominates, and 
when it was on the downswing the end it discourse dominates. The PCG swings back and forth between the two with one never quite totally dominating the other. Prolong it signifies the cultural discourse that one should be loyal to the patient and do whatever it takes to prolong life. End it refers to the discourse that arises when the suffering of the patient trumps life because prolonging life is really prolonging the suffering.

The patient's decline becomes a rhythm of life for the PCG. Communicatively, some of the families swing within the competing discourse of prolong it-end it' but with an ever downward spiral toward the end it' discourse. The back and forth within the competing discourse is spiraling inversion according to RDT (Baxter, 2011; Baxter Montgomery, 1996; Considine, \& Miller, 2010). The prolong it-end it is a downward spiraling inversion that eventually ends with the death of the patient. All through this process conversations are happening between everyone involved.

Rose tells of the final decline of her mother before her death. She starts by mentioning the putting off of the signing of a DNR.

I felt that she just was not that close that it was necessary. And that's crazy, I know. But I tell you what, I...I just walked in there...that morning and found her there, I just couldn't believe it. I went "no". You know it was several days before that the nurse had told us 'there are the physical things going on with your mom right now and if these continue...' She...you know, we were both like, you know like (bang noise made). The information was right here but to see her there....and for weeks...after that it was like...it was really tough. It was like you are almost in denial, like did this happen, now wait, this wasn't supposed to happen. And you know when you are...I don't think you are ever really ready for it, It's crazy (pause). She always bounced back, always. 
When these two discourses openly compete within a family, they cause conflict. Jen and her husband visited the oncologist who, from Jen's perspective, gave them good news, a new drug that might prolong her husband's life.

And there was this drug that came on the market; it could have brought him like 4-6 months. But it was like 3000 dollars a shot. And my husband looked at me and he said 'nah, we are not going to do that.' But I just literally...I didn't let him see me, but in my mind, Ok he is about to give up, he is about to give up. After we got over that initial shock, OK, this is where we are, he is not doing that, then you put it out of your mind. You said, OK we are not going to think about that. It is just too painful, it is too painful.

To Jen's chagrin and shock her husband chose end it. The end it discourse is also very powerful when it is spoken by the PCG. Usually it is voiced through a prayer. The death prayer will be considered in the second part of the results. In our culture, the only one who has the right to voice the end it discourse is the patient or a close family member. Brenda's husband was ill for 5-6 years. She said he was basically her shadow because he did not have the ability to go anywhere on his own. When encountered with the end it discourse she said:

I really got frustrated with Baylor. They just pinned me down and said "You got to know that he is dying. I said that "I know that but you don't have to cram it down my throat." I mean I was so angry and I hadn't cried too much until then but I began to cry. I made them go into the other room; I would not let them be in the room with him.

The prolong it-end it discourse tends to shift back and forth in dominance depending on the circumstances. Rose, a PCG for her mother, related her thoughts on this issue with her best friend.

I mean my best friend tells me, she is 69 and she has a lot of physical problems and, you know, she told me, she said "You know Rose, sometimes I wish that 
Jesus...sometime I just want to go home and be with Jesus." And, you know, my first thought was, you know, don't you dare say that. You fight with everything you have. But then there was the real part of me inside and said "Yea, Betty I understand, because sometimes I feel that way too."

In summary, the prolong it-end it discourse inverts repeatedly as the patient and family experience the dying trajectory of a chronic illness. In addition, sometimes after the bad news of a terminal prognosis, various family members could be on opposite ends of the spectrum.

\subsubsection{Does Hospice Mean Prolong it or End it?}

Does hospice mean prolong it or end it? In reality, it means both. This was a continuing discursive struggle for many of the PCGs. Many of the PCGs acknowledged that they did not know that hospice care was more than short term. In one case a PCG expressed during the interview that she thought that there were two types of hospices, the short term consisting of 1-2 weeks and the long term. Once the patient entered hospice the PCG had to continuously explain to friends and family the difference. Kala relates that she had the conversation with a number of people.

Looking back, (pause) I think we had people say "are you expecting her to die?" And it was "No we are not expecting her to die, we just know that she is not doing as well as she was." And the extra care that hospice provides, hopefully we could have some quality time with her. And ah...we realized that she was not going to have physical therapy anymore. I think the first thought when they have hospice that they are going to die right then. But we really did not look at it that way. You know it is going to happen, saying it sometimes is difficult.

Kala equated the hospice idea of "extra care" to prolong it. "We did not expect her to die as quickly as she did. I felt that she was going, then with them coming in and the extra care, I thought that really ah...that she might live longer." 
Some of the PCGs did mention a concern about the use of morphine and the effect that morphine had on shorting the life of the patient. Pat believed that this was a common belief about hospice in the past. "...the old belief that they just came in and watched them die, and hurried it up (laugh). Have you heard that before now?" Pat was right, but it is not just an old belief but a very current debate being carried out within the medical profession. It is a concern that patients and their families have about hospice.

\subsubsection{The Advocacy of the Hospice Materials for Prolong it}

The hospice was very careful, in their materials, to frame their services as prolonging life. PCGs often needed to educate family and friends that hospice does not necessarily mean death is imminent.

Interviewer: Sometimes when people hear hospice they think...

Ginger: Death. I had people ask me "why did you call hospice?" It was for their care and it would make it easier on the family. It wasn't because that tomorrow they were going to die. Actually it was a weight off the shoulders, of my mom and myself.

Interviewer: You had to explain that to people often?

Ginger: Yea, because they think automatically (snap fingers) death and that is not the case.

The hospice materials framed the prolong it discourse as the journey. Most of the artwork on the brochures and on the website picture people walking together along a path, or just a picture of an empty path. The journey is framed by the materials with such words as "your journey, "choice," "control," and the use of the word "treatment." The competing discourse of prolong it-end it is the interplay of the competing forces of being passive or active. The promotional materials provide a good example of this competing discourse. The hospice promotional materials refer to the end it discourse as a myth. The myth states that a referral to hospice means "nothing more can be done." Sara mentioned this in her conversations with the 
rest of the family. "The one thing that...that...everybody wanted to make sure that she wasn't going to be like asleep all the time and not be communicative because that was kind of the picture you had." The myth says that the use of hospice means "the fight for survival" is all over, death is only a matter of time and the family is passively awaiting death. The competing discourse is:

Hospice care means there is much that can and should be done for the patient and their (sic) families. Relief from pain and other discomforts are at the center of good hospice care. There are numerous interventions that hospice can provide, including spiritual and emotional support (Hospice Plus, 2012a).

The hospice utilizes the prolong it discourse as a non-passive acceptance of death including proactive choices that involve treatments and interventions. "No one can tell you the moment someone will pass. What is known is that everyone will take this journey."

The meaning of hospice had to be explained by the PCGs to friends and family members. The average person equates hospice with lingering death. Hospice recognizes this. The Hospice Plus promotional brochure Enhancing Quality of Life frames the competing discourse as a common myth about hospice.

Myth: Hospice is about dying.

Fact: Hospice is about living. It's about the choice for you or your loved one to live with comfort and dignity while enjoying the love and support of family and friends around you.

The next competing discourse is closely related to the prolong it-end it struggle. PCGs that care for the patient in the home are subject to the distinctive open-hidden discursive struggle.

\subsubsection{Open-Hidden}

The open-hidden discourse expressed in the interviews revolved around the PCG revealing or concealing details of the dying process to family and friends. The expressions of 
the messiness of the dying process were competing with the façade that was put into place to maintain the dignity of the dying person and/or the competency of the PCG. The open-hidden competing discourse is unique but similar to the openness-closedness competing discourse found in several RDT studies. What they share is the discursive struggle of expression or nonexpression. What they differ in is what they express. The openness-closedness competing discourse takes place as a thought process, while the open-hidden competing discourse takes place as a behavior. In other words, one is a question of expressing what you are thinking; the other is the question of expressing what you are doing. Under normal circumstances, the interactions between couples often contain competing discourses about how their relationship should be publically communicated.

This study focused on open-hidden competing discourse, meaning the patient and PCG limited communication with those on the outside about what went on inside the home. The PCG and patient had to balance communicatively the discourse of being open and forthright about the dying process with the competing discourse of privacy, control, and not wanting to burden family members with details.

The PCGs regulated how much and what kind of information was given out to the rest of the family and friends about the dying process of the patient. The motive of the PCG for keeping or dispensing information varied. Sometimes it was to protect the family memory of the patient, other times the patient wanted to put up a façade. In other cases, the PCG communicated the dying process openly to friends and family. Open communication was either a recruitment strategy for help or to prove to the rest of the family that the situation was dire.

During a surprise birthday party for her husband, Beth told the family that her husband was going to die soon. The severity of the news surprised the family. Up to this point in time the dying process was behind closed doors.

While he was entertaining I would take a couple of them aside at a time and I told them that weekend that hospice had told me, that the nurses had told me 
and I could see that he didn't have very much longer. They were very shocked. I think they thought that I was being over dramatic. In fact his younger son from his previous marriage got upset and emotional about it and kind of walked away. But I did not think it was fair for them not to know how close we probably were cause I was the one who was putting him to bed at night and getting him up in the morning and seeing what a struggle he was having just getting dressed and getting to the kitchen to take his medications and things like that. Beth went on to explain why this came as a surprise to so many of the members of the family.

Even when they spent the night here, we went behind closed doors to get him, you know, ready for bed. He would sit here and entertain everybody and laugh and he would have such a good time. I did tell them that they didn't see everything. But unless you are handling it, you don't understand.

When asked "what were the most challenging issues to talk about during this whole period of time with people?" Lace responded "Ah, well, ah, a lot of them did not realize what all I went through...just the lifting and the feeding. He also had problems going to the bathroom. Sometimes he would not want me to change him." Two sisters took care of their mother on rotating 12 hours shifts for over a year. When asked if they communicated the dying process with others, one of the sisters said "You know, it was just between me, sister, and dad, and we just handled things." Brenda's husband was suffering from heart disease but there were several other chronic issues, including seizures. Brenda did not talk to anyone about the dying process her husband was going through.

I didn't like to ask people to stay because I never knew exactly when he was going to have a seizure. He had seizure once when I went to church and my daughters were here. And I got a call about a minute before I got home and they were hysterical and they called 911 Well when I got home I said "It is OK 
and he did understand that you didn't know what was happening, he couldn't tell you what was going to happen." Those are just life experiences that you have to go through.

Brenda's comment that "he did understand that you didn't know what was happening" points out that her daughters did not know about the seizures. There were several other issues that were not talked about such as the signs of approaching death, verbal abuse from the dying husband or parent, and the patient's negative personality changes. Often, except for the hospice team, the outside world was not told. Sometimes even the hospice team was kept in the dark. During the grieving process almost all PCGs talked about the good memories of the patients but they all avoided mention of the negative aspects of the dying process. Two wives made distinctions in what they shared about their husbands after death. Lace said, "I do talk about him. But I talk about the funny memories. I don't talk about his suffering. That's in the past. It is easy to let go." Faith expressed reserve in sharing about the death of her husband. "I don't talk about him dying. Sometimes I just talk about him because he is so much in my life. But I am not a real chatty person. I mean I don't do that in general."

The open-hidden discourse was found to be absent from the hospice materials although the pre-hospice promotional materials had an emphasis on privacy, the rights of the patient, and the family being in control. Hospice Plus (2012a) brochure mentions that one of the myths about hospice is that PCG is no longer in control. The myth is countered with the fact "Hospice does not limit your healthcare choices. You and your family are involved in all aspects of decision making and development of your treatment." Hospice reinforces the idea that the patient and PCG are in control of the dying process without detaching it completely from hospice. Any lack of decision-making power in this regard is considered a violation of the dying person's basic human rights. Hospice voices the dignity of the dying process in terms of independence, autonomy, and control. Control over informing outsiders as to the nature of the dying process discursively puts in motion the open-hidden competing discourse. 
The reserve of the PCGs to share the dying process with others after the death of their husbands brings us to the next section which focuses on communication of grief and the tension of move on-don't move on discourse.

\subsubsection{Move on-Don't Move on}

Move on-don't move on is the discourse tension that PCGs experienced during bereavement. It is the tension that resulted from hearing people tell them they should be moving on from their grief or not moving on. Traditionally, both psychoanalysis and popular belief held that expressions of grief were an essential component of successful mourning. The culture assumes that mourning is normal and a lack of mourning is abnormal after the death of a loved one. Thus, the bereaved must endure the additional stress of having to express sadness and grief. Additionally, the culture also assumes that grief has a time limit, which is another unproven assumption. The move-on discourse involves conversations by family members and friends encouraging or demanding that the PCGs stop talking about their grief and move on with their lives. Sometimes this included anticipatory grief.

Sara grieved after her mother received a terminal six month prognosis. "I didn't eat much for a long time. OK, this is it, there isn't anything now that is going to give her a longer and quality life." But Sara's daughter said "You know, you need to stop, you need to stop doing this." But Sara replied “No, you don't understand, you must just go through it.” One and a half years after the death of Pearl's husband, her family did not want to talk about the death. Pearl was confronted by her son who demanded that she stop grieving.

They don't want to talk about it. They say "Mama, it's the past, leave it in the past. Why do you cry, it's almost two years mama. Let it be. We are Catholics," and they say that when we cry I don't let him go. But I don't believe in that. I don't believe in that.

Jen felt the pressure from her parents to "suck it up." Jen tried to talk to her father about her grief. 
I tried talking to him right after my husband died, and I remember sitting there one evening and I said "dad, I just miss him so much." And he never said a word, he never said a word. And I said then to myself, I will never bring it up to him again...So now I just let it go, I don't bring him up. And I thought maybe they don't want to hear about my grief then I thought maybe people thought I should be doing better. I should be kind of moving on with my life. I'm not nearly there yet.

The move on discourse took place not only because family or friends were uncomfortable with the continued mourning but sometimes it was the result of friendly advice. In Rose's case her best friend told her after the funeral of her mother that the grief will lessen over time. The tears will stop.

Well the things that everybody says that it just takes time. You gonna, you gonna, you never will forget this, it will always be...but over time you are not going to feel like you do now and you are not going to cry. And at the time I was like...I wasn't saying it but in my head "how can you feel this way?"

This was a very hard discursive struggle for Rose. It was common for this sort of "it will get better" discourse to be spoken to the PCGs. Part of them knew it was true, another part could not let it be true. "And I wrote it off to her being cold. But it wasn't. It was just that I couldn't see that because she been through it. I was, I was at this point while she already been over here. It's tough."

The don't move on discourse is usually the result of a long chronic illness where the PCG has had plenty of time for anticipatory grief. Lace's husband had Parkinson's for 21 years before he died. To the public she did not grieve. "The only time I really cried was his birthday. No reason. I kind of felt that people thought I should cry, but I didn't." Ironically, we as a culture expect a show of grief, but not too much. This involves a number of unspoken rules. If you break the rules there comes into play a grief-relief conflict. This probably explains why some 
cultures have a ritualized mourning period. A lack of grief sometimes resulted in the PCG having guilt feelings. Holly took care of her mother for two years. It was a slow, emotional, hard decline. She refused to get into any details but summarized by saying her mother "did not put her best foot forward." The rest of the family was marginally involved and communicated to her their confusion over her not grieving. Holly was confused also. Holly struggled with her lack of grief.

My sisters cried more than I did. I said "I did love her." And I tried to do the best I could, but, you know, I don’t know, I just saw her struggling and everything and just tired and so I just haven't been super sad even though I do feel guilty that I haven't grieved enough, cried enough, you equate that with no care but that really is not true.

A sub-category of the move on-don't move on competing discourse is grief-relief.

\subsubsection{Grief-Relief}

How to grieve, how much to grieve, and how long to grieve, can be communicatively hard to manage. The grief-relief conflict reflects the discourse that death of a loved one should result in grief and the discourse of relief that the burden of care has been lifted. Publically, the expression of relief is almost taboo. Grief is real for the PCGs, but they were often uncertain of how to talk about their relief. Usually the PCG or the family developed a strategy that straddled the conflict with such words as the patient is "better off now." The following PCG was married to her husband for 52 years. For the last 21 years they managed together his Parkinson disease. The last couple of years were extremely hard. She was eventually convinced by her family and primary physician to seek care and support from hospice. At the end of the interview I asked her about the grieving process.

Lace: Now I haven't cried (long pause).

Interviewer: Why?

Lace: I don't know. 
Interviewer: You cried here.

Lace: I feel guilty because of what happened. But I feel a relief. I could do things now that I couldn't do. I don't feel guilty doing them.

Interviewer: It is hard to talk to people about that.

Lace: Yea. I can talk to my best friend about her husband but I don't talk to her about my husband...I kind of felt that people thought I should cry, but I didn't.

\subsubsection{Hospice Bereavement Materials Mediation of Move on-Don't Move on}

The move on-don't move on competing discourse was found in the hospice bereavement letters. For example, "Each person's grief is individual and each person deals with it differently. Grief may last longer than society in general recognizes. It cannot be hurried." RDT would label the societal reference as centripetal, the dominant discourse. This is the move on discourse. The competing discourse is "it cannot be hurried." This is the don't move on discourse.

The bereavement materials, letters sent out monthly for 13 months, present the strategy for handling grief progressively. The early letters emphasize don't move on, "take your time," "deal with the grief" and the later letters emphasize the need for personal growth and moving on. Sometimes the counsel is that the PCG should be free to talk about the death, and other times there is an emphasis on the need to move on. It is a mixed message, take time to grieve, but not too much time. Typical expressions that convey the idea of to move on are "resolution," or "readjustment to reality." Other times there is the theme of not to move on. "Occasionally you may wonder whether or not your feelings are normal or if you are grieving in the right way. It is important to remember that there is no right way, there is just your way." Also, "Express your grief openly. When you share your grief outside yourself, healing occurs." The openness in communication theme is the emphasis of the six-month letter and educational packet. There is a brochure Silence Is Not an Answer in the Time of Grief. The hospice is stressing the move on- 
don't move on discourse. An interesting narrative is presented in the brochure about a young lady whose brother died.

To a few, I said, "Perhaps you didn't know my brother died." The response as muffled, "Oh yes... I'm sorry." I stopped volunteering this information: it was awful to realize that these people, through all the banality, knew about Albert, and said nothing. Some people undoubtedly kept silent in the hopes that I would approach them to talk and they could then be duly supportive. This was a gross error in judgment. I needed to have friends voluntarily open their hearts in sympathy, as I was feeling vulnerable and afraid that those I turned to might turn me away. To me, the silence said, “Leave me alone, I don’t care.”

This brochure presents the conflict of openness-closedness in conversations. It is teaching the PCG that it is normal to have the conflict move on-don't move on, when talking to family and friends.

Another aspect of the move on-don't move on competing discourse is the theme of psychological struggle. This normally included various types of stages of grief and the need to work through them in order to achieve resolution. In order for the PCG to move on, various stages of grief needed to be worked on. On the other hand, there is the theme of personal growth that one should move on through making new friends, activities, self-acceptance, and making plans. Understandably, the move on theme is very strong in the 12-month letter.

The move on-don't move on tension is not an either/or proposition. Most expressions or non-expressions of grief can be heard as the articulation of two competing discourses that are salient in our American society, the right to privacy and the right to the freedom of expression.

\subsubsection{Theodicy}

Theodicy is the enterprise of trying to come to grips with the eternal problem of the goodness and power of God and the existence of evil and suffering. Expressions of this discursive struggle is commonly found in classic texts such as the 4,000 year old Egyptian $A$ 
Dispute Over Suicide (Wilson, 1969) and the book of Job found in the Bible. In both cases there are competing discourses: in the Egyptian text, a struggle about the worth of life in the face of death, and in the Biblical text, a continuing argument between Job and his friends about the goodness and justice of God in light of the recent tragic death of Job's sons and daughters.

Within the Judeo-Christian tradition, theodicy was an apologetic response to the evidential problem of evil and suffering in light of the existence of an omnipotent and omnibenevolent God. As John Milton's said in Paradise Lost, theodicy is the attempt to justify the ways of God to men. Theodicy is by definition both a competing discourse and how one theologically handles the competing discourse. Theodicy touches upon both research questions.

It was not unexpected to hear spiritual and religious speech codes peppered throughout the interviews. Interestingly, in light of the importance of religion or spirituality in the American experience, there are few studies on how people make meaning of death, especially the elderly population. Wortmann and Park (2008) write "Given the pervasiveness and centrality of religiousness and death in the human experience, surprisingly few studies have addressed the role of religion/spirituality in adjusting to the death of a loved one" (pp. 721-722).

Theodicy was defined in the context of two competing religious discourses found in the interviews. The discourses were: God is good, all powerful and loves everyone. God has a plan and is just. The competing discourse is God does not care and is not just. Why does God permit people to suffer?' Maybe God is not able to intervene; maybe God is not all powerful. Maybe God does not exist. Respectively, these discourses have been labeled the God voice and the why voice.

Most of the interviews included God as part of the conversation without prompts by the interviewer. The suffering of the patient was the cause of much ambiguity. Most PCGs accepted the patients suffering as either part of God's plan or believed suffering was a human problem having nothing to do with God. A smaller number were angry at God regarding how the patient 
had to suffer. Some PCGs expressed a struggle with their faith; others expressed growing closer to God. There was no interview question that directly addressed this issue but I was highly sensitized to the subject due to the volume of material provided by the hospice on the topic. The bereavement materials provided personal narratives of this struggle. As an example, the following is from the hospice bereavement program that included a letter from the chaplain and a piece of educational material dealing with theodicy.

I accepted long ago that she is gone; she's with God. I take great comfort in the fact that God has given her the greatest gifts he possess for any of us. But I still have moments where I get a little ticked with Him for giving them to her so early in her earthly life.

The hospice materials stressed that anger is the emotion normally connected with this struggle. One of the guides provided by the hospice for dealing with grief states "Where is God? Why did God do this or let this happen?" The hospice addressed the issue without resolution.

Two competing discourses found in the interviews was the why voice and the God voice. The why voice is the voice of logic or reason and the God voice is the voice of faith. These two voices have historically and culturally been at odds with each other, in one form or another, at least since the enlightenment. This study found that when PCGs spoke the why voice they acknowledged prior and contrary voices that sought to engage them. On the other hand, it was found that when the PCGs spoke the God voice there was a lesser degree of acknowledging the presence of a contrary voice.

The why voice was dialogically expansive because it explicitly referenced alternative viewpoints. The God voice was dialogically contractive because it tended to close down the space for dialogic alternatives, although there were notable exceptions.

\subsubsection{The Why Voice}

Every Sunday I go to mass I am sitting there; I can never go to mass without thinking about the day my husband died. Oh yea, God and I have this 
conversation all the time. You got all these bad people out here and you took such an important part of our life, you know why? Why? I don't believe all this stuff "Oh it was his time." It wasn't his time, my husband died at 64 years old. It wasn't his time. Not to be mean, but it was my dad's time before my husband. So I didn’t want to hear all those, you know, clichés. "Oh he lived a good life." He still had a life to live, a good life. Why you tell somebody that? That to me is just an insult.

Jen voices the competing discourse. The conversation started with her husband dying on a Sunday, and each Sunday she goes to mass and gets angry at God. In the above quote she justifies anger toward God by the greater evil in the world. She is upset with the God voice discourse. She does not understand how her husband's death can be part of Gods plan. This is a dialogically expansive text. She voices the why and opposing discourse. By doing so, she brings the competing discourse into bold relief. Culturally speaking, the God voice is the centripetal force for expressing this dialogic tension. But Jen seems to want no part of it. Jen believed that her husband viewed his cancer as a punishment from God. She expresses the God voice discourse and flips it. She voices her husband's struggle with God and cancer with her husband's words "I eaten the right things, I exercised and here I am still being slapped with this here sentence. You know, God's punishing me. I had done something."

Kim was upset with God. She perceived that her mother's death was a divine injustice. But at the same time she was open to competing voices of her mother's belief and a chaplain from the hospice. This shows again the expansive nature of the why voice.

You know my mom was a God-fearing, loved God all her life. And I was a little angry after she died that she had to suffer like she did. Because she did suffer. I did not think it was fair. This woman did not deserve to suffer. And that upset me for quite a long time. It still does. You know, the last moments of your 
mother's life and you watching, you know, you watching and you are never

going to forget that. And I called hospice and they sent a clergy man.

There is no theodicy without suffering. Suffering is one of those issues that are a part of prolong it-end it and the open-hidden competing discourses. It is at this point that the three competing discourses overlap semantically. The semantic overlap means that one competing discourse is never isolated from other competing discourses. The meaning of a conversation is derived from the context in which it was spoken but the context is boundless. In that sense, theodicy is part of the other discourses in this study.

Theodicy is composed of the why voice and the God voice, which compete with each other. The why voice expresses that God does not care or God is not just. It wonders why God would permit the patient to suffer. The God voice is expressed by saying God is good, loves everyone, and God has a just plan.

\subsubsection{The God Voice}

The majority of the PCGs who talked about God's role in the death of the patient came to make meaning out of the tension within the competing discourse through framing the situation within the realm of God. The analysis here also touches on RQ2. It is hard to separate the identification of theodicy from how it was communicatively managed. The PCGs managed the conflict between the God-voice and the why-voice in different ways, each one being a different theodicy. When the interviewer brought up the possibility of other theodicies, the PCG either dismissed it or simply said they never thought about it in that way. Lace came to an acceptance of the suffering of her husband through conversations with the people who visited after the death of her husband.

Lace: "We had a lot of church friends come by and a lot of other friends. They said he had suffered with this a real long time and they thought it was a blessing that he had gone"

Interviewer: "And that was OK to hear that?" 
Lace: "Oh yes because I thought the same thing, the whole family did."

Ed appealed to the afterlife as a way of understanding.

I thought it not the fact that God was making her suffer but that he was preparing her for the day that, you know, be with him. And I just looked at it like that. I didn't have any anger toward God and I was thankful that he had provided her with a long and happy life

Beth framed the conflict in terms of God's plan.

Sometimes I wondered how he...how he was being alive so long the way he was struggling to breathe, that last year especially. I guess I knew that it was so imminent that...and I believe in God's plan and in God's time and it just, ah...wasn't that time.

Ed and Beth responded in a dialogically contractive manner. When Ed said "And I just looked at it like that," he implied that his position was natural and as if it was a transparent representation of the ways things are. The source of the discourse for Ed could have been religious teaching or a faith community. Many people follow faith traditions for the purpose of making sense of life, death, and life after death. His response contracts or minimalizes the dialogical tension between the social-cultural discourse that God cares and God does not care. Rose's response, on the other hand, was dialogically expansive. Ambivalence and the catch-22 idea are in bold relief in the following quote.

Rose: I just don't understand God. I just don't understand the whole thing, I don't understand it.

Interviewer: What part of that?

Rose: Well, you know, God's plan, the way he made life. Things, you know, it's almost cruel sometimes, you know, but that's the way it is. And that acceptance is...if you don't have any faith, any hope that's it's going to be better after this...because this is, this is good, we are able to experience, to love, dance, 
and you know, enjoy people, and you know communicate, and make this world a better place, but when it all comes down to it, this world, it just gets scarier, and scarier, and you know it makes you wonder like, this can't be.

Rose entertains the dialogic alternative. Her statement reflects a struggle with God voice, God's plan, and the afterlife and with the why voice. "God has put good in the world" is combined with "it is almost cruel and scarier." In the end she can't quite put it all together by saying "this can't be." You can almost see her mentally checking off the pros and cons.

Theodicy can conceptually be understood as a term used for how people communicatively make meaning out of the competing discourse of a good, caring, and all powerful God and human suffering where God seems not to care, is not just, or maybe is not all powerful. This will be discussed further in regards to $R Q$ 2: How do primary caregivers communicatively manage competing EOL discourse?

In summary, the first $R Q$ asked the question: What competing $E O L$ discourses are experienced by PCGs? The interviews found five competing discourses: cure-care, prolong itend it, open-hidden, move on-don't move on, and theodicy. The text analysis of the hospice materials supported four of the five themes. The materials did not mention the open-hidden theme.

\subsection{How do PCGs Communicatively Manage Competing EOL Discourse?}

RQ2 focuses on the ways that the competing discourses are negotiated communicatively by the PCGs. Baxter and Montgomery (1998) labeled this communication praxis and, later, dynamic interplay (Baxter, 2004). The recent revision of RDT has shifted more emphasis to the ways in which discourses can interpenetrate and how individuals construct meaning from the interplay of discourses, or as Baxter (2011) writes: "meaning is wrought from the process of discursive struggle" (p. 121). Many of the statements made by the PCGs in regards to the first research question also apply to the second. It is at times hard to separate the 
discourse from how the discourse was communicatively managed. An overview of the results for $R Q 2$ is found in appendix $B$.

\subsection{Cure-Care}

The cure-care discourses are generally dominant before the patient enters hospice and compete with each other in regards to the plan of care. The cure discourse voices the continuing curative treatment of the patient and the care discourse voices a palliative approach, seeking to provide only comfort for the patient.

How the PCGs managed the cure-care discourse was dependent upon where and with whom the competing discourse was being voiced. Two broad categories were found. The discourses had to be voiced and dealt with by the PCGs both in the medical community and within the family.

\subsubsection{Passive Medical Voice}

Most of the PCGs had some sort of cure-care story. Usually the medical voice was passive, in the sense that they presented the options and let the patient and PCG decide. For example, the two sisters' mother needed a pacemaker. The doctors left the decision up to the family. The decision to have the pacemaker put in prolonged their mother's life which resulted in extended suffering. "Did we make her suffer? That is probably the only thing that comes back in our mind that to question if we did things right or wrong." The Parkinson's doctor for Lace's husband never told Lace that her husband was terminal, but Lace herself made the discovery through internet research. Often doctors avoided breaking bad news to patients. The following is Pat's answer to how she got involved with hospice. The doctor's avoidance of breaking the bad news is disturbing.

I mean once a week, once every two weeks. I didn't know what was going on, but I went to his doctor and I said "Something is wrong, he never been this sick before." And so he said "why do you think your brother can't walk?" And I assumed it was from the stroke and the heart attacks. So the next time I went 
back to the cardiologist he gave me a sheet with all the things photocopied where the cancer had metastasized and everything but still his primary care doctor who we have been going to for 7 years had never told me he had cancer. So I took this paper in when he was so sick and told him, I said "Doctor, he is very, very, sick and this is not normal" and so I handed him this paper. "Have you seen this, do you know what's wrong with him? Have you seen this from doctor so and so?" And he said "yes, I have a copy of it." So I said to him, "The cancer he was treated for 7 years ago, the prostate cancer", he never check him not once after that, in that 7 years for that prostate cancer, so I said "The cancer has metastasized hasn't it doctor?" And he said "yes." And I said, “Well he is very sick now." He hadn't been sick before this, and so he started to tell me some things but my brother was kind of upset a little bit so I told him "I come back, I make an appointment for tomorrow and I came back and talk to you about this, OK?." And so I did. I made an appointment and went back to the doctor. And he said "It is not a matter of months, it is a matter of weeks." And he said "I would assume that it is about 10 to 12 weeks."

Following this discussion Pat brought in hospice. The way most of the PCGs managed the cure-care competing discourse was to abandon the cure discourse when the patient was diagnosed as terminal and to adopt the care discourse and explain to family and friends that the hospice care was about prolonging life not ending it. Lake comments on this.

For me, if you do not give a person hope, and I don't care how terminal you are, they have nothing. So we would always talk about...you know...just...trying to get her through...over her, you know her tough times because you know I just felt she really needed that. And when she found out that there was nothing else that they could do is when she chose hospice. 


\subsubsection{The Family's Voice}

The choice of entering hospice often was the choice of choosing the care discourse over the cure discourse. At this point there was often in place a six month terminal diagnosis and conversations about a DNR. The choice was not simple. The choice was usually a familyinformed decision. Sara explains the choice of care over cure through the decision making process in her family.

So ah...when this came, the question was, do we fight this like we have fought all the others, because obviously she was a fighter and she can survive or do we draw a line somewhere.

PCGs were found to be proactive at this point. There were attempts to involve all the family in the decision. Again, Sara voices this idea.

And I had sent things to my brothers about what I had found and so forth, WebMD and those kinds of things. And I had sent information about her MRI and all of this kind of stuff. So we had the medical information, we had done some research. The cancer doctor had talked to us about our options. So we had clearly delineated options. And we talked through them.

Pearl recounts "'Let me talk to somebody', she (the doctor) told me. And so then she called me and said 'Pearl, the people from hospice are going to talk to you. Tell your older son to be there.' We all did this together, the family." The support of the family voice was critical for the final swing within the competing discourse to the care discourse. But it was not always smooth. Jen recounts:

We had a family meeting. Once we met and signed the papers, I let each one of them look at the packet that I got. I said "read it and write down anything which you have a problem with." The hospice person said put it all out there. And I said “Once we go down this road I don't want you all coming back and saying 'They didn't tell me about that.' My husband's sister who lives here, she 
was a nurse, and she is a little bit older than he is. They are anti-hospice. In fact, she somehow solidified his anti-hospice. She was just "all they are going to do is kill him, they basically going to kill him." And I just felt like when I told her I said that "this is what we need. I know that you are against it and we just have to live with it." "Feel free to come over. If you want to come over and see how...how everything is working then do it." She never did.

In summary, PCGs had to work through passive and sometimes avoidance behavior by the medical community regarding the nature of the illness of the patient. Once the medical community communicated the terminal nature of the illness there usually followed a six month prognosis and conversations about the DNR. These were the road signs that signaled to the PCGs the need to shift from a cure discourse to a care discourse. The shift was not done alone; usually it was started with the solicited consent of the family voice.

\subsubsection{Prolong it-End it}

Prolong it-end it is a discursive struggle about the life of the patient that is event driven. As has previously been mentioned, the patients for this study were dying of chronic illnesses. Chronic illness has its own unique dying trajectory of crisis and disorientation followed by a recovery and a new normal. Overall, however, it is a downward trend like a rollercoaster with life's momentum slowly dissipating. Baxter $(1988 ; 2011)$ refers to this sort of fluctuation within competing discourse as segmentation. The basis of the inversion of dominance of the competing discourse is due to the change in events, activities, or circumstances. Brenda said "I didn't want to face it, at least I didn't. It hurt to accept it. So you put off the hurt as long as possible. It was my thoughts. No one else might be that way." Most PCGs were this way. The pattern of patient recovering often led the PCG back to a prolong it discourse and a false sense that things will continue. Rose, speaking of the death of her mother, was torn between the two discourses. "I don't think you are ever really ready for it, I really don't...no matter...and I knew and my brother knew, how crazy is that? It's crazy. (pause). She always bounced back, always." 
The statement was made in the context of a discussion about the characteristics of the dying process. Most hospices provide PCGs with a list or a booklet that explains signs that indicate the coming of the death of the patient. During the interviews, the subject of these death signs was one of the most common topics of discussion.

The prolong it-end it competing discourse is chronological. The prolong it discourse starts when the cure discourse ends. The prolong it discourse is communicatively very important during hospice. This is one of the ways that hospice frames its services. The death signs are important to the PCG and family because they provide a framework to know that death is close. When the death signs appear, the end it discourse starts within the family. A typical list of death signs include a loss of appetite, sleepiness, confusion, cool hands and feet, skin discoloration, and uneasy, noisy breathing (Excel Publishing, 2002). Rose and her brother talked about the signs. They had a DNR, they were given a six month prognosis, hospice was involved, and still the prolong it discourse in some form was present to the end. The following quote was very emotional and hard to follow, but the gist of it is that the nurse showed Rose the death signs present in her (Rose's) mother, and she still could not accept it.

It is crazy, because of all the things that you know, you know, you know and you walk in there and here they are, you just don't expect it. They can come up to you 2 hours before they are going to die and say "she is going to die in two hours." You think pissss, you know. And they had the seal of approval from God, he sending down lighting into a rock and they hand it to you, and you not, I didn't... it is so funny because I knew that was going to happen.

Jen and her family were made uncomfortable by the death signs, but the death signs helped transition them out of the prolong it discourse and prepared them for the end.

There is like a check list that came with the packet, and I refused... what the check list was, was when they are doing certain things this means that they are at this certain point. So the check list was the hardest for me and my children. 
My son...I don't think my son even read all of them. Because once he saw that my husband had already reached 8 or 9 , he just pushed it and said "Mom, I just don't...mom you know what is best for dad, you know what's best.' My daughter just broke down. When she saw you know how many of those key things my husband was already at. And I...I...I have to say I just totally didn't believe it. I just looked at it as "this is just some generalization. Everybody is different; you can't really use a check list to gauge how long somebody is going to be on this earth. Who in their mind came up with this stupid thing?" So I read it, and just pushed it out of my mind. But the check list is the one thing now in retrospect, that check list was so on point that it is scary.

The dying trajectory of chronic illness directly influences the use of the prolong it-end it competing discourse. Our culture tends to think of this discourse as letting go or not letting go of the patient. The two most common ways that the PCGs communicatively managed the competing discourse were carnivalesque and the death prayer.

\subsubsection{Carnivalesque}

Carnivalesque is a term first used by Bakhtin (1984) which refers to communication that is carnival-like toward the dominating discourse. As used in this study, it is a speech genre that uses black humor to subvert the trappings of coming death. The communication makes fun and has a playful tone. Baxter (2011) writes 'The carnivalesque spirit features a mock de-crowning of all that is normally accepted as appropriate" ( $p$ 145). It is satire, parody, and laughter at the centripetal discourse and leaves breaches for alternative discourses to be heard and relished. Bakhtin (1984) believes that the principle of carnival and a carnival sense of the world can destroy the barriers of all "self-enclosed systems of thought" (134). By the use of humor the PCG and patient communicatively managed the day to day ups and downs of the dying process. Humor enabled the mention of end it and the competing discourse of prolong it together. 
Several PCGs mentioned the use of humor to simply to talk about and laugh about the dying process and death. When Lake was asked about the communication within the family at the coming death of her sister she responded:

It was never, it was never something that we...that we shut up. One day she made the comment that...she said ah...she said that 'I am too sick to die.' You know we joked about it. We knew that it was going to happen. We didn't...we didn't...I mean if it come up with her...we pretty much would follow her lead. Anything that, that she said is what we would go with. You know...ah...I would get up in the mornings and...'Are you still alive?' And she says 'Yea.' And I poke my head around the corner and she would say 'boo.'

Usually during the interviews the PCGs still laughed about some of the stories they told. The carnivalesque still dominated in grief. In other words, the PCGs utilized carnivalesque to communicatively negotiate the prolong it-end it and the move on-don't move on discourses. "I think that was what kept us going, a sense of humor" (Lace). Beth talked about the dying process of her husband and the arduous daily task of taking care of him and the maintenance on the home.

It bothered him that he was a burden and I just laugh it off. You know, I would be out working in the yard to get the yard ready, we did have somebody to mow but I did everything else. He would say something about feeling bad about me having to do it all, but I would say "When you were well it didn't seem to bother you all that much" (laugh).

Ginger's mother only had a few days left to live. The hospice nurses showed Ginger the physical signs that her mom's death was approaching. "We talked about the times with my mom and dad, you know, and the funny times, we sat here and we laughed." Two sisters took care of their mother in 12 hour shifts for a couple of years. It became obvious that their mother would 
die in a few days. At the time of the changing of the shift, one of the sisters entered the bedroom to say hello.

"Mom, what you doing?" She was lying in bed with covers over her head and she just looked at me and said "Well, I am just laying here and dying." (both sisters laugh). That's really kind of funny at the time but kind of hit me like she really does realize that she is passing away.

Prolong it-end it competing discourse was managed by black humor or carnivalesque between the patient and PCG and sometimes between the patient and the family. The second way the PCG expressed the prolong it-end it competing discourse was the death prayer.

\subsubsection{Death Prayer to End it}

The death prayer is a prayer by the PCG to God for the death of the patient. This is the moment of the inversion of the competing discourse. This is the last act of the prolong it-end it competing discourse. The momentum of the rollercoaster has come to an end. This prayer was mostly motivated by the suffering of the patient. It often was said when the prolonging of life was now only at the cost of great physical pain and suffering of the patient. The death prayer is how the PCG communicatively managed the prolong it-end it competing discourse. Sara and Ed prayed for her mother's death at the end. In response to the question "Did that cause a conflict? I mean was this the right thing to pray for?" Ed prefaced his response by mentioning he first talked to his pastor, and then he said: "I wanted her to have a quality of life to the end; I mean I wanted this to end because there wasn't a quality of life that we wanted for my mother in-law." Jen watched her husband slowly die over a six month period. Even at the end, she and her husband refused to accept the coming death. She had fantasies that her husband was just playing a joke on her. Near his death and in great conflict she prayed: "God take him, take him, just don't let him keep on laying here struggling, just take him." As with the competing discourses of curative versus palliative treatment, the DNR was for some the symbol of giving 
up hope for a cure. The death prayer was similar. This seemed to be a common event. The not letting go became letting go of the patient, the death not yet please became death please. Faith explains:

When I went on hospice, I mean I gave up hope that he had years to live. But I don't think I gave up hope of one more day. Until...well no, I take that back, until he got to the point when he couldn't wake up without being in acute pain. That is when I prayed for him to die.

That was not an easy prayer for Faith. Faith fully embraced the prolong it discourse during her husband's illness. The prayer was very conflictive.

\subsubsection{Open-Hidden}

Open-hidden discourse is "for your information" and "too much information." The dying process is messy. A tendency was found in the PCGs to manage communicatively the day-today happenings that involved the physical care of the patient. Sometimes privacy was the reason to keep it hidden. Pat said, "I have always been very independent, so when he needed me I was there. We didn't call on friends. We were a closely knit family." At other times the reason behind the hidden discourse was to protect the memory of the patient. During the dying process the patient often became confused and frustrated, and this sometimes resulted in verbally abusing the PCG. It was found that this was rarely communicated to the rest of family. Lace explained that, due to her husband's medication and pain, she experience anger from him during the last couple of months of his life. She did not communicate this to her daughter. It was kept out of sight. "Because sometimes I just get angry, angry, and when I am angry I talk to my friend. And I can say things about him that I know that my daughter would find very hurtful." Lace tries to remember her husband in a positive light. "I do talk about him. But I talk about the funny memories. I don't talk about his suffering. That's in the past. It is easy to let go." Jen kept her husband's dying process to herself. Even with the presence of hospice she did not talk about it. 
Interviewer: When hospice came in, were you then talking about it?

Jen: When Wendy said you need somebody here all the time that is when I became more open to talk about it.

Interviewer: Did you talk to the hospice people about it?

Jen: No. Because I didn't want them to think that I couldn't handle it

The subjects of the dying process and death are avoided. Lake, who herself was a palliative nurse, was familiar with the dying process but in regards to her sister's dying process she said: "That was kind of challenging for me because I have always been the type of person, you know, that...you might not like this, if you don't have a little lie somewhere you are not going to give that person some hope of getting better."

On the other hand, other PCGs were very open to family members about the dying process. Ed, in talking to his brother-in-law, the son of the patient, said:

You really can't tell a person's expressions when you don't see them face to face. Sometime people understand but they don't show that empathy, or they don't show that concern. I felt that they miss out on an opportunity when she was still lucid and able to talk and see. One of Sara's brothers came here and he said to me "Ed, I am glad you got us guys in involved because I didn't know what all was involved." He didn't know that I had to go in here and take care...move mother and change her and so forth. And he said "This is my mother, man, and you are taking care of her like that." And I said "Yea, of course." But until they came and experience what was going on here did they really understand. Sometimes you can talk to people about something but until they are right there with it, they don't understand it. So that was some of the problems we experienced with Sara's three brothers, she has three brothers and also her sisters. 
On a few occasions the PCGs put together a family gathering in order to inform the family about the dying process. Often the hospice nurse was the one who came up with the suggestion. Beth made known the dying process to the family through her husband's birthday party.

I did tell them that they didn't see everything. But unless you are handling it, you don't' understand (death process). So I did communication to them that week-end that they were all here for his birthday...that we were probably, were looking at the end. I am so glad I had that party.

Jen's friend Wendy suggested Thanksgiving for the communication.

Wendy was a friend of my daughter and she would know all the signs. She would come over and we would have barbeques and she would just notice little things. And she, being a hospice person, she kind of started to tell my daughter "I think this Thanksgiving." My husband died in December, she would start telling my daughter ah..."have everyone come over and see him, everybody that loves him, you know, tell them to come on over.

\subsubsection{Move on-Don't Move on}

Our culture has a fuzzy time limit about when to stop the don't move on and to move on. Sometimes during the grieving process these social voices will compete. When the PCGs were engaged by the move on-don't move on competing discourse they responded in three different ways. The way they responded was usually influenced by who they were talking to.

First, the PCGs who had a spouse or sibling in the home with them during the decedent's stay with hospice had a freedom for both the move on and not move on discourse to be expressed. Second, PCGs were generally encouraged to move on by family members who were not part of the care process. This was resisted with the don't move on discourse. And third, the PCGs carefully regulated the sharing of expressions grief with non-family. 


\subsubsection{Freedom to Grieve}

The PCGs generally expressed a freedom to grieve with a partner who helped with the care of the patient. Usually the spouse was the primary person that the PCG talked to about their grief. Ginger cared for both parents, in the parents' home, with the help of hospice. Both parents died within the past year and half. Between the deaths of her parents she married Fred.

I would say to most people, yea, I had my moments and they would say "That's good. That means you really cared about your parents and if you need to talk about it, let's just talk about it." "You need to feel it, that's how you know you really loved them because you really miss them." They want to talk about it. I mainly talk to Fred about it, or my sister-in-law or brother. I just don't put it out there. I really limit. I really talk to him about it more than anybody. He was here the last 7 months taking care of my mom. And he was on the phone with me a lot of those 3 weeks that was with my dad. So actually he has been through the whole process with me.

Ginger regulates who she talks to about her grief. Her husband is the principal person to whom she communicates her grief. The rationale she uses was that Fred experienced the dying process of her parents with her. It is reasonable to assume that those who share the open-hidden tension of the dying process share something unique. Sara, in response to a question about what were the most challenging issues to talk about in regards to the death of her mother, said:

I know exactly what it was and I would only talk about it to my husband and older daughter, which was I was tired of watching her linger. I wanted to wake up and she not be breathing. I just, you know...I felt like she was suffering, and she wasn't suffering in pain or anything like that, but it was like God how long must this go on? 
Sara speaks of her death prayer for her mother but she limits the conversation to her husband and daughter. At this point we can see that the various competing discourses can intersect. For example, the open-hidden tension in the hospice situation is about disclosure or nondisclosure of some of the messy details of the dying process, details that many PCGs felt uncomfortable sharing. The end it discourse comes about due to the suffering of the patient, in Sara's case, a death prayer. The sharing of the dying process as part of communicating grief is highly regulated. There is no way to know how common it is for the PCG to be non-expressive about the grief related to the dying process.

Rose and her brother, following the death of their mother, communicatively managed the grief by embracing the don't move on discourse. Both were involved in the care of their mother, they both recognized the death signs which pointed to her coming death, and they both had a very hard time accepting her death. Later on in the interview Rose did give examples of how she regulated her grief outside of the family. The following quote is a good example of a don't move on discourse.

We clung together. We were like, for two weeks there, we just cried and cried and walked around in kind of a cloud. You are like, you just, and your whole life changes at that moment. Everything changes. Neither one of us knew what to say. We didn't have any appetite, there was not schedule, there was no, we would just walk from one couch to another or one chair to another. It was hard, it was difficult because we....the denial part is, is, a big part. It is just reconciling with the fact that she actually was gone and the grief on top of it and missing her. I mean it took us, it really took us a lot longer than that to be able to carry on without... you know and function without breaking down.

\subsubsection{Resistance to the Move on Discourse}

The move-on discourse was voiced by family members who were not part of the care process. The family sometimes felt free to voice the move on discourse. Other times it was 
expressed through a lack of response when the PCG expressed grief. Both Sara and Pearl voiced their resistance to the move on discourse. Pearl said she heard the move on discourse from her three boys. "Well my kids don't like for me to cry. It is what I told you 'Let it go mama.' But I cry." In regards to chronic illness, the bereavement period does not necessarily start at death but usually begins before death and is referred to as anticipatory grief. Most of the PCGs grieved before the death of the patient. Some family members found this inappropriate. Prior to the death of her mother, Sara had a discussion with her daughter about grief.

I have been through that with my oldest daughter. And this was even prior to my mother's death. When the experimental chemo did not have any effect on her tumors, that's when I started grieving. As a matter of fact I started to grieve when she had the prognosis. I didn't eat much for a long time. Ok, this is it, there isn't anything now that is going to give her a longer and quality life....and she was like "You know, you need to stop, you need to stop doing this." I said “No, you don't understand, you must just go through it. There are some things that you just go through, it may be painful and all this, but we are going to go through this." And she has had a very hard time with that. But I said "I don't care what you think I got to go through this."

Faith related a conversation with her family members about her grief and how she reacted when they asked her about moving on with her grief.

Well I did with my aunt, I did with my daughter for a while, but it turns out a lot of that was miscommunication. I think she thought that if I was OK my life would really look different. And it was a misunderstanding of what my life would look like if I was OK. Everyone was worried that I start drinking, that I couldn't cope, I am not sure exactly what they thought but everyone thought that I couldn't cope. And my daughter weirdly was worried for me to be around my grandkids. 
She was terrified that I develop an inappropriate relationship with them. Like be emotionally dependent on them and it is not true.

Jen's situation illustrates the difference between family members who were involved with the dying process and those who observed from a distance. Jen felt she had the freedom to talk about her grief with her son and daughter.

My son and I very seldom talk about it because that's the way he chooses to deal with it. He will do things. "Let's go out to eat." My daughter lets me cry. We cry together all the time especially holidays like Easter coming up. It is one of those things, we grieve our way, and my son grieves a different way.

But the rest of the family managed the communication about the death of her husband through avoidance and silence and Jen felt like she had to 'suck it up."

When I look at my immediate family, my parents are in their 80 s, and every time I go home I feel like I have to suck it up because my parents really don't want to talk about death. My sisters don't want to talk about death. I hardly mention my husband's passing unless there is just something that comes up.

\subsubsection{Regulated Grief}

PCGs regulated their expressions of grief with those outside the family in various ways. Rose communicatively managed the move on-don't move on discourse with common sense.

Well I am not stupid. I mean I know when to shut up (laugh). But the people I deal with on a regular basis know me and so they can tell if there is something on my mind. And of course over this last year I had gone through a lot of different processes to where I got to the point where I don't talk about it as much.

Lake regulated her sharing of grief by sizing up the person who introduces the move on-don't move on discourse. Lake used the contractive "just" which is reflective of shutting down the conversations. "Yea, I mean, yea I shared when someone would ask me 'how are you really 
doing?' I had one that asked me that and I would just tell her 'OK, but I still have my times that I think about her."”

Jewel managed her conversations about her grief by talking only to those with whom she felt safe.

Interviewer: Do you talk to anyone about your husband's death?

Jewel: The chaplain.

Interviewer: Anyone else?

Jewel: Not if I can help it. I don't care to talk about such thing if it weren't about such a negative situation with our marriage. I am just hurting; I don't want to talk about it all the time. It's hurting. I talk to the Lord all the time. Also I have my little friend that I can call; I am closer to her than my cousin.

Jewel also mentioned that conversations about grief hurt. Loneliness was a very common theme. It is something that many PCGs felt they could not talk about. They communicatively managed expressions of loneliness by silence.

Interviewer: You mentioned you have a hard time talking to people about your loneliness...

Brenda: I don't even like to think about that I am lonely, but I am very lonely.

Interviewer: So why do you not talk to people about your loneliness?

Brenda: It hurts me worse if I talk about it.

When I first introduced the subject of grief, many of the PCGs talked about the patient, but not their grief. Through the interview process I discovered that I needed to say 'grief', not 'loss.' When asked about how they talked about their loss, the PCGs usually mentioned that they talked about the decedent through the sharing of memories. When asked about how they communicated their grief, they usually talked about the move on-don't move on discourse.

In summary, how the PCGs communicatively handled the move on-don't move on discourses was influenced by the social context. So it is only natural to assume that if a social 
context was constructed to invite both discourses to be voiced it could be very powerful. Such a context would be the funeral.

\subsubsection{Rituals as Expressions of Grief}

For the PCGs in this study the funeral was a positive experience wherein the move ondon't move on discourses did not compete. The funeral mixed mourning with celebration like vinegar and oil in a salad. The funeral usually entailed two parts, the recognition of loss and a future reunion in heaven or just a better future. The cultural discourse of move on-don't move on has a chronological aspect to its expression. Culturally, immediately following death one is expected to express a don't move on discourse. Sometime later one should begin expressing a moving on discourse. We tend to communicatively handle this through expression and nonexpression. The funeral ritual communicatively and publicly expressed both sides of the dialogic tension simultaneously. Daisy expressed it as "The best thing that I could think of at that time was knowing that my mom was holding my daddy's hand. So from that point you know it was sad yet was happy times. It is strange how it all comes together." Sara said:

One year later we celebrated the...I call it the anniversary of mom's ascension. And so we went down to her gravesite in Houston. And when I left Houston I felt like I just had left the funeral. So, ah, I do...it was good to just accept it. I don't feel bad about it (the grief) being continuous. So that is how I can just talk about it."

Very similar to the lack of competing discourses found in the funeral ritual were the lack of expressions of conflict spoken by the PCGs to the patients at the time of death. All PCGs expressed the belief that the decedent was now going to "a better place." Along with this expression came religious expressions about reunions in heaven. Research has been found to support the widely held assumption that religion and spirituality are generally helpful in adjusting to bereavement (Wortmann \& Park, 2008). This sort of religious discourse, if the circumstances permitted, was part of the last words to the patient before death. Here are some examples. 
Pearl: I ended telling him, "It is OK, you are OK, God got his arms around you and taking you. It's time to go, OK?"

Sister: And her blood pressure would go way down. And I would say "It's OK mom, It's OK. Take Jesus' hand and step on across."

Brenda: And I said "you wait for me on the far banks of the Jordan." That was a song he liked and we knew it. He understood what I was saying to him.

Ginger: My dad, I just held his hand and told him that mom and I will be OK, that we were here. And you know, God was going to take care of us. And that he can go home because we were going to be OK

Daisy: So I laid down beside her and put my arms around her and said "Mother can you hear me?" And she said "Yes." And I said "Do you know who I am?" and she said "Yes." And I said "Mother I love you more than life itself. Daddy has his hand reached out for you. And he is waiting on you" (crying). And I said "will you let go?"

Kala: Finally we each had to say "Mom, it is OK to let go." (Long pause, some crying) And that's the hard part, you got to let go. And that is not easy. But here I am still crying. It's OK. "Mother, you have to go to that place."

As at the funeral, the last words to the patient did not have dialogical tension. The PCGs usually were very conflicted inwardly, but most of the PCGs encouraged the patient to "let go" at the point of death.

\subsubsection{Theodicy}

Theodicy is the negotiation with a competing discourse. Theodicy can be approached dialectically, meaning a synthesis of the theoretical problem of a good and all powerful God and his permission of the suffering of innocents. Kant (1965) and a host of others have rejected this synthesis because they claim it is impossible for humans to have empirical knowledge of God and therefore God's relationship to evil. Although on a theoretical level theodicy has its 
problems, practically the PCGs held to some form of it. Theodicies have an important bearing on the manner in which the PCGs and their families communicatively coped with bereavement (Wortmann \& Park, 2008).

In their hospice admission papers, all PCGs claimed to be of the Judeo-Christian faith. The results seem to indicate that what was voiced was part of the utterance chain from a religious point of view. The similarity of the expressions, sometimes speech code-like expressions, reflects a social construction found in religious discourse. This study does not presuppose that the PCGs' use of the God voice means some sort of escape acceptance or escapism. In respect to $R Q 2$, three approaches to how the patient's suffering were commutatively managed by the PCG, the family, and friends were found. First, the suffering and pain was stated as being part of God's plan. Second, the why voice in regards to suffering was not within the realm of human understanding. Third, the PCG appealed to the afterlife.

\subsubsection{Justification of Suffering as Part of God's Plan}

Part of the God voice discourse is the plan of God. The plan of God is a religious idea of divine providence, meaning that all events are permitted to happen by the divine. Beth believed that the suffering of her husband was part of the overall plan of God. She does not question the plan of God, she simply accepts it.

He loved life, and he loved his family and so forth, ah...he....ah...he never wanted to go sooner and I didn't want him to go sooner. Sometimes I wondered how he...how he was being alive so long the way he was struggling to breathe, that last year especially. I guess I knew that it was so imminent that...and I believe in God's plan and in God's time and it just, ah...wasn't that time.

The two sisters shared the responsibility of caring for they mother for several years. They did this in alternating 12 hour shifts. The last few years their mother started to deteriorate physically and to experience increasing pain which was complicated by the onset of dementia. The entire experience was interpreted as God telling them that it was all under control. 
Sister 2; Sometimes I think God uses those things to make you aware of, well "OK, let go," and "I am in control here."

Sister 1: Those nightly fights were hurting mom, it was hurting dad, it was hurting me, and she had to do that to get me to let go.

Both sisters communicatively managed and made meaning out of the negative experiences with their mother at the end of her life through the God voice. Meaning was constructed by interpreting the circumstances as part of God's plan to help them emotionally let go of their mother. The God voice discourse at this point overlaps with the end it discourse discussed previously. Brenda tells a story about her husband and two daughters. She was not home and her daughters were taking care of their father. The father started suddenly to physically spiral downward. The daughters, in a panic, called their mother. Brenda interpreted the whole episode as "It is a way that God tells you are about to lose a loved one." The statement brings to mind Soeren Kierkegaard's Fear and Trembling. It is a declaration of and resignation to God's plan. The statement is dialogically contractive; it does not leave room for an alternative voice. She does not voice the why, she explains the why.

\subsubsection{Suffering Beyond Human Understanding}

The second way that PCGs communicatively managed the competing discourses of the why voice and the God voice was to diminish the why voice by attributing it to a lack of the understanding of God. In relation to Rose's grief over the death of her mother she said: "You know, driving home from work one day, you know, and you're just bawling your eyes out and that is a process. That is what's supposed to happen. I just don't understand God. I just don't understand the whole thing, I don't understand it." In the process of coming to grips with the death of her mother she did not embrace either discourse but rather expressed a hybrid of both. Faith expressed the same sort of approach with the expression of both discourses.

I read a book and he talked about how he had trouble believing in God and how he was really angry at God but God never owed me. If God had somehow 
promised me that my husband would be alive, then I would have doubts, or I would be angry with God when it happened. But, you know, he had a good life, it was not what I wanted, but it only proves that I am not God and I don't get everything I want.

Her use of "but" in the first and last sentences signal both discourses are in play. On the one hand, the book she read communicated the why voice. Her second sentence entertains hypothetically the why voice for argument sake. The God voice makes distance between her and God. She does not dismiss the why voice, rather she diminishes it by stating it does not fit her circumstances.

\subsubsection{Patient is Now in a Better Place}

We have already looked at the end it discourse in which the PCGs prayed for the death of the patient or spoke to the patient about "crossing over," "taking the hand" of a spouse who had already died, and other sorts of expressions that imply an afterlife. The appeal to the afterlife took the end it discourse one more step. It contributed to the bereavement process. Two death specific religious beliefs helped the survivors cope and adjust during bereavement: the belief in the afterlife, and the belief in continued attachment to the deceased after death. Both of these beliefs were expressed by PCGs as being part of the meaning making process.

Lace: That he had suffered with this a real long time and they thought it was a blessing that he had gone.

Interviewer: And that was OK to hear that?

Lace: Oh yes, because I thought the same thing. The whole family did. We talked about it before he passed away. He was a Christian and we felt like he went to heaven. And that's important.

Ed said:

I remember the pastor talking to me to look at this time as her preparation. And I thought it not the fact that God was making her suffer but that he was 
preparing her for the day that, you know, be with him. And I just looked at it like that.

Sister 2 said:

There are people who cannot deal with death at all. It is like this is the end, but because it wasn't the end we realized that it was a transitional period, for mom and that it was something that, you know, that God was taking us through, and we will see her again, and that was not something that was a hard thing.

Religious discourse frames death as living in another place. None of the PCGs expressed death as non-existence, but conceptualized it in living terms. Death gained its meaning in its juxtaposition to life. Most of the theodicies used by the PCGs communicatively managed the suffering of the patient in this life with a future better life.

In summary, EOL communication can be illustrated by a fish in a boat, violently flipflopping. This is EOL communication in a hospice environment. People are caught by a series of uncontrollable changing circumstances. Communicatively, the PCG or patient oscillates between acceptance of death or denial. This acceptance or denial may change within the same statement. Are they just confused? They are struggling with competing discourses. Their struggle is part of a social construction. Often what changed was the physical condition of the patient. Ironically this fact might be the only predictable element to EOL communication, that physical changes of the patients will produce competing discourses. The path people walk at the EOL is communicatively muddy, it is not clearly delineated. Any communication theory that does not take into account the messy nature of EOL communication within a hospice environment fails to appreciate the complexity and messiness to EOL communication. 


\section{CHAPTER 5 \\ DISCUSSION}

The discussion is divided into seven sections. The first is a summary of the results which includes a discussion of similar research findings in other studies. The second section is the implications of the dying trajectory and its absence in other RDT research. Third is an outline of the differences between RDT and Bakhtin and the implications of these differences. This section will explore the unique contribution that this study makes to EOL communication and RDT. The fourth section bridges the gap between clinical practice and scientific study of EOL communication. The focus is on the key insights of the study from the perspective of explaining the findings to a hospice Inter-Disciplinary Team (IDT). Fifth, the connection is made between competing discourse and its impact on the social-economics of EOL communication. Sixth is the limitations of this study, and, seventh, directions for future research.

\section{$\underline{5.1 \text { Summary }}$}

EOL communication research has focused most of its attention on the psychological and social stages of the acceptance of the terminal prognosis by the patient, the PCG, the family, and the medical community (Ragan et al. 2010). It was found in this study that the presence of competing discourses was closely connected to the physiological health of the patient. This suggests that EOL communication needs to be understood in light of the physicality of the dying process and the dying trajectory of the patient. This study identified five competing discourses in the lives of PCGs of hospice patients that reflected the dying trajectory: cure-care, prolong it-end it, open-hidden, move on-don't move on, and theodicy.

\subsubsection{Cure-Care Discourse}

The cure-care discourse was in play pre-hospice and was expressed as a conflict between curative treatment and palliative care. The discourse was spoken either between the 
medical community and the hospice patient's family or within the family itself. The medical community was at times ambivalent towards making a decision on a particular course of treatment. Doctors often communicated to the PCG options for treatment and let the PCG and patient decide which path to pursue. At other times doctors aggressively advocated a curative treatment as an approach to delaying death. The medical community's advocacy for curative treatment differed by the nature of the illness. Matsuyama, Reddy, and Smith (2006) found that the aggressive advocacy of the cure discourse was a trend among oncologists. They concluded that there needs to be better decision aids and honest, unbiased sources to inform patients of their prognosis.

Wittenberg-Lyles, Goldsmith, and Ragan (2011) also found the cure-care competing discourse in their study. The terms they used were "hospice narrative" for the care discourse and "hospital narrative" for the cure discourse. They defined the hospice narrative as threefold: "patient, family, and clinician embrace an open awareness of dying and death; relocation from curative-only care to include comfort care; (and) comprehension of terminal status" (p. 305). The hospital narrative was defined as "Communication behavior reveals a closed awareness of dying and death; (and) suppressed comprehension of dying and a blinding emphasis on curative-only and restorative care" (p. 305).

Their study outlined a progression in the acceptance of the terminal prognosis. The degree of acceptance voiced by the PCG was described as a journey. The progression was the family's and patient's growing understanding of the terminal state of the patient and the growing acceptance of the approaching death. The current study suggests that the awareness and acceptance of the terminal prognosis was based on the day-to-day health of the patient and was closely tied to the dying trajectory. Communication was messy, not progressive. The journey was defined by the physical health of the patient instead of a cognitive awareness and acceptance of death. In other words, the findings of this study suggest a close correlation between the physiological and psychological health of the patient. Social acceptance of the 
terminal condition of the patient was not a clear independent variable, but rather, was dependent on the dying trajectory.

This study suggests a relationship between the dying trajectory and competing discourses. In past studies (Glaser \& Strauss, 1968; Prigerson, 1992; Maciejewski, et al., 2007) the dying trajectory was the basis for understanding the stress of families and the medical community during critical stages of the patients' failing health. This study proposes that EOL communication can be studied through the rubric of competing discourses with the understanding that these competing discourses come into being due to the dying trajectory of the patient.

The current study found that upon the six month terminal prognosis the cure-care competing discourse usually ended and the new focus became solely on the care discourse. But even though, for all practical purposes, the cure discourse dissipated, its shadow reemerged in the form of a prolong it discourse.

\subsubsection{Prolong it-End it Discourse}

The prolong it-end it competing discourse was expressed by the PCGs during the hospice stay. The medical community normally shifted from the cure discourse to the prolong it discourse, and often voiced the prolong it discourse to the family in the wake of a six month terminal diagnosis. In other words, the extending of the life of the patient was the primary purpose of the medical community. This competed with the care discourse of the hospice.

Lowery (2008) found communication similar to the prolong it-end it discourse in her review of 158 journal articles that addressed the expression "letting go" before the death of a loved one. She concluded that the key concept of "letting go" involved a shift in the thinking of the patient's family to the acknowledgement of the impending death. The shift that Lowery documented in her studies of "letting go" closely parallels the shift in the prolong it-end it discourse. Although there is a large body of literature addressing the "letting go" concept, none address it in relationship to the competing discourse of holding on. "Letting go" is a point people 
reach, but the current study found that it was not the final point. Often the PCG would communicatively move back and forth between the prolong it and end it discourses.

The PCGs normally stated the prolong it discourse when they desired the extending of the patients' lives for as long as possible. The let go language was found to be part of the end it discourse that was voiced during times of a patient's downturn in health. The prolong it discourse dominated during non-crisis times, and the end it discourse dominated during times of crisis. Which discourse was expressed depended on the dying trajectory. This shift in discourse was motivated by the suffering of the patient, and oscillated back and forth depending upon the health of the patient.

\subsubsection{Open-Hidden Discourse}

The open-hidden discourse is the result of a communication wall erected between the PCGs and the outside world. The day to day routine of the PCGs and patients were not voiced but were kept hidden and only occasionally was the veil lifted, usually when the PCGs needed physical help from the family. How much to share was the issue. After the death of the patient the hidden discourse still existed because the PCGs controlled what was shared about the dying process. The memory of the decedents primarily motivated PCGs to keep from public discourse much of what went on behind "closed doors" during the dying process. Only occasionally in the interviews did PCGs voice that the hidden discourse was part of their unspoken grief.

Most of the studies that broach upon the open-hidden competing discourse in EOL communication refer to the open-hidden discourse as caused by the psychological effects of the dying process. Zhang and Siminoff (2003), from a family systems approach, referred to this discourse as a phenomenon of silence; Hooghe, Neimeyer and Rober (2011) referred to it as a conspiracy of silence. What Zhang and Siminoff's study found was a psychological causation. In a similar study to Zhang and Siminoff, The, Hak, Koëter, and van der Wal, (2000) found that a common reason for the families of patients to not talk about the terminal illness was that it 
signaled the loss of hope, whereas staying with a recovery story kept hope alive for patients and caregivers even if it was false optimism. This is very similar to family communication studies which focus on performance and privacy within families (Vangelisti, 1994; Caughlin \& Petronio 2004)

However, the findings of this study suggest that the silence of the PCG in relationship to the family was often related to the physiological aspect of the death. The PCG did not feel comfortable sharing the physical messiness of the dying process with the family. This is not to deny the previous studies; rather it adds another dimension to EOL communication.

The open-hidden competing discourse emerged during the coding process by a synthesis of various codes. The codes identified as expressions of what was required to care for the patient were: dealing with the patient's anger and frustration, changing and washing the patient after an accident, dealing with the changed personality of the patient, the grind of day to day care, the exclusion of sharing the dirty death with the family during hospice and bereavement, expressions of the lifted burden after the death of the patient and resulting guilt, and the expression that others would not understand. It makes sense that this discursive struggle is the one that would almost elude detection in the literature. The PCGs are reluctant to share such details with outsiders. On the other hand, practitioners are familiar with the dirty death issues because they help the PCG and patient behind the "closed doors." This gap between practitioner and researcher will be further articulated in section four of the discussion.

Palliative care literature advocates the concept of a good death. A good death discourse is very similar to the open discourse. Ariès (1981) writes that the good death discourse had its origin in Victorian modesty "which shrank from mentioning bodily excretions, as well as long habituation to disagreeable smells, and to the disfiguring effects of pain" ( $p$. 568). One such example of the articulation of a good death in the literature is by the former British Medical Journal Editor Richard Smith (2000). Smith proposed 12 principles of a good death which included the following: knowing when death was coming, retaining control, having a 
choice over where death occurs, having access to spiritual or emotional support, controlling who is present, having time to say goodbye, and choosing not to have life prolonged pointlessly. The PCGs shared stories of good deaths. A bad death is, by default, the absence of these principles. There are certainly good deaths and bad deaths. This study suggests that most deaths also include the negative aspects of death. Death is dirty. PCGs expressed that there is a dark side, a bad side to death: the messiness of keeping the patient clean, the smell of death, the verbal abuse, and sometimes physical violence that occurred as part of the dying process.

PCGs involved in hospice care are often framed as heroic by the hospice team and the culture. They have literally sacrificed a part of their lives to care for their loved ones. This means that the public version of death is a death with dignity. But often, behind closed doors, in the privacy of the PCG and patient relationship, the dying process is one of humiliation for the patient. This is the dirty side of EOL communication. The day to day grind the PCGs experience during the hospice period is rarely voiced as part of the grieving. The PCGs do not want to publicly disrespect the memories of their loved ones. The PCGs expressed the desire to impress upon the minds of family and friends a dignified death of the patient. Often the expressed rationale was, "who would understand unless you gone through it yourself?"

Some found strength in humor. It certainly was a black humor, carnivalesque, a laugh at the messy end of existence. Others found strength in God. Most expressed relief that the burden of care was lifted at the time of death. For some of the PCGs, the hidden discourse will never be freely expressed. Their silence is long and this seems to be the lasting heroic act by the PCG for the patient. It is my impression that the open-hidden competing discourse is the one least discussed within the family environment. The reason for the lack of communication within the family might be as Goffman (1959) suggested: the PCG and patient are a "performance team" (p. 85). "If a performance is to be effective it will be likely that the extent and character of the cooperation that makes this possible will be concealed and kept secret" ( $p$. 
108). The hidden discourse is ever present but communicatively tightly controlled. This is certainly a topic for future study.

\subsubsection{Move on-Don't Move on Discourse}

The move on-don't move on competing discourse consisted of cultural expectations and interpersonal voices which the PCGs heard during the grieving process which communicated to them the need to either start or stop grieving.

The move on-don't move on competing discourse is closely related to many of the bereavement studies that used RDT. Toller $(2005 ; 2008 ; 2009)$ observed that after the death of a child, parents had an openness-closedness tension when communicating with their social network about their child's death. As discussed previously, the move on-don't move on discourse is very similar to Toller's openness-closedness discourse. The main difference between this study and Toller's is where the dialogue is taking place. If the utterance is the context for discourse then the conflict was externally voiced from some outside source. But if the conflict was an internal struggle of to speak or not to speak then the conflict is an internal psychological struggle. This then means that the emphasis is on intrapersonal dialogue or how one internally manages competing discourse and Toller's internal dialogic struggle to be open or closed is appropriate. However, the emphasis for this study was on the interpersonal and cultural discourse, not a state of being (such as being open or closed). Thus it was thought best to express the tension in a concept that is spoken (a verbal statement to move on or not to move on) rather than a concept that is thought.

To move on was voiced by family members and friends who thought the grieving period of the PCG was longer than normal and who encouraged the PCG to move on with his or her life. The don't move on discourse was particular to those PCGs who either experienced a long period of anticipatory grief before the patients' deaths, or who were of a more stoic personality. Whatever the situation, the don't move on discourse questioned the PCG's lack of public grief. 
This finding is in agreement with Hagman (2002). Hagman reviewed recent research which questioned the assumption that lack of mourning is a diagnostic indicator that an individual is not processing loss correctly. The current study proposed that the lack mourning was often the result of anticipatory grief. Anticipatory grief is more prevalent in cases in which the patient had a long dying trajectory.

\subsubsection{Theodicy Discourse}

For this study, theodicy was defined as the cognitive and discursive struggle between acceptance of the process of death and the belief in God. Religion or spirituality is an important force in the lives of people. The participants in the study all indicated in their hospice admission papers that they were of the Judeo-Christian tradition. Generally, polling data shows that $82 \%$ of Americans believe in God and another $9 \%$ believe in some sort of universal spirit or high power. Eighty five percent of Americans consider religion at least somewhat important in their daily lives (PollingReport.com, 2006).

Ariès (1981) argues that the west's modernization process was accompanied by a shift from an acceptance of death (called a tamed death) to the denial of death. Ariès asserts that, dating from the beginning of the twelfth century, attitudes toward death began to transform alongside the emergence of individualism. In the past 50 years theodicy has found greater expression in EOL communication due to the rise of prolonged suffering related to the rise of chronic illness.

This study suggests that theodicy was the approach chosen by the PCGs to manage the competing discourses in the presence of the patients' suffering. Wortmann and Park (2009) found a significant religious/spiritual struggle or conflict in the lives of their study participants. The conflict centered on the experience of the death of a loved one and the PCG's understanding of God. The type of theodicy used by the PCGs created meaning out of the conflict of a caring God and the continuing suffering of the patient. The current study proposes that theodicy was expressed as the competing discourse between the God voice and the why 
voice. The PCGs expressed the God voice by stating that the patients' suffering was part of God's plan or they expressed the God voice by dismissing that God was the cause of suffering. Cook and Wimberley (1983) found similar results in their study of theodicy in regards the reaction of parents to the death of their children. The theodicies that they found were that the parents either questioned the goodness of God, the child's death was a judgment from God, or the child's death was part of Gods plan. The present study suggests that the God voice stood in contrast to the why voice. The why voice questions the logic that a good and caring God would permit suffering of good people. The God voice discourse is contractive in the sense that it minimalizes the competing discourse, and the why voice discourse is expansive in the sense that it vocalizes both discourses.

\subsection{The Dying Trajectory}

The dying trajectory is the nexus of much of this study. The shape of the physical decline of chronic illness, which is the graph of physical health or function over time, shapes directly the EOL communication (see appendix C). The dying trajectory can force the discourse of cure into a discourse of care. This spiral inversion eventually ends with the family accepting the approach of death. The transition often is not clear, but the PCG and patient have to conceptually switch from the sick role to a dying role. As the family travels this journey there are road signs such as the signing of DNR, hospice admission, and a six month prognosis. As the dying trajectory continues, the family swings between the prolong it-end it discourses. These swings become a pattern which continues into the bereavement period. Just as there were bad days during the process of dying, bad days continue in grieving process.

The findings of this study have shown that EOL communication is messy. The study indicates that the reason for the messiness in communication is that communication was closely tied to an unpredictable dying trajectory. Other RDT studies on EOL and bereavement have found similar competing discourses; however, the other RTD studies do not take into account the connection between EOL communication and the dying trajectory. Most RDT studies that 
have used RDT for EOL communication have focused mainly on competing discourses during bereavement (Toller, 2005, 2008; Toller \& Braithwaite, 2009). These studies focused on the sudden death of a child. The children who died, died primarily of still birth, suicide, or accident. There was also a category of death by illness but no time frame as to length of illness was mentioned. The sudden death trajectory (see appendix C) was not a variable that these studies used. The one RDT that did focus on EOL communication before death was Baxter et al. (2002). Their research was focused on the EOL communication of the wives of dementia patients. The dying trajectory of dementia patients is physical and cognitive failure (Figure 1). The current study suggests that EOL communication in the hospice environment was directly linked to the physical condition of the patient.

No previous RDT studies make the connection between dying trajectories and communication. This study linked the shape of the dying trajectory to the occurrence of competing discourses. In the area of bereavement, the shape of the dying trajectory is connected to anticipatory grief. As mentioned above, anticipatory grief of the PCG contributed to the don't move discourse.

Morson and Emerson (1990) concluded in their analysis of Bakhtin that one of Bakhtin's global concepts was the messiness of communication. This makes RDT a good fit for the study of EOL communication. In contrast to other RDT studies, this study suggests that there is an emphasis on the messiness of communication due to the unpredictable nature of the dying trajectory.

\section{$\underline{5.3 \text { RDT and Bakhtin }}$}

Bakhtin's theory of dialogism frees the reader or speaker from the need to seek a synthesis of opposing viewpoints. The goal of Bakhtin dialogism and also, by association, Baxter's RDT, is not predictive nor to seek causal explanations. Instead, it is used as an analytical and heuristic tool to render competing discourses intelligible. 
In the current study, the lack of understanding of the messiness of EOL communication often led the PCG's medical and social network to interpret contradictory messages from the PCG as mental lapses, intentional denial of the terminal condition, and, in some cases, deceit. EOL communication is often counter-intuitive and irrational. Observations of conversations in this study show PCGs expressing denial of death, then acceptance, and then back again to denial. Often such expressions were found within the same sentence.

This study reaffirmed 25 years of working in and around the field of palliative care and it is believed that RDT is very useful for understanding and describing EOL communication. Additionally, prescriptive communication theories which attempt to prescribe roles, rules, or structure to EOL communication fail to describe the messiness of EOL communication and are of limited value. EOL communication is better understood as a messy package of competing discourses closely tied to the dying trajectory. A theory that can describe such a phenomenon has extraordinary value.

Baxter's RDT has, over the years, progressively adapted Bakhtin's literary critical theories. Baxter (2011) states that her theory is not interested in the study of the "psychological tension within the individual" (p17). She does not deny its existence, but states that "an individual's utterance is conceived not as a psychological phenomenon but instead as a social unit in which discourses that are already spoken is in play with anticipated responses from real or imagined addressees of the utterance" (p18). Her emphasis is on the utterance itself, not internal dialog.

Baxter is focused on the communication aspect of discourse, in which those communicating are not privy to the internal dialog. Bakhtin, however, is focused on the literary aspect of discourse which includes the internal dialogue of the individual. Bakhtin's (1973) book on Dostoevsky's Poetics is in large part the literary analysis of the narrative of internal and external discourse of Dostoevsky's characters through time. Both Bakhtin's and Baxter's theories are descriptive, but the unit of analysis differs due to the medium. 
This difference does have an effect on the approach to the study of EOL communication. The subject was touched upon in the previous discussion on the dying trajectory. Bakhtin focused on the literary analysis of narrative. Competing discourses grow out of narrative. Unlike previous RDT studies which sought to understand competing discourses synchronically, this study recognized the import of Wittenberg-Lyles's (2006; 2009) narrative approach to EOL communication in which EOL communication is understood as a journey. Although this study did not find the progression of the acceptance of death advocated by Wittenberg-Lyles, it did find narrative development of competing discourses.

RDT studies have focused on the synchronic aspects of competing discourses. This does not mean that RDT studies ignore the sources of various discourses. Toller $(2005,2008)$, Toller and Braithwaite (2009) and Baxter et al. (2002) do not address how competing discourses change over time. This study proposes that they do change over time, at least for PCGs of the terminally ill. The cure-care discourse morphed into the prolong-end it discourse, and the open-hidden discourse found expression in the move on-don't move on discourse. This seems to suggest that all EOL competing discourses are not formed in a discursive vacuum but are developed from prior discourses. It would seem that EOL communication studies that use RDT could benefit from paying closer attention to situational changes such as the dying trajectory.

\section{$\underline{5.4 \text { Interdisciplinary Team Summary }}$}

Sandler, Balk, Jordan, Kennedy, Nadeau, and Shapiro (2005) wrote for the Bridging Work Group of the Center for the Advancement of Health that "Many practitioners regard research as holding little relevance for their work, and many researchers believe that clinical practice has little to contribute to the scientific study of bereavement" (p. 93). The quotation describes the current state of EOL practice and research. This section attempts to bridge the gap. The following discussion is written with the practitioner in view. 
The hospice philosophy consists of three points: the physical, the non-physical, and education. Like a three-legged stool, the absence of any one of the legs will cause the stool to collapse. These three points provide the foundation for how hospice cares and supports the patient and family during the time of approaching death.

First, hospice communicates to the patient and family by the medical voice. The medical voice explains pain control and the use of medicine. It involves the nurse and doctor of the hospice team communicating with the PCG and the supportive social network in regards to the physical aspects of the dying process. The second leg of the stool is the life voice. This usually is communicated through the hospice's social worker and chaplain. This voice cares for and supports the patient and family by helping them to become engaged with the dying process, including the importance of social networks and spiritual issues. The study suggests that medical and life voices are very much intertwined. The third leg of the stool is educational; the hospice team is continually educating patients and families in regards to the hospice philosophy of the dying process.

The make-up for most interdisciplinary teams (IDT) in Texas includes medical director (MD), nurse, social worker, and chaplain. The team also includes medical aides but they usually do not attend IDT meetings. The IDT is required by law to meet every fourteen days. During the IDT meeting the team reviews all patients under the care of the hospice with each discipline contributing its perspective when appropriate. The following are themes from the study I believe to be salient points for the IDT.

First, I think it is critical that all members of the hospice team be aware that the dying trajectory of chronic illness to a large degree affects stress levels within the family. The trajectory changes the conversations within the family. The dying trajectory might affect the level of pain medicine. Crisis moments may cause the family to seek help from their social network, the medical community, or government agencies that could relieve emotional or financial stress. The hospice team is very familiar with the dying trajectory phenomena, but not with how the 
patient, PCG, and family communication and behavior changes with each downward slide. It is normally during these low points that patients are brought up for protracted discussion in the IDT meeting. It is at the times of medical crisis that the IDT should remind the family of the Do Not Resuscitate order, and that they should not call 911 but rather the hospice. The team should be aware that the PCG might be beginning to voice the 'end it' discourse and might ask permission from the hospice team to do so.

Second, the death prayer is not the same as the family saying goodbye to the patient. Hospice teams are trained to encourage the family to verbally say goodbye to the patient and to encourage the patient to 'let go.' But also, more behind the scenes, there is often the death prayer that is not talked about. The hospice team should be aware that the PCG struggles with the physical suffering of the patient and a death prayer is something not to be discouraged. The social worker and chaplain should be aware that the study found that the death prayer was almost universally uttered and almost always caused guilt. The hospice should express support for the PCG's end it discourse but should also be sensitized to the fact that it could swiftly switch back to a prolong it discourse.

Third, a number of the PCGs said that they did not verbalize acknowledgment of the terminal nature of the patients nor did they behave as if the patients were really terminal. The PCGs expressed a sense of frustration with their families and the hospice teams because at times they did not have the freedom to communicatively practice selective denial of the dying process in order to ease the stress that resulted from the patient's dying process. The hospice team needs to be sensitive to the fact that the PCG might be very aware of the situation, and may have accepted the coming death, but still needed to have the freedom to behave and express denial.

Fourth, most PCGs did not remember any of the hospice materials provided except one. Although almost a non-issue in this study of competing discourses, the frequent and extensive use of the death signs pamphlets and handouts was a surprise. After reflecting with 
other practitioners on why this was the case, it became obvious. The death signs document has both social and psychological import to the PCG and family. The death signs document was an educational tool for the family to understand that death was close. It enabled the family to prepare. Knowledge of the death signs gave the families permission to shift the subject of conversation from talking about the patients living longer to the beginnings of planning for the patients' deaths. The death signs literature was a dose of reality. The death signs declared the truth whereas people beat around the bush. It might be helpful to unobtrusively provide the death signs literature in the hospice packet and then, at a later time when the signs are present, to refer the family to the document and let them process it. The death signs literature can also be used as a mediating tool for discussing with the family the reality of the approaching death of the patient. Several of the PCGs in the study did mention that the nurse engaged them about the approaching death by way of the death signs.

Fifth, the open-hidden discourse was not found in any of the hospice materials. The hospice materials reflected the hospice management's view of the major issues that the patient and PCG faced during their involvement with hospice. The dirtiness of the dying process and the unwillingness of the PCG to talk about it is a topic that the hospice should mention. The hospice team is familiar with the dying process and should have supporting literature to explain the dirtiness of the dying process .A lack of supportive literature on the open-hidden discourse by the hospice seems only to reinforce the hidden discourse.

\subsection{The Social-Economic Impact of EOL Communication}

This study suggests that the medicalization of death and the commercialization of hospice shape and are shaped by competing discourses. The two potentially most important social/economic developments that have influenced EOL communication and will continue to influence it within the hospice environment are the medicalization of death and the increasing commercialization of hospice. Ariès (1981) makes the point in his book on the history of death that for a thousand years humankind practiced a tamed death, where death was accepted as 
part of existence, it was familiar and its importance diminished. But with the coming of the enlightenment, the medical revolution of the 17th century, and the medicalization of the West, there resulted the process of turning away from social and divine responses to illness and toward "professional" medical interventions (Mortimer 2009). The medicalization of death has been criticized. Ariès (1976), for instance, claimed that in medicalization of death, the medical community has removed it from the cultural/personal realm and transformed it into a technical ordeal. He accused physicians of robbing individuals of their capacity to accept death as a meaningful aspect of life.

Today, most Americans will grow old and accumulate diseases for a long time before dying. Our health care system skillfully supplements our physical shortcomings by manufacturing the extension of one's life journey "in the valley of the shadow of death." Should we fear the success of modern medicine in transforming acute causes of death into chronic illnesses? How do we talk about this? No characters on evening television are cracking jokes while dealing with Grandma's wandering and incontinence. No movies show the physical and emotional adjustments needed to live with cystic fibrosis. A patient once told me, "No one in the Bible died like this." I think about Israel wandering in the desert for 40 years, a whole generation died. Desert wandering is not friendly to chronic illness. People find little direction when they look to our ancient texts for comfort and guidance on how to live while tottering on a tightrope of serious illness and frailty, propped up by modern medicine.

The PCGs expressed a fuzzy understanding of the difference between cure and care treatments. As mentioned previously, De Haes and Koedoot (2003) found that $40 \%$ of breast cancer patients undergoing chemotherapy would be willing to accept chemotherapy even if it had no clinical benefit at all, with zero gain in survival rate. Davis, Clarke, and Hopkins (1996) found patients with a malignant brain tumor would still choose to receive radiation to the brain knowing that it had no effect on survival. These studies demonstrate that patients and their families are comfortable pursuing curative treatments when a cure is not possible. Carpentier 
and Brussel (2012) believe that the key behind today's cure discourse is the element of control brought by medical science. Culturally we believe that humanity is not helpless in the face of death. The modern discourse says death must be accepted as a part of our existence, but not as something about which nothing can be done. This sort of behavior is a social construction that reflects the power of the curative discourse within American society. Culturally, we fight illness and death. Because of the strong belief in medical advancement, death is regarded as an extreme example of illness. The family encounters conflict when the stopping of curative treatment is seen as an act of killing.

Many people believe that hospice care hastens death. When a patient enters hospice care all treatment of the illness ends. Most people assume this will cause death to come quicker. Some of the PCGs expressed concern over the use of morphine by the hospice to hasten the death of the patient, some welcomed it, and others opposed it until the very end. The use of morphine is considered by many to have two effects on the patient. First, it sedates and lessens the pain in terminally ill patients and second, it shortens the patient's life (Fohr, 1998). This is referred to as the double effect of pain medication. Ethically the argument is worded that death is hastened slightly as a 'foreseen but unintentional' by-product of the drugs administered. A key to the debate is whether such a practice amounts to 'slow euthanasia,' or should it rather be seen as part of the physician's responsibility not to abandon patients and their families to unrelieved suffering during dying (Seymour, Bellamy, Gott, Ahmedzai, \& Clark, 2002).

Broadly speaking, this discursive struggle is between the prolong it and end it discourses. These discourses are rooted in two ideologies, a very conflicted, hastened, painless death ideology and a prolong it, sanctity of life ideology. It is hard to change from "for better or for worse, in sickness and in health; from this day forward until death do us part" to the abandonment of that commitment due to the physical suffering of the patient. Our society has no clear discursive boundaries as to when someone's quality of life is so far compromised that the patient's family feels that it is appropriate to express an end it discourse. 
The medicalization of death is certainly a part of the discursive formation of most of the competing discourses found in this study. It is strange, but true, that terminal patients seemed to live longer only when they stopped trying to live longer. For example, a study published in the New England Journal of Medicine (Temel et al., 2010) found that compared with patients receiving standard care, patients receiving early hospice care had less aggressive care at the end of life but longer survival. These types of studies have not gone unnoticed by the promotional arm of hospice organizations. The recent commercialization of hospice has not gone unnoticed by the medical community. Woolhandler and Himmelstein (2004) wrote:

Investor-owned care embodies a new value system that severs the community roots and Samaritan traditions of hospitals, makes physicians and nurses into instruments of investors, and views patients as commodities. (p. 1814)

They also add that it has been found that investor-owned hospices provide less care to the dying than do non-for-profit facilities. This claim has recently been challenged and there is a call for further research on this issue (Perry, \& Stone, 2011). It is hard to say if economics will foster a corruption of the original hospice philosophy of care and support of a dying patient.

This study suggests that the cure discourse dominates pre-hospice communication and morphs into a prolong it discourse during hospice. The difference is the recognition that the patient has a fatal illness. It is tempting for the hospice to engage in the prolong it discourse in order to promote its services. A Google search of the expression "hospice extends life" shows hundreds of hospices informing potential patients of the recent research which concludes that hospice care prolongs the patient's life. The emphasis on the prolong it discourse is a potential subversion of the hospice philosophy of caring and supporting the patient in a pain free environment while maintaining mental awareness for as long as possible. This is critical for EOL communication within the hospice. If patients are confused by the mission of the hospice, which this study seems to have found, then it is that much more critical for the hospice to educate the 
PCG and patient on the care and support aspects of the hospice as opposed to the selling factor of the prolong it discourse.

The medicalization of death and the commercialization of hospice shape and are shaped by the competing discourses found in this study. But the most powerful molder of when and how EOL communication happens is the dying trajectory of chronic illness. The modern dying trajectory is the result of the medicalization of death and it can reasonably be said that it dictates the economics of Medicare costs.

\section{$\underline{5.6 \text { Limitations of the Study }}$}

The major drawback of this study is that access to the participants was filtered and limited by the hospice management. The PCGs interviewed for this study were purposely selected based on their participation in hospice services. All participants used the services of Hospice Plus of Dallas. Hospice Plus of Dallas is a large organization that services more than 1000 current patients, 2000 PCGs in bereavement, and 4000 PCGs in post-bereavement. Hospice management struggled with obtaining participants that met the four criteria of this study. This was due to recent company merges, software glitches, and poor record keeping. The participant names were acquired through memory and the personal records of the bereavement coordinator and chaplains. The study did not have direct access to the whole population but was dependent upon the recommendations of the chaplains. It is not known how consistent the filtering process was between the various chaplains, but it is believed that this in itself is not detrimental to the findings of the study.

\subsection{Future Research}

There is a plethora of potential directions for future studies of EOL communication through the use of RDT within the palliative environment and a great potential for the theoretical development of RDT.

The impetus for this study was the observation that hospice practices in the area of communication are anecdotal and not evidence based. For example, the bereavement materials 
provided by the hospice to PCGs are usually used because particular individuals on the hospice team have in the past found them useful. Hospices do not as a practice ask their clients what was beneficial. Some hospices circulate evaluation surveys, but usually these are arbitrarily put together. A desire to design a quantitative survey about EOL communication within the hospice led to the study of EOL communication using the qualitative approach. Methodologically, I chose the qualitative approach in order to determine what questions to ask. The alternative was to construct a quantitative survey based on a combination of previous surveys, hospice team suggestions, and personal experience. I struggled with that alternative. If the hospice does not know what sort of questions to ask, how would a researcher? I view this study as a foundation for understanding communication issues for those in hospice. I believe the next step would be an informed quantitative study.

There are three areas of future study that would be profitable for a more comprehensive understanding of EOL communication. First is a study that focuses on competing discourses at the EOL from the perspective of the hospice team. Second is a study that would involve the physician. The economical engines of any hospice are doctor referrals of patients to the hospice. The literature indicates that usually hospice referrals are late in the life of the patient (Ragan et al. 2008). What competing discourses do doctors encounter? Is there a difference between doctors who refer patients to hospice and doctors who do not? Third is a cultural discursive study contrasting cancer centers and hospices in order to bring into focus the discursive struggle of how we as a society frame death. This would be a timely study due to the economic issue of the use of expensive EOL care found in the cancer centers and comparatively cheaper EOL care of the hospice.

I also believe RDT is a natural fit for the study of communication within the palliative field. From a palliative viewpoint I believe RDT needs to move forward to a more purely interpersonal and cultural communication theory. It needs to cut its many roots enmeshed with its former focus on labeling competing discourse in terms of intrapersonal communication. Many 
of the competing discourses that have been used in the past palliative studies have been used in a cookie cutter manner. This would result in a change in future nomenclature through the use of terms that are voiced rather than thought.

\section{$\underline{5.8 \text { Afterword }}$}

I would like to end with a narrative. It is important to hear the flow of the voice of a PCG. It is beyond description. Instead of hearing the partial voices of 20 PCGs broken down into thematic categories, dissected, and analyzed, I have included as part of my thesis Jen's account of the last day of her husband's life. Her story is not unusual. Her husband died of cancer at the age of 64 . Both of her children are in their 20s. I interviewed Jen five months after the death of her husband.

The day that he died it was...it was...I kind of have to explain the night before. The hospice nurse was here. And he got to the point that he was in bed. He would kind of had spells when he would wake up. And kind of say a few things and then he would sleep. So I told the nurse because she was in the bedroom with him. I said to her "Anytime he comes to, come and get me." And it was Christmas time, this was Dec. the 11th. My husband loved Christmas. He would go all out, he would want lights everywhere. And we put a CD player in there and we just played Christmas music. And so the Christmas music was going. So he had a little accident, and he was such a proud person. He never wanted the hospice people to take him to the bathroom. So my son and I kind of got him into the bathroom and kind of let him finish what he was doing. I cleaned up the bed and put him back in. And he looked at me, and I said "Are you comfortable?" And he said "I am going home." I said...in my mind...you hear all these...you know how people say things. And I repeated it because I was fluffing pillows and said "Are you comfortable" And he said 'I am going home." At that point when he repeated it I just feel apart. I ran and got my daughter and 
I said...because to me it was like he was saying "I am leaving you." So I ran and got my daughter and said "He is talking about going home." And she said "Mom clam down, calm down, he is on a lot of medication." "He is just probably talking." I knew my husband didn't talk that way. He never, never ever talked that way. And I knew then and I said "he is telling me he is leaving." So ah...the nurse...ah...said "I think you should sleep in another room," he was gasping for breath, "because you probably won't be able to sleep." And I was just at the point that I could not leave him. I just wanted to be with him. So I told her, "No, if it is difficult for you, you leave." I said "I will be in here with him; I am going to sleep in bed with him." So that night I didn't go to bed. I didn't go to sleep until around 5 o'clock. I was just crying, crying and crying. I knew this was going to be our last night. And I would take his hands, and I would constantly put my hand on my face so he could feel my tears. And I just told him "it is ok." Because the hospice, well Wendy to be more specific said "You got to let him know it is ok to go" because they will try to stay. I kept telling him you know "We had 36 years, you did good. You raised beautiful kids and it is ok." That was Saturday and I kind of dozed off. I am Catholic, and I got up to go to mass. And the hospice nurse was sitting in one of the chairs and I told her I was going to mass, mass is at 8 and I will be back at 9 . And she said 'Tell him where you are going." So I leaned over and I kissed him and I said "I am going to mass." And I am going to pray that when I come back you are sitting up in bed laughing." My husband was one of those practical jokers. He loved to pull stuff on us and the kids. And I said "when I come back you are going to be sitting up and saying I gotcha." And when I went to mass and came back, the hospice nurse met me at the door and said "He is starting to let go if you want to come in." And I came in the room and I said "it's ok." And we called a few people. When she said he 
is starting to let go I said "let's call close friends so in that way they could say goodbye." So I really appreciate her giving me that insight because it meant the world. People even now say "I just thank you for calling us and letting us share that." So he got to the point that it was so difficult to see him struggle for, you know, to breath, that I told the nurse, I said "I don't want to watch him anymore." Because she started to show me how the nails started to change color. How the skin starts to get real slack around the face. I think it was her way of saying you know, he is letting go. He is not going to be in pain, he is not going to hurt. He is not going to struggle much longer because you can see the signs. I think she was reassuring us because it was so difficult to see him gasp for that last breath. So we just kind of... at that point...I started to feel better. I said “God take him, take him, just don’t let him keep laying here struggling, just take him." So I told her I don't want to see him anymore. This isn't him. I think his spirit is already gone and all that is left is this shell. I told her I said ah... "after, after it's over just come and get me and let me look at him one more time." They took care of everything; we didn't want to see him being taken out. We just couldn't. So we all just got in a room and stated to talk about some of the crazy stuff he would do and just tried to deal with the fact that he was gone, and that it was over. And you feel relief because you feel like those last few hours were so hard on the body but we all felt that he left long before. They came in and told us, they saved the pillow case for me that his head was laying on. And I still have it.

"There is a sacredness in tears. They are not the mark of weakness, but of power. They speak more eloquently than ten thousand tongues. They are messengers of overwhelming grief...and unspeakable love."-

Washington Irving 
APPENDIX A

CODES FOR RQ1 
Appendix A

Competing end of life discourses experienced by primary caregivers

\begin{tabular}{|c|c|c|c|}
\hline Category name & Defined & Sub Themes & Exemplar \\
\hline $\begin{array}{l}\text { Cure-Care } \\
\text { competing } \\
\text { discourse }\end{array}$ & $\begin{array}{l}\text { Cure: Voices the } \\
\text { curative path of } \\
\text { treatment } \\
\text { Care: Voices the } \\
\text { comfort and support } \\
\text { path of palliative } \\
\text { care }\end{array}$ & $\begin{array}{l}\text { Medical community's } \\
\text { emphasis on the } \\
\text { curative path } \\
\text { PCG accepts the } \\
\text { palliative path over cure } \\
\text { The promise pack } \\
\text { between patient and } \\
\text { PCG not to hospitalize }\end{array}$ & $\begin{array}{l}\text { "They wanted to do radiation and, you know, do different } \\
\text { treatment...it was very difficult to explain what it meant to do } \\
\text { medical care that was for comfort versus healing. Even } \\
\text { though they knew that it wasn't going to be healed." } \\
\text { "He was an outdoor guy. Just being in the house was hard for } \\
\text { him. Not being able to be out and doing stuff. So it was his } \\
\text { choice. Who am I to say, "Oh no you are dying and you are } \\
\text { doing it the wrong way." To me I was a facilitator." }\end{array}$ \\
\hline $\begin{array}{l}\text { Prolong it-end it } \\
\text { competing } \\
\text { discourse }\end{array}$ & $\begin{array}{l}\text { Prolong it: } \\
\text { Expressions of } \\
\text { desire for the } \\
\text { extension of the } \\
\text { patient's life } \\
\text { End it: Expressions } \\
\text { of desire for the } \\
\text { death of the patient }\end{array}$ & $\begin{array}{l}\text { No hope for a cure } \\
\text { Conflicted PCG due to } \\
\text { suffering of the patient }\end{array}$ & $\begin{array}{l}\text { "I was trying to prolong it as long as much as possible and to } \\
\text { keep him as comfortable as possible and to keep it, his life as } \\
\text { good as possible to where he was getting something out of it } \\
\text { instead of just being alive." } \\
\text { "I wanted to wake up and she not be breathing. I just, you } \\
\text { know...I felt like she was suffering, and she wasn't suffering } \\
\text { in pain or anything like that, but it was like how long must this } \\
\text { go on?" }\end{array}$ \\
\hline $\begin{array}{l}\text { Open-hidden } \\
\text { competing } \\
\text { discourse }\end{array}$ & $\begin{array}{l}\text { The PCG publicly } \\
\text { communicates, or } \\
\text { not, the patient's } \\
\text { dying process }\end{array}$ & & $\begin{array}{l}\text { "They didn't see that. Even when they spent the night here, } \\
\text { we went behind closed doors to get him, you know, ready for } \\
\text { bed. He would sit here and entertain everybody and laugh } \\
\text { and he would have such a good time. And then when he got } \\
\text { ready to do all that, then you saw the state that he was in. I } \\
\text { did tell them that they didn't see everything. But unless you } \\
\text { are handling it, you don't' understand" }\end{array}$ \\
\hline
\end{tabular}




\begin{tabular}{|c|c|c|c|}
\hline Category name & Defined & Sub Themes & Exemplar \\
\hline $\begin{array}{l}\text { Move on-Don't } \\
\text { move on } \\
\text { competing } \\
\text { discourse }\end{array}$ & $\begin{array}{l}\text { Move on: The voice } \\
\text { that encourages the } \\
\text { PCG to stop grieving } \\
\text { Don't move on: the } \\
\text { voice that questions } \\
\text { why the PCG is not } \\
\text { grieving }\end{array}$ & Grief-relief & $\begin{array}{l}\text { "They don't want to talk about it. They say 'Mama, it's the } \\
\text { past, leave it in the past.' 'Why do you cry, it's almost two } \\
\text { years mama.' 'Let it be."' } \\
\text { "The only time I really cried was his birthday. No reason. I } \\
\text { kind of felt that people thought I should cry, but I didn't." }\end{array}$ \\
\hline Theodicy & $\begin{array}{l}\text { Theodicy: Why a } \\
\text { good God allows } \\
\text { human suffering }\end{array}$ & $\begin{array}{l}\text { The conflict between } \\
\text { doubt and faith } \\
\text { Questioning and } \\
\text { accepting }\end{array}$ & $\begin{array}{l}\text { "I take great comfort in the fact that God has given her the } \\
\text { greatest gifts he possess for any of us. But I still have } \\
\text { moments where I get a little ticked with Him for giving them to } \\
\text { her so early in her earthly life." } \\
\text { "Every Sunday I go to mass I am sitting there; I can never go } \\
\text { to mass without thinking about the day my husband died. Oh } \\
\text { yea, God and I have this conversation all the time. You got all } \\
\text { these bad people out here and you took such an important } \\
\text { part of our life, you know why? Why?" }\end{array}$ \\
\hline
\end{tabular}




\section{APPENDIX B}

CODES FOR RQ2 


\section{Appendix B}

How primary caregivers communicatively manage competing end of life discourse

\begin{tabular}{|c|c|c|}
\hline Category name & Sub Themes & Exemplar \\
\hline $\begin{array}{l}\text { Cure-Care } \\
\text { competing } \\
\text { discourse }\end{array}$ & $\begin{array}{l}\text { Encountering the active-passive medical } \\
\text { voice } \\
\text { Creating a family voice }\end{array}$ & $\begin{array}{l}\text { "I was trying to work with them (hospital) but it was a very difficult } \\
\text { situation. They wanted to do radiation...that was just not in our medical } \\
\text { plan. My doctor understood that if there was anything to be done it was to } \\
\text { make her life better while she was here. You know, not anything radical, } \\
\text { and even getting (my doctor) to talk to the doctors in (the hospital), that } \\
\text { communication didn't work." } \\
\text { "The (family) question was, do we fight this...or do we draw a line } \\
\text { somewhere? (The family) knew about her diagnosis. and for those of us in } \\
\text { the family who do a lot of research checked on the internet and that kind } \\
\text { of stuff, we had done that, Web-MD and those kinds of things. And I had } \\
\text { sent information about her MRI and all of this kind of stuff. So we had the } \\
\text { medical information, we had done some research. The cancer doctor had } \\
\text { talked to us about our options. So we had clearly delineated options. And } \\
\text { we talked through them. }\end{array}$ \\
\hline $\begin{array}{l}\text { Prolong it-end it } \\
\text { competing } \\
\text { discourse }\end{array}$ & $\begin{array}{l}\text { Carnivalesque, the use of black humor } \\
\text { The PCG prayer for the death of the } \\
\text { patient }\end{array}$ & $\begin{array}{l}\text { "You know... ah...one day she made the comment that...she said ah...she } \\
\text { said that 'I am too sick to die.' You know we joked about it. We knew that it } \\
\text { was going to happen." } \\
\text { "When I went on hospice I mean I gave up hope that he had years to live. } \\
\text { But I don't think I gave up hope of one more day. Until... well no, I take } \\
\text { that back, until he got to the point when he couldn't wake up without being } \\
\text { in acute pain. That is when I prayed for him to die" }\end{array}$ \\
\hline $\begin{array}{l}\text { Open-hidden } \\
\text { competing } \\
\text { discourse }\end{array}$ & $\begin{array}{l}\text { PCG selective disclosure of dying } \\
\text { process }\end{array}$ & $\begin{array}{l}\text { "'This is my mother man and you are taking care of her like that.' And I } \\
\text { said 'Yea, of course.' Until they came and experience what was going on } \\
\text { here did they really understand. Sometime you can talk to people about } \\
\text { something but until they are right there with it, they don't understand it." }\end{array}$ \\
\hline
\end{tabular}




\begin{tabular}{|l|l|l|}
\hline Category name & Sub Themes & Exemplar \\
\hline $\begin{array}{l}\text { Move on-Don't } \\
\text { move on } \\
\text { competing } \\
\text { discourse }\end{array}$ & Freedom to grieve & $\begin{array}{l}\text { "We clung together. We were like for two weeks there, we just cried and } \\
\text { cried and walked around in kind of a cloud. You are like, you just, and } \\
\text { your whole life changes at that moment. Everything changes. We didn't } \\
\text { have any appetite, there was not schedule, there was no, we would just } \\
\text { walk from one couch to another or one chair to another." } \\
\text { Well I am not stupid. I mean I know when to shut up (laugh). But the } \\
\text { people I deal with on a regular basis know me and so they can tell if there } \\
\text { is something on my mind. And of course over this last year I had gone } \\
\text { through a lot of different processes to where I got to the point where I } \\
\text { don't talk about it as much. }\end{array}$ \\
\hline Theodicy & Controlling expressions of grief & $\begin{array}{l}\text { "Yea, and sometimes I think God uses those things to make you aware of, } \\
\text { well "ok let go," and "I am in control here." } \\
\text { "But, you know he had a good life, it was not what I wanted, but it only } \\
\text { proves that I am not God and I don't get everything I want." } \\
\text { There are people who cannot deal with death at all. It is like this is the } \\
\text { end, but because it wasn't the end we realized that it was a transitional } \\
\text { period, for mom and that it was something that, you know, that God was } \\
\text { taking us through, and we see her again, and that was not something that } \\
\text { was a hard thing. }\end{array}$ \\
\hline Suffering beyond human understanding
\end{tabular}


APPENDIX C

DYING TRAJECTORY 


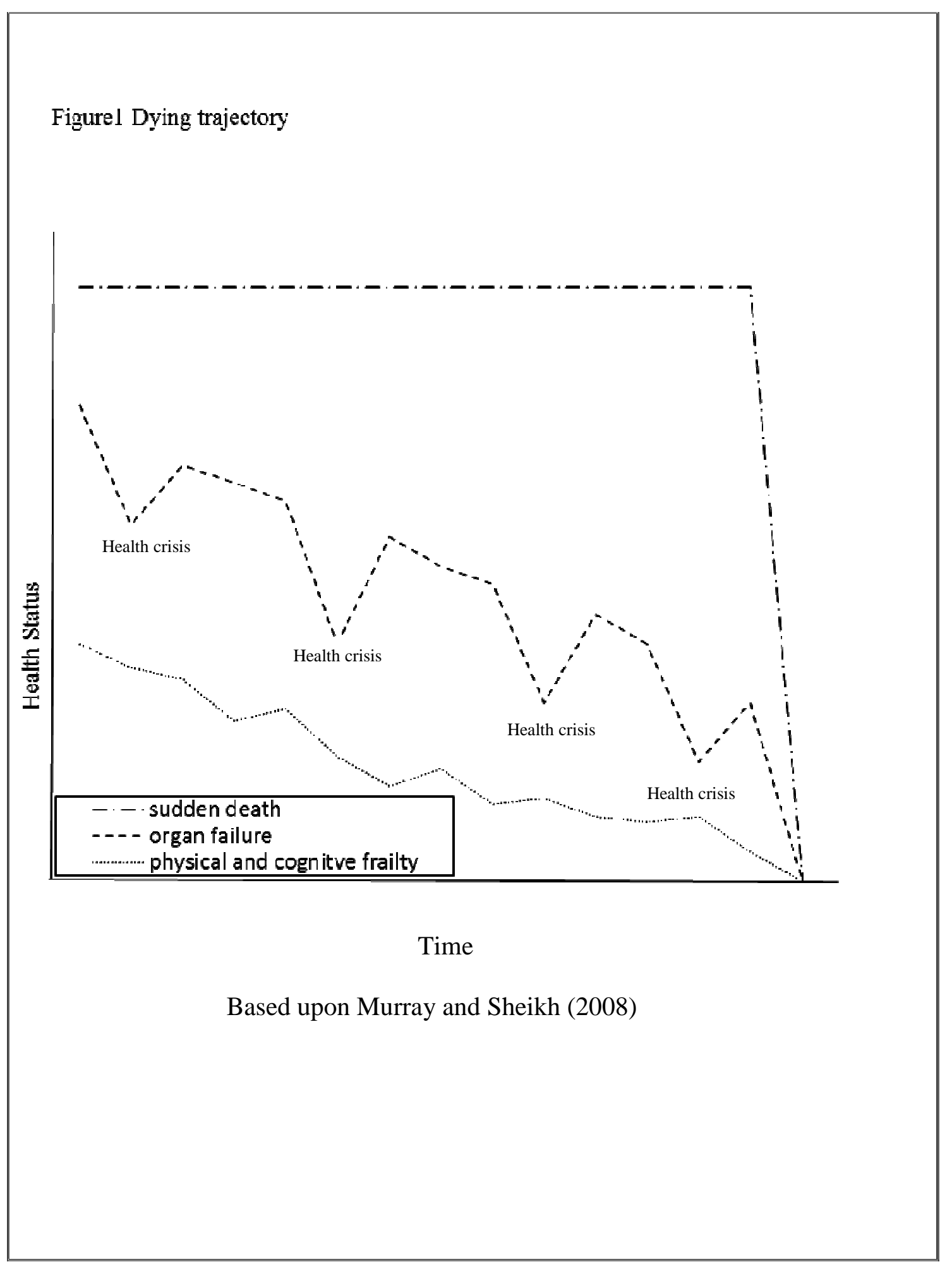


APPENDIX D

INTERVIEW GUIDE 


\section{INTERVIEW GUIDE}

1-What communication challenges did you face in regards to the situation involving before hospice entered the picture?

2-How did you find out about hospice?

3-How would you describe your communication with the family about putting into hospice? (friends, others? Home/facility issue)

4-How would you describe the communication about signing the DNR? (Can you describe any communication that was challenging?)

5-What reading materials from hospice were helpful---hard to understand?

6-How would you describe the communication within the family about coming death? (with hospice team? with the doctor?) (Can you describe any communication that was challenging?)

7-How would you describe the communication on the day died? (Can you describe any sort of communication that was challenging?)

8-What were some things people said or did that were helpful at the time of your loss? (not helpful at the time of your loss?)

9-How likely are you today to talk about your loss (grief)?

To whom do you communicate about your loss (grief) most often? (With whom would you not share?) Why?

10-What were the most challenging issues to talk about during this whole period of time? (are there now topics you avoid talking about with others?) 


\section{REFERENCES}

Ariès, P. (1976). Western attitudes towards death: From the middle ages to the present. London: John Hopkins University Press.

Ariès, P. (1981). The hour of our death. (H. Weaver, Trans.). New York: Vintage Books.

Armstrong, D. (1987). Silence and truth in death and dying. Social Science and Medicine, 24, $651-657$.

Babrow, A., \& Mattson, M. (2003). Theorizing about health communication. In T. Thompson, A. Dorsey, K. Miller \& R. Parrott (Eds.), Handbook of health communication (pp. 35-61). London: Lawrence Erlbaum.

Bachner, Y., \& Carmel, S. (2009). Open communication between caregivers and terminally ill cancer patients: The role of caregivers' characteristics and situational variables. Health Communication, 24, 524-531.

Bakhtin, M. (1973). Problems of Dostoevsky's poetics. America: Ardis.

Bakhtin, M. (1981). The dialogic imagination: Four essays. Austin: University of Texas Press.

Bakhtin, M. (1986). Speech genres \& other late essays. Austin: University of Texas Press.

Baxter, L. (1988). A dialectical perspective on communication strategies in relationship development. In S. Duck (Ed.), Handbook of personal relationships: Theory, research and interventions. New York: Wiley and Sons.

Baxter, L. (1994). A dialogic approach to relationship maintenance. In D. Canary \& L. Stafford (Eds.), Communication and Relational Maintenance (pp. 233-254) New York: Academic Press.

Baxter, L. (2004). A tale of two voices: Relational dialectics theory. The Journal of Family Communication, 4, 181-192. 
Baxter, L. (2006). Relational dialectics theory: Multivocal dialogues of family communication. In D. Braithwaite \& L. Baxter (Eds.), Engaging theories in family communication: Multiple perspectives (pp. 67-89) Thousand Oaks, CA: Sage Publications.

Baxter, L. (2007). Problematizing the problem in communication: a dialogic perspective. Communication Monographs, 74, 118-124.

Baxter, L., \& Braithwaite, D. (2006). Social dialectics: The contradictions of relating. In B. Whaley, B. Bryan \& W. Samter (Eds.), Explaining Communication: Contemporary theories and exemplars (pp. 275-292) NJ: Erlbaum.

Baxter, L., \& Braithwaite, D. (2010). Relational dialectics theory, applied. In S. W. Smith \& S. R. Wilson (Eds.), New directions in interpersonal communication research. (pp. 48-66) Thousand Oaks, CA: Sage Publications.

Baxter, L., Braithwaite, D., Golish, T., \& Olson, L. (2002). Contradictions of interactions for wives of elderly husbands with adult dementia. Journal of Applied Communication Research, 30, 1-26.

Baxter, L., \& Montgomery, B. (1996). Relating: Dialogues and dialectics. New York: Guilford Press.

Baxter, L., \& Montgomery, B. (1998). A guide to dialectical approaches to studying personal relationships. In B. M. Montgomery \& L. A. Baxter (Eds.), Dialectical approaches to studying personal relationships (pp. 1-16) New Jersey: Erlbaum.

Benore, E., \& Park, C. (2004). Death-specific religious beliefs and bereavement: Belief in an afterlife and continued attachment. The International Journal for the Psychology of Religion, 14, 1-22.

Berger, P. \& Luckmann, T. (1966). The social construction of reality: A treatise of the sociology of knowledge. New York: Doubleday.

Brashers, D., Neidig, J., \& Goldsmith, D. (2004). Social support and the management of uncertainty for people living with HIV and AIDS. Health Communication, 16, 305-331. 
Brueggemann, W. (1997). Theology in the Old Testament: Testimony, dispute, advocacy. Minneapolis: Fortress Press.

Buck, J. (2009). 'I am willing to take the risk': politics, policy and the translation of the hospice ideal. Journal of Clinical Nursing, 18, 2700-2709.

Callahan, D. (1993). The troubled dream of life: Living with mortality. New York: Simon \& Schuster.

Caplan, S., Haslett, B., \& Burleson, B. (2005). Telling it like it is: The adaptive function of narratives in coping with loss in later life. Health Communication, 17, 233-251.

Carpentier, N., \& Brussel, L. (2012). On the contingency of death: A discourse-theoretical perspective on the construction of death. Critical Discourse Studies, 9, 99-115.

Caughlin, J., \& Petronio, S. (2004). Privacy in families. In A. Vangelisti (Ed.), Handbook of family communication (pp. 379-412). London: Lawrence Erlbaum.

Chang, V. \& Sambamoorthi, N. (2009). Decision making in palliative care. In J. Werth \& D. Blevins (Eds.), Decision making near the end of life: Issues, developments, and future directions (pp.143-168). New York: Routledge.

Cherlin, E., Fried, T., Prigerson, H., Schulman-Green, D., Johnson-Hurzeler, R., \& Bradley, H. (2005). Communication between physicians and family caregivers about care at the end of life: When do discussions occur and what is said? Journal of Palliative Medicine, 8, $1176-1185$.

Christakis, N., \& Iwashyna, T. (2003). The health impact of health care on families: A matched cohort study of hospice use by decedents and mortality outcomes in surviving, widowed spouses. Social Science and Medicine, 57, 465-475.

Connor, S. (2007). Development of hospice and palliative care in the United States. Omega: Journal of Death and Dying, 56, 89-99.

Connor, S. (2009). Hospice and palliative care. New York: Routledge. 
Connor, S., Pyenson, B., Fitch, K., Spence, C., \& Iwasaki, K. ( 2007). Comparing hospice and nonhospice patient survival among patients who die within a three-year window. Journal of Pain and Symptom Management, 33, 238-246.

Considine, J, Miller, K. (2010). The dialectics of care: Communicative choices at the end of life. Health Communication, 25, 165-174.

Cook, J., \& Wimberley, D. (1983). If I should die before I wake: Religious commitment and adjustment to the death of a child. Journal for the Scientific Study of Religion, 22, 222238.

Craig, R. (1999). Communication Theory as a Field. Communication Theory, 9, 119-161.

Davis, E., Clarke, C., \& Hopkins, A. (1996). Malignant cerebal glioma: Perspectives of patients and relatives on the value of radiotherapy. British Medical Journal, 331, 1512-1516.

De Haes, H. \& Koedoot, N. (2003). Patients centered decision-making in palliative cancer treatment: A world of paradoxes. Patient Education Counseling, 50, 43-49.

Em, G. (2009). A first look at communication theory. New York: McGraw Hill.

Excel Publishing (2002). Journey's end: characteristics of the dying process. Kansas: Excel Publishing Services.

Field, M. (2009). How people die in the United States. In J. Werth, \& D. Blevins (Eds.) Decision Making Near the End of Life: Issues, Developments, and Future Directions. (pp. 57-65) New York: Routledge.

Fohr, S. (1998). The double effect of pain medicine: Separating myth from reality. Journal of Palliative Medicine, 1, 315-328.

Foucault, M. (1970). The order of things: An archaeology of the human sciences. New York: Vintage Books.

Foucault, M. (1972). The archaeology of knowledge and the discourse of language. New York: Pantheon Books. 
Funk, L., Stajduhar, K., Toye, C., Aoun, S., Grande, G., \& Todd, C. (2010). Part 2: Home-base family caregiving at the end of life: a comprehensive review of published qualitative research (1998-2008). Palliative Medicine, 24, 594-607.

Gawande, A. (2010, August). Letting go: What should medicine do when it can't save your life? The New Yorker. Retrieved from http://www.newyorker.com/reporting/2010/08/02/100802fa fact gawande

Gentry, J., Kennedy, P., Paul, K., \& Hill, R. (1994). The vulnerability of those grieving the death of a loved one: Implications for public policy. Journal of Public Policy \& Marketing, 13, 128-142.

Gillotti, C., Thompson, T., McNeilis, K. (2002). Communicative competence in the delivery of bad news. Social Science \& Medicine, 54, 1011-1023.

Glaser, B. \& Strauss, A. (1965a). The constant comparative method of qualitative analysis. Social Problems 12, 436-445.

Glaser, B. \& Strauss, A. (1965b). Awareness of dying. New York: Aldine Publishing Company. Glaser, B.,\& Strauss, A. (1968). Time for dying. New York: Aldine Publishing Company.

Goffman, E. (1959). The presentation of self in everyday life. London: Penguin Books.

Hagman, G. (2002). Beyond decathexis: Toward a new psychoanalytic understanding of treatment or mourning. In R. Neimeyer (ED.), Meaning reconstruction \& the experience of loss (pp. 13-31). Washington, DC: American Psychological Association.

Harding, R. Higginson, I. (2001). Working with ambivalence: Informal caregivers of patients at the end of life. Support Care Cancer, 9, 642-645.

Herbert, R., Prigerson, H., Schulz, R., \& Arnold, R. (2006). Preparing caregivers for the death of a loved one: A theoretical framework and suggestions for future research. Journal of Palliative Medicine, 9, 1164-1171.

Holquist, M. (1990). Dialogism: Bakhtin and his world. London: Routledge." 
Hooghe, A., Neimeyer, R., \& Rober, P. (2011). The complexity of couple communication in bereavement: An illustrative case study. Death Studies, 35, 905-924.

Hospice Plus. (2012a, May). About Hospice Plus. Retrieved from http://hospiceplus.net/AboutHospicePlus.aspx

Hospice Plus. (2012b, May). Frequently asked questions. Retrieved from http://hospiceplus.net/FAQ.aspx

Hsieh, H., \& Shannon, S., (2005). Three approaches to qualitative content analysis. Qualitative Health Research, 15, 1277-1287.

Imhof, A. (1985). "The Fielding H. Garrison lecture": From the old mortality pattern to the new: Implications of a radical change from the sixteenth to the twentieth century. Bulletin of the History of Medicine, 59, 1-29.

James, J. \& Friedman, R. (1998). The grief recovery handbook: The action program for moving beyond death, divorce, and other losses. New York: Harper Collins Publisher.

Jennings, B., Ryndes, T., D'Onofrio, C., \& Baily, M. (2003). Access to hospice care: Expanding boundaries, overcoming barriers. Hastings Center report Special Supplement, 33, S3S59.

Jennings, B., Kaebnick, G., \& Murray, T. (2005). Improving End of Life Care: Why Has It Been So Difficult? (Special Report 35). New York: Hastings Center.

Kant, I. (1965). Critique of pure reason. (N. Smith, Trans.). New York: St. Martin's Press.

Karpel, M. (1980). Family secrets: Implications for research and therapy. Family Process, 19, 295-306

Kleespies, P., Miller, P., \& Preston, T. (2009). End-of-life choices. In J. Werth \& D, Blevins (Eds.). Decision making near the end of life: Issues, developments, and future directions (pp.119-139). New York: Routledge.

King, D., \& Quill, T. (2006). Working with families in palliative care: One size does not fit all. Journal of Palliative Medicine, 9, 704-715. 
Kubler-Ross, E. (1969). On death and dying. New York: Routledge.

Larson, D., \& Tobin, D. (2000). End-of-life conversations: Evolving practice and theory. Journal of the American Medical Association, 284, 1573-1578.

Lindell, H., \& Scott, R. (1996). A Greek-English lexicon: Ninth edition with a revised supplement. London: Oxford University Press.

Lindemann E. (1944). Symptomatology and management of acute grief. American Journal of Psychiatry, 151, 155-160.

Lindlof, T., \& Taylor, B. (2011). Qualitative communication research methods. Thousand Oaks CA: Sage Publications.

Lowery, S. (2008). Letting go before a death: a concept analysis. Journal of Advanced Nursing, 63, 208-215.

Maciejewski, P., Zhang, B., Block, S., \& Prigerson, H. (2007). An empirical examination of the stage theory of grief. Journal of the American Medical Association, 297, 716-723.

Main, J. (2002). Management of relatives of patients who are dying. Journal of Clinical Nursing, $11,794-801$.

Martin, J., \& White, P. (2005). The language of evaluation: Appraisal in English. New York: Palgrave Macmillan.

Matsuyama, R., Reddy, S., \& Smith, T. (2006). Why do patients choose chemotherapy near the end of life? A review of the perspective of those facing death from cancer. Journal of Clinical Oncology, 24, 3490-3496.

Mauk, J. (2003). Communication at the end of life. In W. Forman, J. Kitzes, R. Anderson \& D. Sheehan (Eds.), Hospice and palliative care (pp. 67-85). Sudbury MA: Jones and Barlett Publishers.

McCracken, G. (1988). The long interview. Newbury Park CA: Sage Publications.

McDaniel, J., \& Clark, P. (2009). The new adult orphan: Issues and considerations for care providers. Journal of Gerontological Nursing, 35, 44-49. 
Mick, K., Medvene, J., \& Strunk, J. (2003). Surrogate decision making at end of life: Sources of burden and relief. Journal of Loss and Trauma, 8, 149-167.

Miller, S., Mor, V., Wu, N., Gozalo, P., \& Lapane, K. (2002). Does receipt of hospice care in nursing homes improve the management of pain at the end of life? Journal of the American Geriatrics Society, 50, 507-515.

Mishler, E. (1981). Social contexts of health, illness, and patient care. Cambridge: Cambridge University Press.

Mishler, E. (1984). The discourse of medicine: Dialectics of Medical Interviews. Norwood New Jersey: Ablex Publishing Corporation.

Morson, G., \& Emerson, C. (1990). Mikhail Bakhtin: Creation of a prosaics. Stanford CA: Stanford University Press.

Mortimer, I. (2009). The dying and the doctors: The medical revolution in seventeenth-century Woodbridge England: The Royal Historical Society.

Murray, C., Toth, K., \& Clinkinbeard, S. (2004). Death, dying and grief in families. In P. McKenry \& Price, S. (Eds.), Families and change: Coping with stressful events and transitions (pp. 75-101). Newbury Park CA: Sage Publications.

Murray, J. (2001). Loss as a universal concept: A review of the literature to identify common aspects of loss in diverse situations. Journal of Loss and Trauma, 6, 219-241.

Nadeau, J. (2001). Family construction of meaning. In R. Neimeyer (Ed.), Meaning reconstruction \& the experience of loss (pp. 95-111). Washington DC: American Psychological Association.

Nadeau, J. (2004). Meaning making in family bereavement: A family systems approach. In M. Stroebe, R. Hansson, W. Stroebe \& H. Schut (Eds.), Handbook of bereavement research: Consequences, coping, and care (329-347). Washington, DC: American Psychological Association. 
Nakhoda, Z. (2010).End-of-life and the Medicare Hospice Benefit: The high cost of the end-ofcare. Journal of Financial Service Professionals, 64, 24-28.

National Hospice and Palliative Care Organization, (2011). Retrieved from http://www.nhpco.org.

Neimeyer, R. (Ed.). (2001). Meaning reconstruction \& the experience of loss. Washington DC: American Psychological Association.

Parsons, T. (1951). The Social System. London: Routledge.

Perry, J., \& Stone, R. (2011). In the business of dying: Questioning the commercialization of hospice. Journal of Law, Medicine \& Ethics, 39, 224-234.

Pearce, W. (2009). Communication and social construction: Claiming our birthright. In G. Galanes \& W. Leeds-Hurwitz (Eds.), Socially Constructing Communication (pp. 33-56). New Jersey: Hampton Press.

Phillipson, C. (1911). The international law and custom of ancient Greece and Rome. London: MacMillan.

Phipps, W. (1988). The origin of hospices/hospitals. Death Studies, 12, 91-99.

Planalp, S. \& Trost, M. (2008). Communication issues at the end of life: Reports from hospice volunteers. Health Communication, 23, 222-233.

PollingReport.com, (2006, April 6-9). CBS News Poll. Retrieved from http://www.pollingreport.com/religion2.htm

Prigerson, H. (1992). Socialization to dying: Social determinants of death acknowledgment and treatment among terminally ill geriatric patients. Journal of Health and Social Behavior, 33, 378-395.

Ragan, S., Wittenberg-Lyles E., Goldsmith, J., \& Sanchez-Reilly, S. (2008). Communication as comfort: Multiple voices in Palliative care. New York: Routledge.

Randall, F., \& Downie, R., (2010). End of Life choices: Consensus and controversy. New York: Oxford University Press. 
Raye, N. (2009). A hastened death. In J. Werth \& D, Blevins (Eds.), Decision making near the end of life: Issues, Developments, and future directions (pp.47-60) New York: Routledge.

Sandler, I., Balk, D., Jordan, J., Kennedy, C., Nadeau, J., \& Shapiro, E. (2005). Bridging the gap between research and practice in bereavement: Report from the center for the advancement of health. Death Studies, 29, 93-122

Sharf, B., \& Vanderford, M. I. (2003) Illness narratives and the social construction of health. In T. Thompson, A. Dorsey, K. Miller \& R. Parrott (Eds.), Handbook of health communication (pp. 9-34). London: Lawrence Erlbaum.

Schulman-Green, D., McCorkle, R., Cherlin, E., Johnson-Hurzeler, R., \& Bradley, E. (2005). Nurses' communication of prognosis and implications for hospice referral: A study of nurses caring for terminally ill hospitalized patients. American Journal of Critical Care, 14, 64-70.

Schulz, R., \& Beach, S. (1999). Caregiving as a risk factor for mortality: The caregiver health effects study. Journal of the American Medical Association, 282, 2215-2219.

Seymour, J., Bellamy, G. Gott, M., Ahmedzai, S. \& Clark, D. (2002). Good deaths, bad deaths: care providers. Journal of Applied Communication Research, 35, 177-196. Older people's assessments of the risks and benefits of morphine and terminal sedation in end-of-life care. Health, Risk, \& Society, 4, 287-303.

Siebold, C. (1992). The hospice movement. New York: Twayne Publishers.

Smith, R. (2000). A good death. An important aim for health services and for us all. British Medical Journal, 320, 129-130.

Sparks, L., Villagran, M., Parker-Raley, J., \& Cunningham J. (2007). A patient-centered approach to breaking bad news: Communication guidelines for health care providers. Journal of applied Communication Research, 35, 177-196 
Stajduhar, K., Funk, L., Toye, C., Grande, G., Aoun, S. \& Todd, C. (2010). Part 1: Home-based family caregiving at the end of life: A comprehensive review of published quantitative research (1998-2008). Palliative Medicine, 24, 573-593.

Strauss, A. \& Corbin, J. (1990). Basics of qualitative research: Grounded theory procedures and techniques. Newbury Park CA: Sage Publications.

Temel, J., Greer, J., Muzikansky, A., Gallagher, R., Admane, S., Jackson, V., Lynch, T. (2010). Early palliative care for patients with metastatic non-small-cell lung cancer. The New England Journal of Medicine, 363, 733-742.

Teno, J., Clarridge, B., Casey, V., Welch, L., Wetle, T. Shield, R., \& Mor, V., (2004). Family perspectives on end-of-life care at the last place of care. Journal of the American Medical Association, 291, 88-93.

The, A., Hak, T., Koëter, G., \& van der Wal, G. (2000). Collusion in doctor-patient communication about imminent death: An ethnographic study. British Medical Journal, $321,1376-1381$.

Thorne, E., Kuo, M., Armstrong, A., McPherson, G., Harris, S., \& Hislop, T. (2005). "Being known": Patients' perspectives of the dynamics of human connection in cancer care. Psycho-Oncology, 14, 887-898.

Toller, P. W. (2005). Negotiation of dialectical contradiction by parents who have experienced the death of a child. Journal of Applied Communication Research, 33, 44-66.

Toller, P. W. (2008). Bereaved parents' negotiation of identity following the death of a child. Communications Studies, 59, 306-321.

Toller, P., \& Braithwaite, D. (2009). Grieving together and apart: Bereaved parents' contradictions of marital interaction. Journal of Applied Communication Research, 37, 257-277.

Tolstoy, L. (1886/1960). The death of Ivan Illych and other stories. New York: Signet Classics. 
Trice, E., \& Prigerson, H. (2009). Communication in end-stage cancer: Review of the literature and future research. Journal of Health Communication, 14, 95-108.

Vangelisti, A. (1994). Family secrets: Forms, Functions, and Correlates. Journal of Social and Personal Relationships, 11, 113-135.

Vangelisti, V. \& Caughlin, J. (1997). Revealing family secrets: The influence of topic, function, and relationships. Journal of Social and Personal Relationships, 14, 679-705.

Valdimarsdottir, U., Helgason, A., Furst, C., Adolfsson, J., \& Steineck, G. (2004). Awareness of husband's impending death from cancer and long-term anxiety in widowhood: A nationwide follow up. Palliative Medicine, 18, 432-443.

Walsh, F., \& McGoldrick, M. (1991). Loss and the family: A systems perspective. In F. Walsh \& M. McGoldrick (Eds.), Living beyond loss (pp. 1-29). New York: W. W. Norton.

Weinstein, J. (2009). 'So that's a completely different story': Competing narratives in the lives of relatives caring for dying patients. At the Interface / Probing the Boundaries, 58, 13-31.

Werth, J., \& Blevs, D. (2008). Decision making near the end of life: Issues, developments, and future directions. New York: Routledge.

Wilkins, V., Quill, T., \& King, D. (2009). Assessing families in palliative care: A pilot study for the checklist of family relational abilities. Journal of Palliative Medicine, 12, 517-519.

Wittenberg-Lyles, E. (2006). Narratives of hospice volunteers: Perspectives on death and dying. Qualitative Research Reports in Communication, 7, 51-56.

Wittenberg-Lyles, E., Goldsmith, J., \& Ragan, S. (2011). The shift to early palliative care: A typology of illness journeys and the role of nursing. Clinical Journal of Oncology Nursing, 15, 304-310.

Woolhandler, S., \& Himmelstein, D. (2004). The High Costs of For-Profit Care. Canadian Medical Association Journal 170, 1814-1815. 
Wortmann, J., \& Park, C. (2008). Religion and spirituality in adjustment following bereavement: An integrative review. Death Studies, 32, 703-736.

Wortmann, J., \& Park, C. (2009). Religion/spirituality and change in meaning after bereavement: Qualitative evidence of the meaning making model. Journal of Loss and Trauma, 14, 17-34.

Zhang, A., \& Siminoff, L. (2003). Silence and cancer: Why do families and patients fail to communicate? Health Communication, 15, 415-429.

Zhang, B., Wright, A., Huskamp, H., Nilsson, M., Maciejewski, M. (2009). Health care costs in the last week of life. Archives of Internal Medicine, 169, 480-488. 


\section{BIOGRAPHICAL INFORMATION}

Paul Kozar earned a M.Div. from Grace Theological Seminary in 1987. This degree was followed with a Th.M. in the field of Old Testament studies in 1991. His particular area of study was the use of rhetoric and competing discourse in the Psalter. His thesis was "A Critical Evaluation of the Movement from Pain to Hope in Psalm 42/43." He was in pastoral ministry from 1987 to 2011 and has been involved with hospice since 1997. He selected the topic of endof-life competing discourse due to his previous thesis, his current involvement on a professional level with hospice, and his desire to integrate informed scholarly research with practical experience in regards to end-of-life communication. 